\author{
Title I Design Report
}

\title{
Fermilab Main Injector
}

Project No. 92-G-302

Volume 2

Civil Construction

August 1992

Revision 0

Fermi National Accelerator Laboratory

Batavia, Illinois
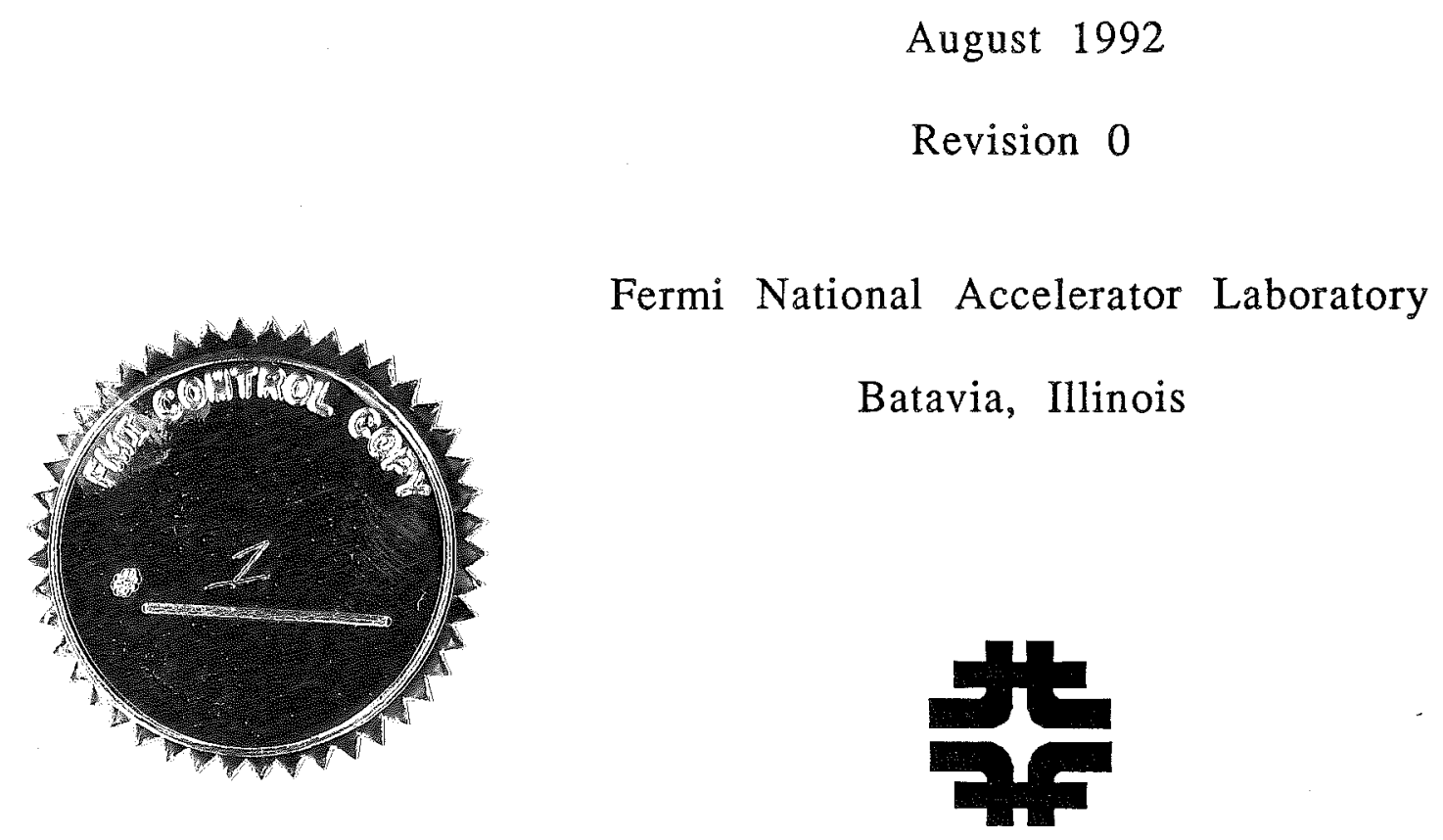

Operated By Universities Research Association Inc.

Under Contract with the United States Department of Energy 
Title I Design Report

\section{FERMILAB MAIN INJECTOR}

Project No. 92-G-302

Volume 2

Civil Construction

August 1992

Revision 0

Fermi National Accelerator Laboratory

Batavia, Illinois

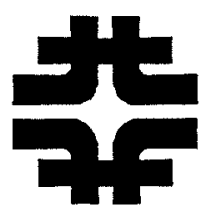

Operated by Universities Research Association Inc.

Under Contract with the United States Department of Energy 


\section{CIVIL CONSTRUCTION}

\section{TABLE OF CONTENTS}

I. OVERVIEW

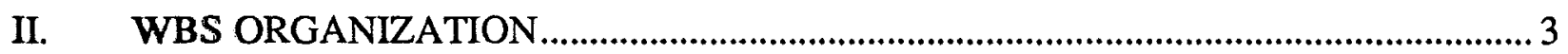

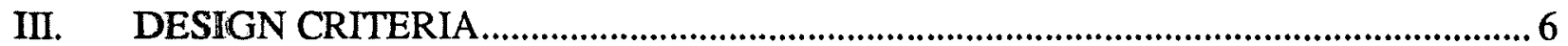

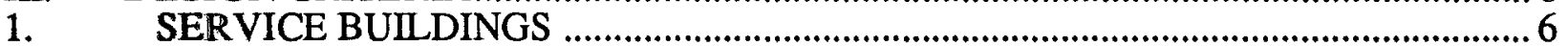

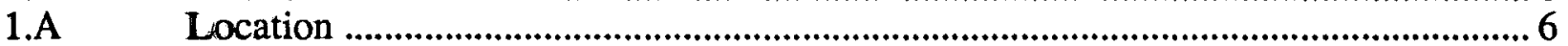

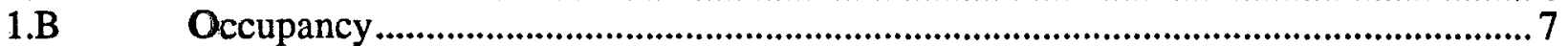

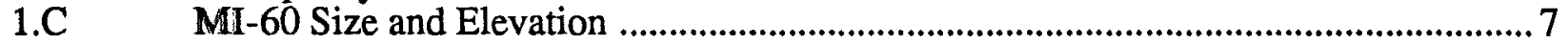

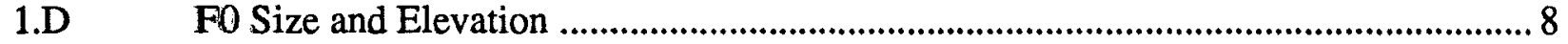

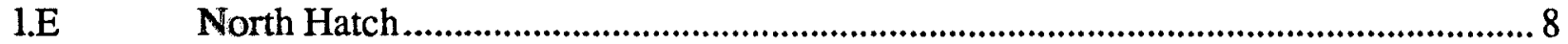

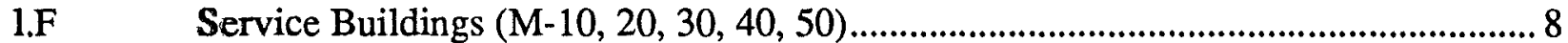

1.G Kicker Service Building (MI-52, 62) .................................................................. 9

1.H Kicker Service Building (F-17) .............................................................................. 9

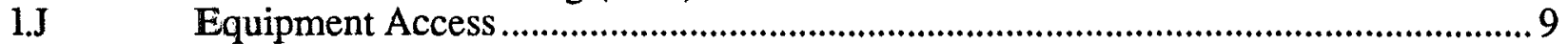

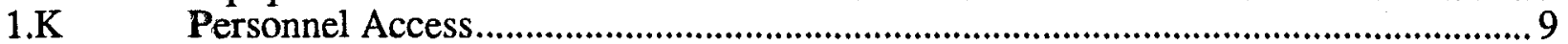

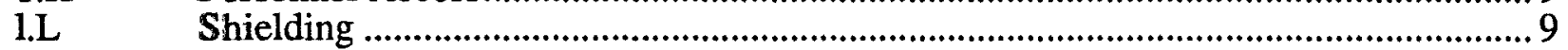

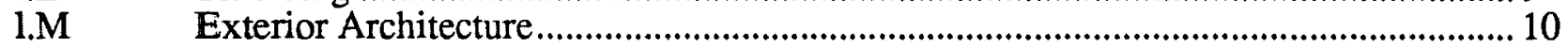

1.N Access Roads. Hardstands and Parking ..................................................................... 10

$1.0 \quad$ Process Equipment Heat Loads and Circulation Rates .................................................... 11

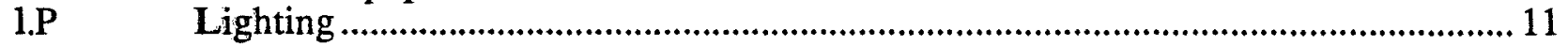

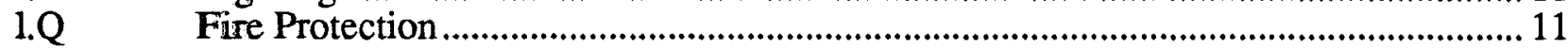

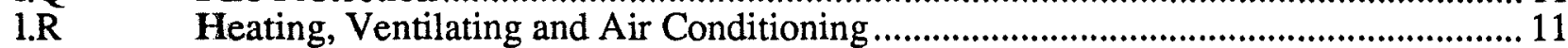

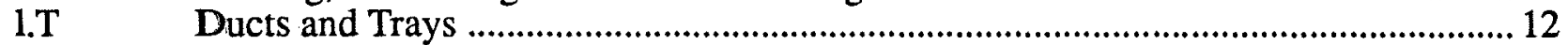

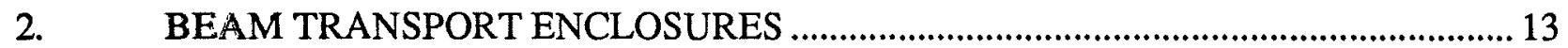

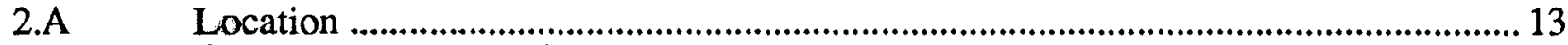

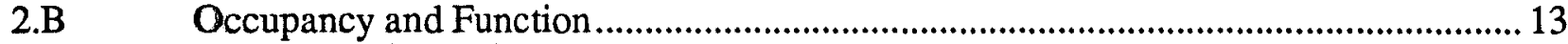

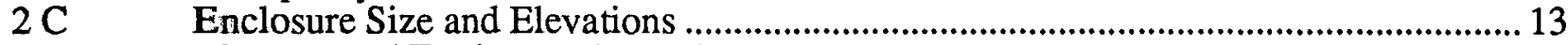

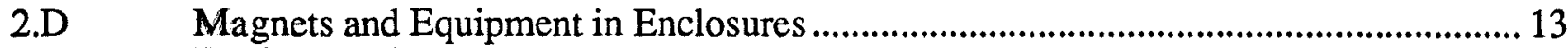

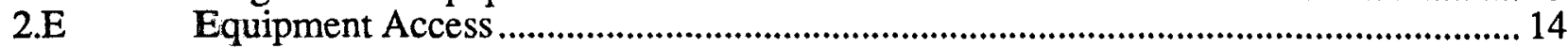

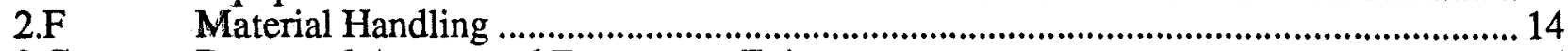

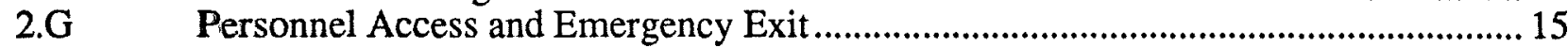

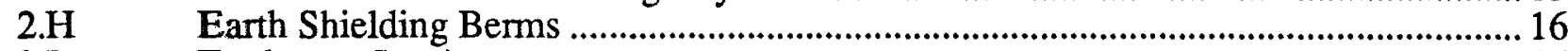

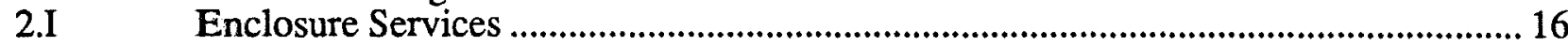

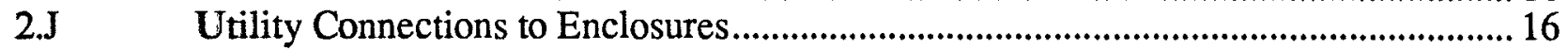

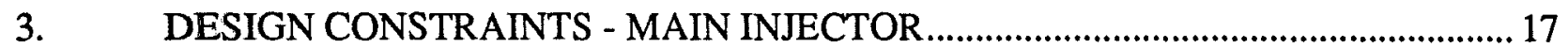

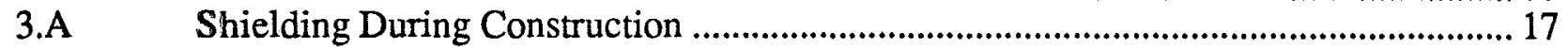

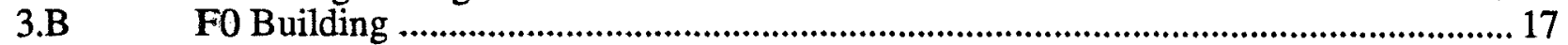

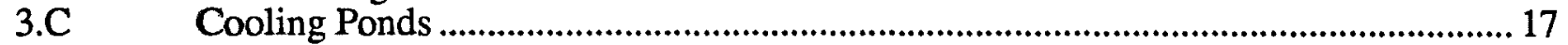

4. DESIGN CONSTRAINTS - FERMILAB SITE …............................................ 18

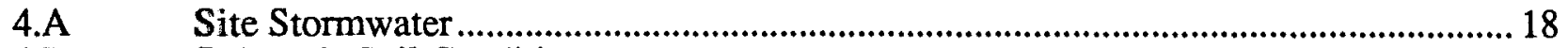

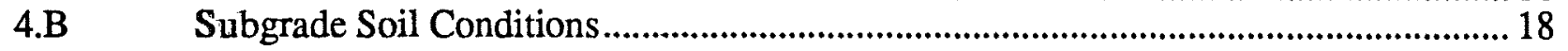

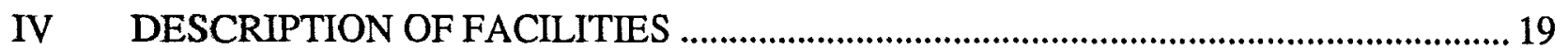

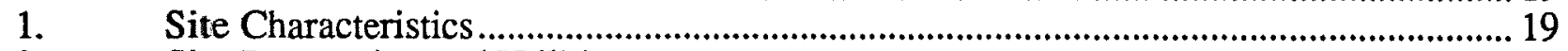

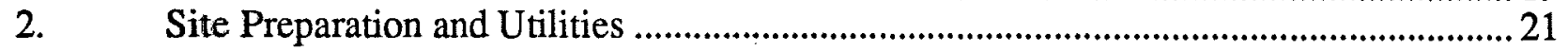




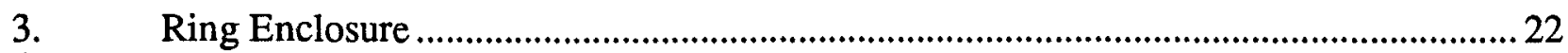

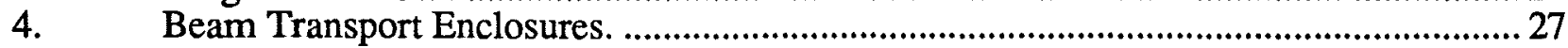

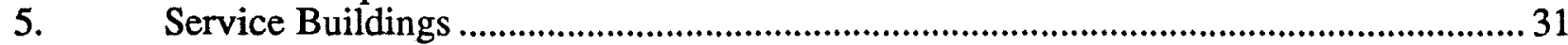

6. F0 Enclosure …

7. Foundation Systems, Earth Retention and Active Soil Control..........................................39

8. Kautz Road Master Substation and Power Distributions ...................................................... 40

9. Primary Cooling and Mechanical Systems …….............................................................4 42

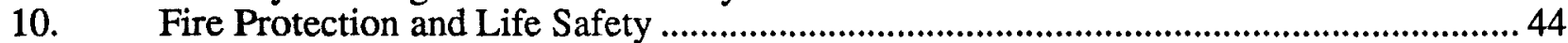

11. Environmental Concerns and Actions ........................................................................... 45

12. Energy Conservation ..................................................................................................... 47

V. OUTLINE SPECIFICATIONS AND SYSTEM DESCRIPTIONS ....................................49

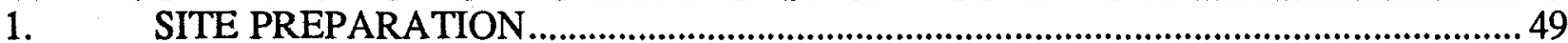

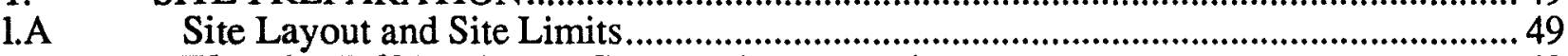

1.B F0 and MI-60 Enclosure Construction Protection ........................................................49

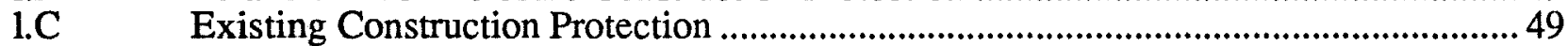

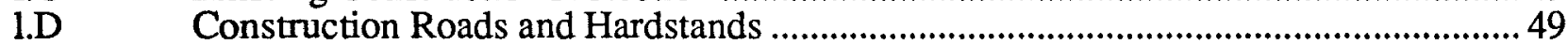

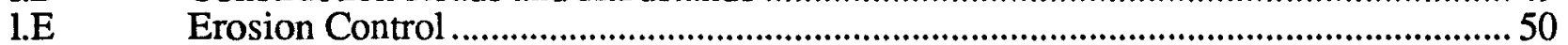

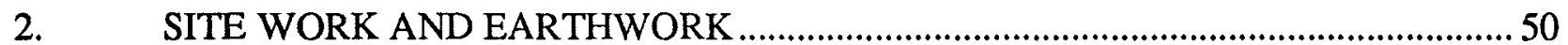

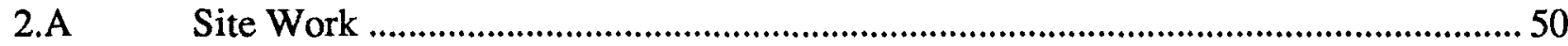

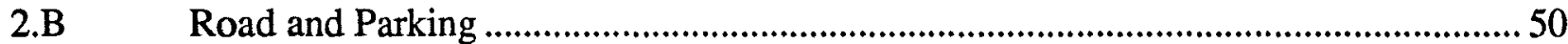

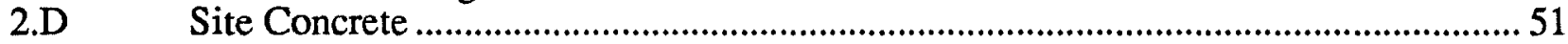

2.E ICW (Industrial Cold Water) Piping ..............................................................................5 51

2.F DWS (Domestic Water System) Piping ……..................................................................5 51

2.G Storm Water Drainage Piping ......................................................................................... 51

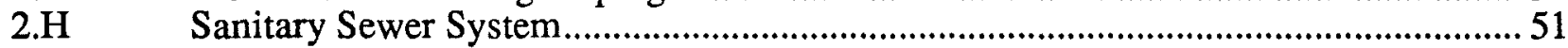

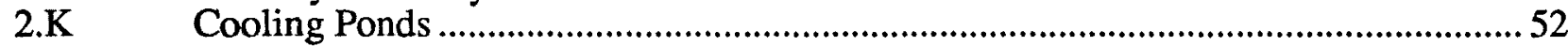

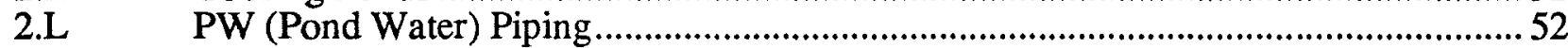

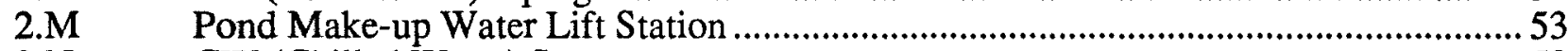

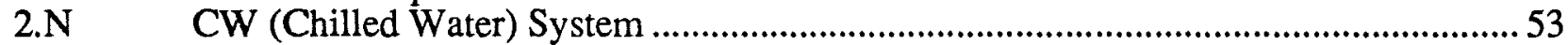

2.P Underground Electrical and Communication Ducts ...................................................5 53

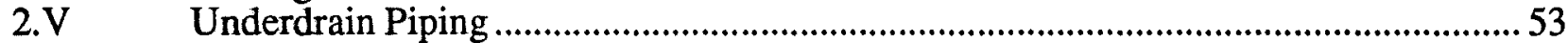

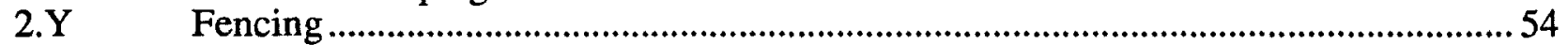

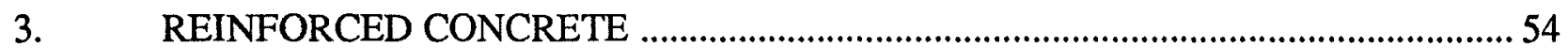

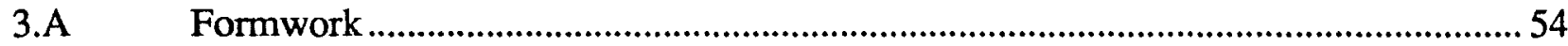

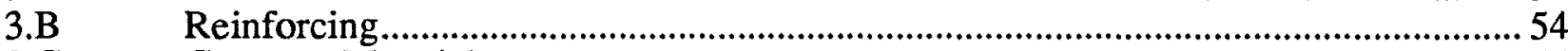

3.C Concrete Materials .....................................................................................................5 55

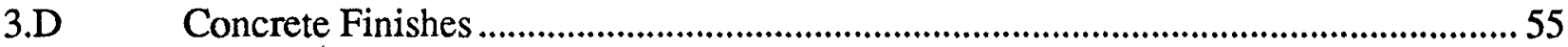

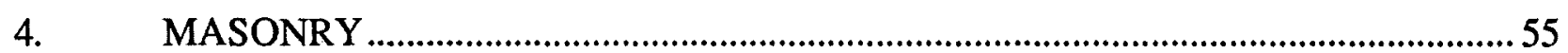

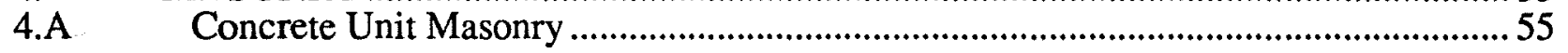

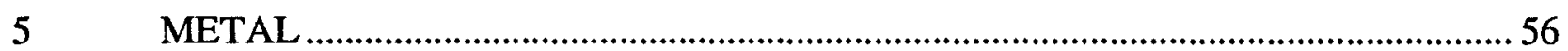

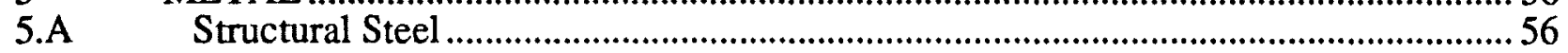

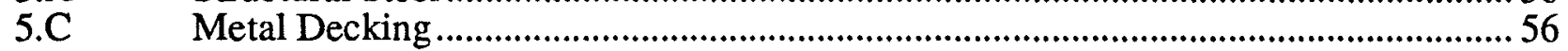

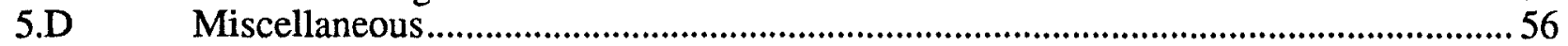

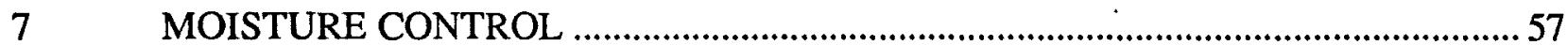

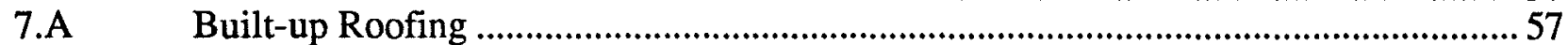

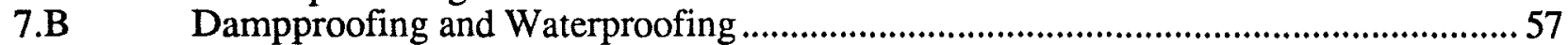

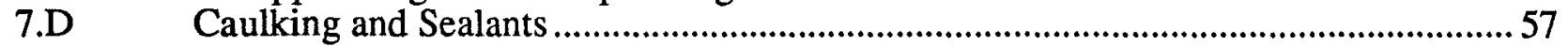

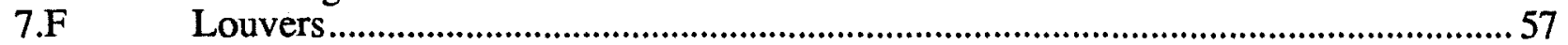

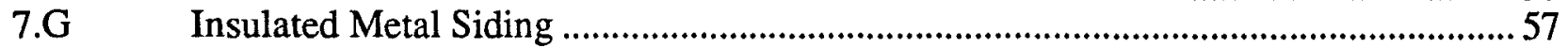

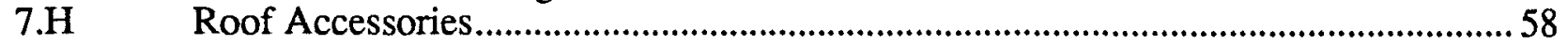


Overhead Sectional Doors

Roll-up Doors

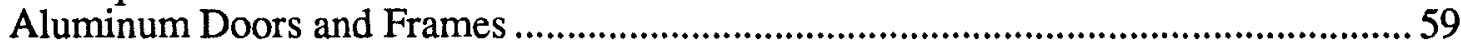

8.D

Aluminum Windows

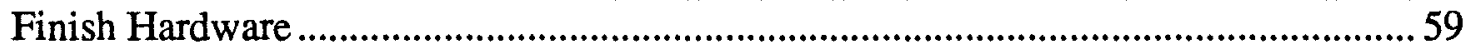

8.G

Glass and Glazing

10.

Painting

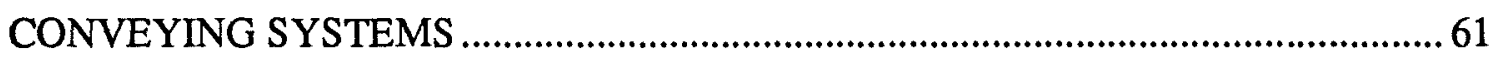

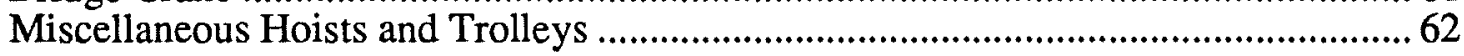

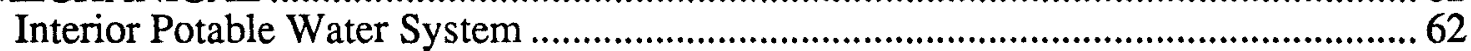

Drainage Sump Pumps In Alcoves and Exit Stairs ............................................................6 64

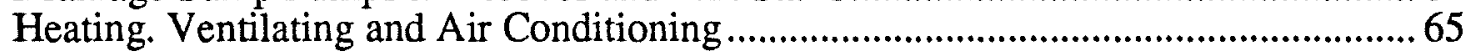

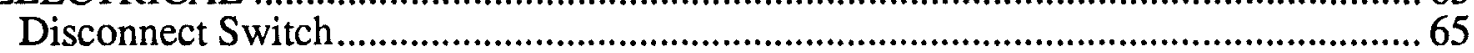

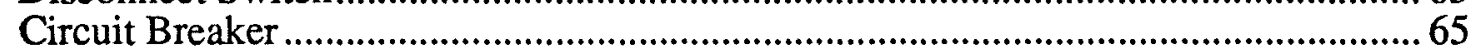

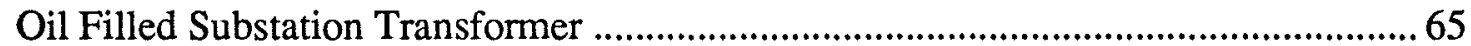

Oil Filled Substation Transformer ..............................................................................66

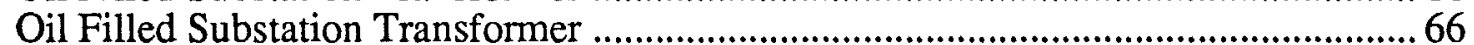

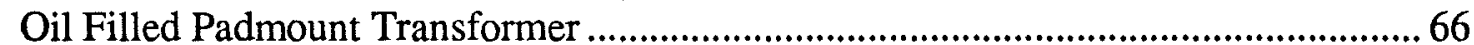

Oil Filled Padmount Transformer ............................................................................66

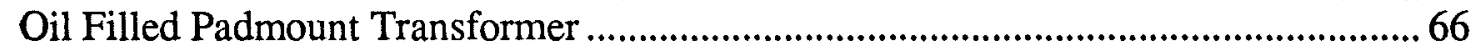

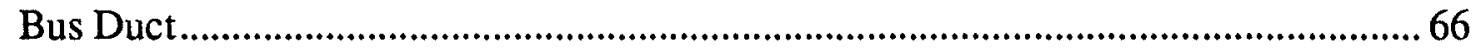

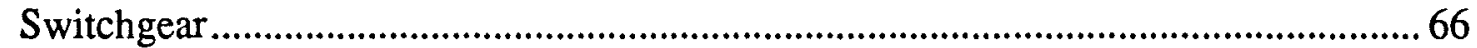

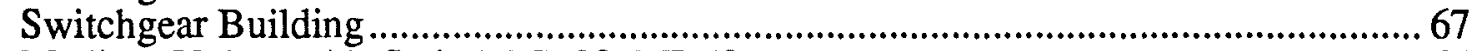

Medium Voltage Air Switch MI-30, MI-50 ........................................................ 67

$16 . \mathrm{N}$

$16 . \mathrm{O}$

16.P

16.Q

16.R

16.S

16.T

Medium Voltage Air Switch MI-50.

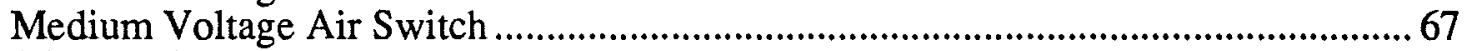

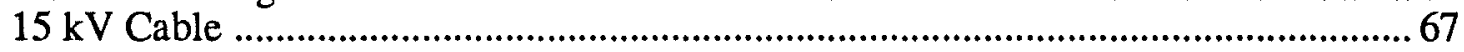

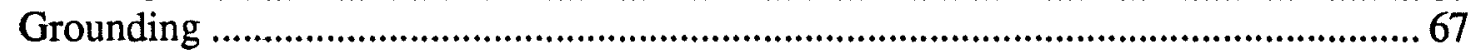

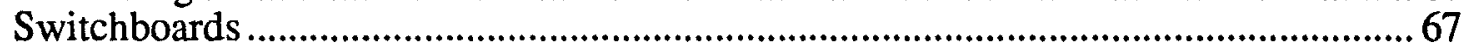

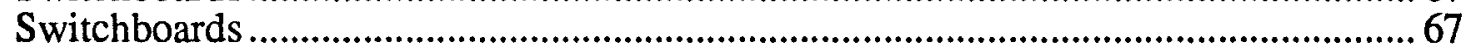

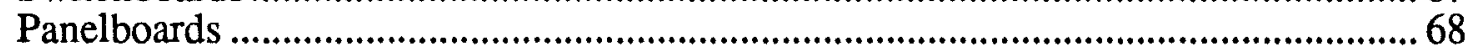

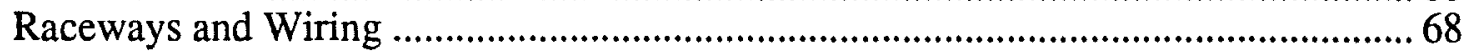




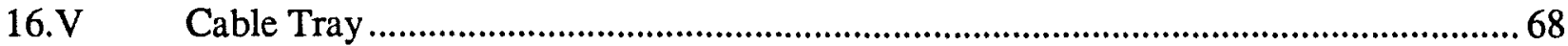

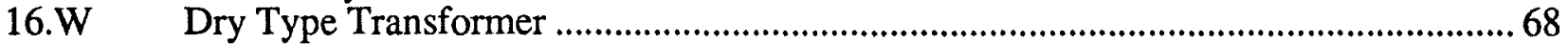

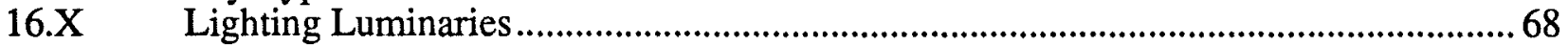

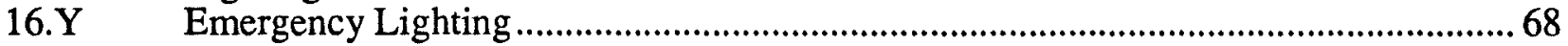

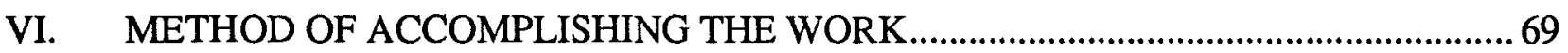

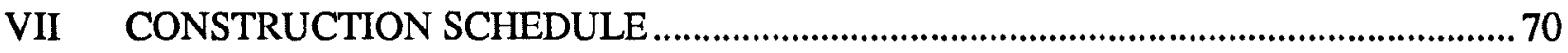

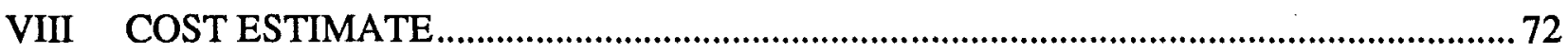

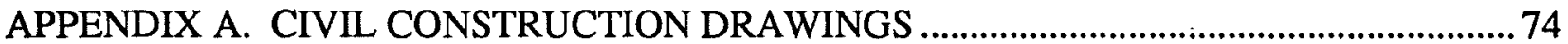




\section{CIVIL CONSTRUCTION}

\section{OVERVIEW}

The civil construction for the Fermilab Main Injector (FMI) includes all below-grade beamline enclosures with connections to the existing Booster and Tevatron enclosures; passive earth and steel shielding; equipment, utility and personnel access structures; above-ground service buildings; and site work such as wetland mitigation, roads, parking, storm drainage, cooling ponds, utilities and services to accommodate the equipment for, and operation of, the FMI.

The below-grade enclosures include the FMI ring enclosure and the various beam transport enclosures which provide for the following beam transport lines:

1. $8 \mathrm{GeV}$ protons from the Booster to the FMI,

2. $150 \mathrm{GeV}$ protons from the FMI to the Tevatron,

3. $150 \mathrm{GeV}$ antiprotons from the FMI to the Tevatron,

4. $120 \mathrm{GeV}$ protons from the FMI to the Antiproton Source,

5. $8 \mathrm{GeV}$ antiprotons from the Antiproton Source to the FMI, and

6. $120 \mathrm{GeV}$ protons from the FMI, via the Main Ring remnant in the F-sector, to the beam extraction lines for the fixed target areas.

The FMI project requires 13,000 linear feet (1.f.) of underground beamline enclosures and 46,500 square feet (sq ft) of new service buildings. As described in this Title I Report, the work will include over 1,100,000 cubic yards (c.y.) of excavation, 1,000,000 c.y. of backfill, 25,000 c.y. of cast-in-place (CIP) concrete, 1,900 precast concrete enclosure elements, 12,800 l.f. of new or relocated roadway, 18.8 acres of cooling pond surface, 12,000 tons of shielding steel, 1,400 tons of sheet piling, 330 tons of structural steel, a 13,200 l.f. $345 \mathrm{kV}$ transmission line and a substation with two new 40 MVA transformers. The estimated cost of the conventional construction, exclusive of ED\&I, is $\$ 66,538 \mathrm{~K}$ in 1991 dollars.

The conventional construction has been planned to permit completion of the entire MI (Main Injector) enclosure, the majority of the $8 \mathrm{GeV}$ enclosure, all the new MI service buildings and access structures, and to provide utility systems concurrent with full operation of the Fermilab accelerator complex and the experimental areas. Construction will be sequenced to permit early occupancy of the MI-60 Enclosure and MI-60 Service Building to accommodate R\&D and testing work for power supplies and controls, and to provide equipment access to the MI enclosure for magnet delivery and storage. The last phases of the underground work, consisting of the $150 \mathrm{GeV}$ enclosures and the F0 (pronounced F-Zero) enclosure connecting the FMI to the Tevatron and the $8 \mathrm{GeV}$ enclosure link at the Antiproton and connection to the Booster, will be accomplished during a seven month shutdown period. The relocation of Main 
Ring quadrupole magnets, harmonic filters, heat exchangers, LCW pumps and other equipment to the FMI will also be accomplished during this shutdown. Hence, the civil work will be completed in a sequence which corresponds to the needs of the technical development, assembly and testing of the FMI with only a minimal interruption of Fermilab operations.

The FMI conventional design is very similar to previously utilized and proven structural systems and construction methods developed for other Fermilab projects. The industrial, utilitarian architectural style of the above-ground buildings reflects, and is harmonious with, existing nearby buildings. Existing wetlands, topography, vegetation, natural habitat, road system and site boundaries have been carefully observed in the planning of the new construction. All these aspects have been thoroughly addressed in the Environmental Assessment (EA) for the FMI which resulted in the issuance of a Finding of No Significant Impact (FONSI) by DOE on July 6, 1992.

Safety provisions for radiation, fire protection, and conventional life safety are included in this Title I report and further detailed in the Preliminary Safety Analysis Report (PSAR) for the FMI. Energy efficient construction techniques will be incorporated into all new structures. Quality assurance provisions will be part of all project phases including preliminary and final design, construction and construction management. 


\section{WBS ORGANIZATION}

The Work Breakdown Structure (WBS) for the civil construction has grouped the project elements in a logical schedule sequence as well as by facility function or type of construction work involved. While this WBS organization presents a reasonable construction scenario, it probably will not be identical with the ultimate scope of the actual subcontract packages nor is the sequence of work inflexible. Funding constraints, procurement strategies, required design periods or changing requirements of the technical parameters of the FMI will all influence the ultimate design and construction packages and the work sequence. But the WBS does provide a convenient means of sub-dividing the conventional work scope into well-defined elements which can then be accurately monitored in terms of the project schedule and cost control.

WBS 1.2 represents all the conventional construction. The third level indicates one of the four major phases of construction with WBS 1.2.3 indicating work to be accomplished during the accelerator shutdown. Level four summarizes work of the same general type or character such as enclosure construction. The following WBS listing for the civil work is referenced throughout this Title I Report.

\section{Phase 1 - Site Preparation}

- WBS 1.2.1.1 - Wetland Mitigation - Including all of the compensatory floodplain construction and fencing of archaeological sites.

- WBS 1.2.1.2 - Site Preparation - Survey monuments, temporary power, construction access roads, tree protection, storm water diversion and the excavation, lining and riprap for cooling ponds.

- WBS 1.2.1.3 - Roads and Utilities - Injector Ring Road (to be named Indian Road) and relocated Kautz Road crushed stone base, power and communication duct banks, $13.8 \mathrm{kV}$ power feeders, and underground utility systems including industrial cold water (ICW), domestic water, sanitary sewer, and chilled water supply and return.

\section{Phase 2 - Construction During Accelerator Operation}

- WBS 1.2.2.1 - Injector Enclosure at MI-60 - MI underground ring enclosure between MI-52 and MI-62, including the first phase of the earth retention system, portions of the transition enclosures for the $150 \mathrm{GeV}$ beamlines, service penetrations at MI-60, exit stairs, equipment/personnel access labyrinths and shafts to the MI-60 service building and shielding berm.

- WBS 1.2.2.2 Injector Enclosure Between MI-62 and MI-52 - Encompassing the remainder (and majority) of the underground ring enclosure including alcoves with utility penetrations to service buildings, five stair/labyrinth connections to service buildings, emergency exit stair/labyrinths to grade, the abort area and beam dump, 8 
$\mathrm{GeV}$ injection area, slurry wall, and shielding berm with culvert penetrations at major stream crossings.

- WBS 1.2.2.3 Service Buildings MI-10, MI-20, MI-30, MI-40 and MI-50 - Including service corridor connection to stairs leading to MI enclosure, utility penetration extensions, underfloor pond water piping, ICW connection for sprinklers, hardstands, underground ducts, foundations and pads for exterior power equipment, HVAC systems, and conventional power connections.

- WBS 1.2.2.4 Kicker Service Buildings MI-52 and MI-62 - Including utility penetration connections, ICW connection for sprinklers, underground ducts, foundations and pads for exterior power equipment, hardstand, HVAC systems, and conventional power connections.

- WBS 1.2.2.5 Service Building MI-60 - Including utility penetration connections, hydraulic elevator, overhead bridge crane at equipment access, toilets, cooling water pump room, ICW and chilled water connections, HVAC systems, hardstand, foundations, pads and underground ducts for exterior power equipment and conventional power connection.

- WBS 1.2.2.6 Service Building F0 North Addition - Including relocation of Main Ring Road and some underground utilities with all work accomplished while the existing F0 (RF) service building remains operational.

- WBS 1.2.2.7 $8 \mathrm{GeV}$ Beam Enclosure - With connection to the MI enclosure, equipment access and utility penetrations at the North Hatch Building, exit stair labyrinths to grade and a shielded temporary access hatch with monorail hoists (exclusive of WBS 1.2.3.2 and 1.2.3.3).

- WBS 1.2.2.8 North Hatch Building - Providing typical service building functions including cooling water pump room, personnel and equipment access with overhead crane, toilets, HVAC systems, hardstand, foundations, pads and underground ducts for exterior power equipment, ICW, domestic water and sanitary sewer connection and conventional power connections.

- WBS 1.2.2.9 345 kV Transmission Line - From Kautz Road Substation to Commonwealth Edison corridor at eastern site boundary, including switching station with access to two $345 \mathrm{kV}$ feeders.

- WBS 1.2.2.10 Kautz Road Master Substation - Including two new 40 MVA transformers, relocation of two transformers from the existing Master Substation, main breaker, motor operated breaker switches, bus, bus supports, switchgear enclosure with cable vault, foundations with oil containment basins and related site work. 
- WBS 1.2.2.11 Cooling Water System - Including pond water intake and discharge pipes, pump vaults, pond water pumps, level control system and supply and return piping to the service buildings.

\section{Phase 3 - Construction During Accelerator Shutdown}

- WBS 1.2.3.1 F0 Enclosure. Service Building F0 Modifications and F17 Service Building - Includes demolition of southwest portion of F0 (RF) service building, second phase of the earth retention system, demolition of the Tevatron F0(RF) enclosure, construction of a replacement F0 enclosure with connections to the 150 $\mathrm{GeV}$ beamline enclosures including two monorail hoist assemblies and one bridge crane, exit stair connections, utility penetrations including shielded waveguide shafts, steel and earth berm shielding; interior shielding of existing F0 service building and connecting passageway to MI-60 service building; F17 Kicker Service Building with penetrations to existing Tevatron enclosure and conventional power connection.

- WBS 1.2.3.2 $8 \mathrm{GeV}$ Enclosure at Booster Connection - Including partial demolition of Booster beam enclosure, underpinning of the Southwest Booster Lab, demolition of a portion of the abandoned reverse injection concrete pipe enclosure, support and relocation of existing underground utilities, exit stair labyrinth, and steel and earth berm shielding.

- WBS 1.2.3.3 $8 \mathrm{GeV}$ Enclosure at Antiproton - Including removal of existing precast enclosure elements for a portion of the AP2 and AP3 beamline enclosure, demolition of the base slab, construction of the link connecting the two portions of the $8 \mathrm{GeV}$ enclosure, reconstruction of the Antiproton enclosure with replacement of the precast elements and shielding berm.

\section{Phase 4 - Landscaping and Paving}

- WBS 1.2.4.1 Landscaping and Paving - including bituminous paving of roads and hardstand areas, stockpile and construction yard removal, signage, and site landscaping. 


\section{DESIGN CRITERIA}

\section{SERVICE BUILDINGS}

MI-10, MI-20, MI-30, MI-40, MI-SO, MI-60, MI-52 kicker, MI-62 kicker, F-17 kicker, North Hatch.

\section{A Location}

.1 Site Coordinates:

MI-60 is on the new main injector ring where it intersects the $\mathrm{TeV}$ ring, about $2 / 3$ miles south of Wilson Hall; across from the F0 Building.

MI-10, MI-20, MI-30, MI-40, and MI-50 are spaced approximately equally around the main injector ring with MI-60.

MI-52 and MI-62 are 850 feet to either side of MI-60 on the MI enclosure, beyond the P-150 and A-150 enclosures respectively.

North Hatch is on the $8 \mathrm{GeV}$ enclosure near Kautz Road, just south of the antiproton ring.

F-17 is adjacent to the existing Tevatron berm, and between existing service buildings $\mathrm{F}-1$ and $\mathrm{F}-2$

Refer to C-4 and AS-1 of the Title I drawings.

.2 Arrangement:

MI-60: Single story, immediately west and adjacent to MI enclosure, with MI RF Gallery parallel to and closest to MI beamline. Support areas (Pump Room, RF Development, Tech Area, etc.) are immediately west of MI RF Gallery, creating a long rectangle. MI- 60 craneway is a high bay projection connected on the west of the main rectangle. The enclosure access hatch is in the craneway, and the stairs and service elevator are between the craneway and MI RF control room in the Gallery. F0: Single story, east of and connected to MI-60 via a passageway above the MI enclosure and $\mathrm{TeV}$ enclosure. The $\mathrm{TeV}$ RF Gallery is parallel to and east of the $\mathrm{TeV}$ enclosure. The kicker supply room and compressor rooms are on the south end, and the LCW pump room is on the north end.

North Hatch: Single story, immediately north of the $8 \mathrm{GeV}$ enclosure. West half is low bay, with beamline equipment closest to the enclosure and the pump room, stairway, and toilet rooms behind. The east half is for magnet staging and storage and contains the hatch.

Service Buildings MI- $10,-20,-30,-40$, and -50 : Are outside and adjacent to the MI enclosure, with a service corridor crossing above the MI enclosure and accessing the stairway to the service alcove below. The first third is for the power supplies and the service corridor doorways. The remaining space is occupied by the kicker 
room, control rack room, and LCW pump room, respectively, progressing away from the MI enclosure.

Kicker Buildings MI-52 and -62: Are outside and adjacent to the MI enclosure, south and north of P-150 and A-150 respectively. Each contains the power supply room on the south and the larger kicker room on the north.

Kicker Building F-17: Is outside and adjacent to the existing Main Ring enclosure, and between existing service buildings F-1 and F-2. The south half of the building contains MR kicker equipment and the north half contains the pulser.

\section{B Occupancy}

.1 Operating Periods:

MI-60: Total of 4, male and/or female.

F0: Total of 2, male and/or female.

Other buildings unoccupied.

.2 Shutdown Periods:

MI-60: Maximum 30 male, 10 female. Expected maximum total 24, male and/or female.

F0: Maximum 10; Expected maximum included in MI-60.

North Hatch: Maximum 10 male, 10 female.

Expected maximum total 12, male and/or female.

Others: occupied only for maintenance, maximum 4 per building.

\section{C MI-60 Size and Elevation}

.1 Gallery: $350^{\prime}$ long x $25^{\prime}$ wide, plus MI power supply $60^{\prime}$ long $25^{\prime}$ wide, plus alcoves: totals 12,000 sq ft Floor at elevation 742'-6". Clear height 12'-0" minimum to bottom of roof steel; 2'-6" × $3^{\prime}-6^{\prime \prime}$ cable trench full length with removable plate cover.

.2 Craneway: $100^{\prime}$ long x 50' wide, 5,000 SQ FT, floor at elevation 742'-6", hook height 18'-0" above floor, 47' above MI enclosure; Clear height 25'-6" minimum to bottom of roof steel.

.3 Support Areas:

Floor elevation 742'-6", 12'-0" minimum clear height, to bottom of roof steel.

$1,000 \mathrm{sq} \mathrm{ft}$ at Tech. Room

$1,875 \mathrm{sq} \mathrm{ft}$ at RF Assembly

1,875 sq ft at RF Development

2,000 sq ft at Pump Room

$625 \mathrm{sq} \mathrm{ft}$ at Entrance and Stairway

$625 \mathrm{sq} \mathrm{ft}$ at Toilets and Test area 
Plus: access corridors to anode power transformers

.4 Restrooms:

Handicapped accessible

Male: 2 w.c., 1 urn., 3 lav.

Female: 1 w.c., 1 lav.

Janitor: Mop sink, shelving, mop hangers

\section{D F0 Size and Elevation}

.1 Typical: Floor elevation 742'-6", minimum ceiling clear height 12'-0".

.2 Gallery: $175^{\prime}$ long $\times 33^{\prime}$ wide, with $15^{\prime} \times 35^{\prime}$ notch on north end for LCW pump room; $5,250 \mathrm{sq} \mathrm{ft}$.

.3 Control Room: 40' long x 33' wide, 1,320 sq ft.

.4 Kicker Supply Room: 1,366 sq ft, irregular shape.

.5 Compressor Rooms: 2 at 24' wide $x$ 44' long, total 2,112 sq ft.

.6 LCW Pump Room: 33' long $x$ 24' wide, $792 \mathrm{sq} \mathrm{ft}$.

.7 Restrooms: Existing, unisex, 1 w.c., 1 lav. Janitor: mop sink, shelving, mop hangers

\section{I.E North Hatch}

.1 Typical: Floor Elevation 746'-6".

.2 Beamline Equipment Room: $50^{\prime}$ long x 35' wide, plus alcove; $1,800 \mathrm{sq} \mathrm{ft}$, ceiling clear height 12'-0".

.3 Pump Room: $25^{\prime}$ long $\times 15^{\prime}$ wide, $375 \mathrm{sq} \mathrm{ft}$, minimum ceiling clear height $12^{\prime}-0$ ".

.4 Magnet Staging: Craneway $75^{\prime}$ long $\mathrm{x} 40^{\prime}$ wide; $3,000 \mathrm{sq} \mathrm{ft}$, ceiling clear height 25'-0".

.5 Toilets, Stairs, Miscellaneous: $25^{\prime}$ long x $15^{\prime}$ wide less alcove; $325 \mathrm{sq} \mathrm{ft}$, minimum ceiling clear height 12'-0"; drop ceiling in toilet rooms, 8'-6" clear height.

.6 Restrooms: Handicapped accessible

Male: 1 w.c., 1 lav.

Female: 1 w.c., 1 lav.

Janitor: mop sink, shelving, mop hangers

1.F Service Buildings: (M-10, -20, -30, -40, -50)

.1 Typical Clear Ceiling Height: 10'-0" minimum.

.2 Floor Elevations: Typical 742'-0" except MI-20 is 748'-6".

.3 Power Supply Room: 50' long x 20' wide, 1,040 sq ft with alcove.

.4 Kicker Room: $30^{\prime}$ long $\times 20^{\prime}$ wide, $600 \mathrm{sq} \mathrm{ft}$, with floor slab depressed 3".

.5 Control Rack Room: $30^{\prime}$ long x 16' wide, $480 \mathrm{sq} \mathrm{ft}$.

.6 Pump Room: 24' long x 14' wide, with D.I. bottle alcove, 340 
.7 Service Corridor: 6'-0" wide x 50' long; $300 \mathrm{sq} \mathrm{ft}$, with stairs up to elevation 748'-6" (except at MI-20) on top of berm, 8'-0" minimum clear ceiling height. Connects to stairs which access MI enclosure alcoves.

\section{G Kicker Service Building: (MI-52, -62)}

.1 Typical: Floor elevation 742'-0", clear height 10'-0" minimum to bottom of steel.

.2 Power Supply Room: $25^{\prime}$ long x 16' wide, $400 \mathrm{sq} \mathrm{ft}$.

.3 Kicker Room: $28^{\prime}$ wide x $25^{\prime}$ long, 700 sq ft, floor slab depressed 3"

\section{H Kicker Service Building: (F-17)}

.1 Floor Elevation: 741'-0; clear height 10'-0" minimum to bottom of roof steel.

.2 Overall Dimension: $35^{\prime}-0$ " long, 20'-0" wide, $700 \mathrm{sq} \mathrm{ft}$.

\section{J Equipment Access}

.1 MI-60: To craneway, service door is $12^{\prime}$ wide $x 13^{\prime}$ high, clear opening. 2 roll up doors, $9^{\prime} \times 9^{\prime}$, to power supply areas

$.2 \quad$ F0: Existing 9' $x$ 9' Service Door.

.3 North Hatch: Service door $12^{\prime}$-wide x 13'- high to craneway.

.4 MI-10,-20,-30,-40,-50: 8 ' high $\times 10^{\prime}$ wide roll-up doors at power supply room and personnel double doors at pump and kicker rooms.

.5 MI-52,-62: Personnel double doors at power supply and kicker rooms.

.6 F-17: Personnel double doors on east elevation.

\section{K Personnel Access}

.1 MI-60: Building exits through personnel doors on West elevation.

.2 F0: Personnel doors on north and east elevation.

.3 North Hatch: Personnel doors on east, west, and north elevation.

.4 Service Buildings: (MI-10,-20,-30,-40,-50,-52,-62) Personnel doors on two exterior elev grade.

$.5 \quad$ Kicker Building (F-17): Personnel doors on east elevation.

\section{I.L Shielding}

.1 MI-60 and F0: Area normally occupied; 26'-0" earth equivalent, Main Injector and $\mathrm{TeV}$ enclosures. Personnel labyrinth, two legs with one cul-de-sac, orientation and lengths equal to 26 feet earth equivalent.

.2 North Hatch:. Area normally occupied; $26^{\prime}-0^{\prime \prime}$ earth equivalent, $8 \mathrm{GeV}$ enclosure; 1'-6" concrete shielding blocks over hatch.

.3 Service Buildings: (MI-10,-20,-30,-40,-50,-52,-62, F-17). Area normally unoccupied; 26 feet earth equivalent. 


\section{M Exterior Architecture}

.1 MI-60: Appearance: one story above grade rectilinear building. Two roof levels, each with painted and galvanized steel fascia. Scuppers and downspouts on west elevation. Vertical metal siding to base, horizontal windows on RF Development, Craneway, and Tech Area.

Main entrance, aluminum double door on west elevation.

No doors on north, south, or east elevations. Ramps, three service doors, several personnel doors, main entrance, and projecting equipment areas on west elevation.

.2 F0: One story, above grade, basically rectilinear building, one roof level and galvanized and painted steel fascia. Vertical metal siding to base. No windows. Main entrance and projecting equipment on East side, two pairs of doors on north side, and compressor rooms with service doors on south end.

.3 North Hatch: One story above grade rectilinear building. Two roof levels, each with galvanized and painted steel fascia. Vertical metal siding to base. Main entrance and service door on east elevation; one single door on north elevation; and single door on west elevation. Projecting equipment on south elevation.

.4 Service Buildings: (MI-10,-20,-30,-40,-50,-52,-62, F-17) One story above grade rectilinear buildings, one roof level, with galvanized and painted steel fascia; vertical metal siding to base. No windows. One passage and one service door on "outside" elevation, two double and one single door on adjacent side. Concrete service corridor adjacent on berm at buildings MI-10, $-20,-30,-40,-50$.

\section{N Access Roads. Hardstands and Parking}

.1 Main Access: Closest main site entrance is on Kirk Road. Within site existing and relocated Kautz Road to MI-60, -52, -62, North Hatch; and new Main Injector Road for other MI service buildings; existing and relocated Main Ring Road to F0 and F-17.

.2 Construction Access: Existing entrance on Butterfield Road, Illinois 56, to Kautz Road; thence Main Injector Road and Main Ring Road.

.3 Hardstands: Bituminous pavement on granular sub-base and base. Parking includes one accessible space at each hardstand.

MI-60: 3,600 sq $\mathrm{ft}$ at the south hardstand and 2,000 sq $\mathrm{ft}$ at the north hardstand; automobile parking, 12 spaces.

F0: $6,900 \mathrm{sq} \mathrm{ft}, 7$ spaces.

North Hatchway: $5,000 \mathrm{sq} \mathrm{ft} ; 4$ spaces.

MI-10, -20, -30, -40, -50: 4,500 sq ft, 4 spaces (each).

MI-52, -62, F-17: 2,500 sq ft; 2 spaces (each). 
.4 Roads and Drives: Bituminous pavement on granular sub-base and base, 22'-0" wide with 4'-0" wide shoulders, 2 maximum grade. 20 ' returns at drives.

\section{O Process Equipment Heat Loads and Circulation Rates}

.1 General Requirements:

Refer to M-3 and M-4 of the Title I drawings.

.2 Loads:

\begin{tabular}{lccc}
\multicolumn{1}{l}{ ITEM } & LOAD $(\mathrm{kW})$ & $\begin{array}{c}\text { FLOWS (GPM) } \\
\text { POND WATER }\end{array}$ & $\begin{array}{c}\text { LOW } \\
\text { CONDUCTIVITY }\end{array}$ \\
MI-60 & 2,400 & 1,600 & 1,200 \\
RF Equipment & 3,470 & 2,400 & 900 \\
& & & 900 (chilled) \\
North Hatch & 690 & 500 & 600 \\
MI-10 & 2,380 & 1,600 & 900 \\
MI-20 & 2,370 & 1,600 & 900 \\
MI-30 & 2,370 & 1,600 & 1,200 \\
MI-40 & 2,440 & 1,600 & 900 \\
MI-50 & 2,370 & 1,600 & 900
\end{tabular}

1.P Lighting

.1 Offices, Tech Areas, Equipment Areas: 75-foot candles, $3^{\prime}$ above floor.

.2 Control Rooms: 100-foot candles, 3 ' above floor, with dimmer.

.3 Beamline Enclosures: 10-foot candles, 3'-0" above floor.

.4 Stairs, hallways, passageway: 20-foot candles, $3^{\prime}$ above floor.

.5 Toilet Rooms: 30-foot candles, 3' above floor.

.6 Parking, Walks: 2-foot candles at grade.

.7 Emergency Lighting: 5-foot candles, 3' above floor.

1.Q Fire Protection

.1 Automatic sprinklers throughout, density for ordinary hazard.

.2 Alarm is local with remote readout.

I.R Heating, Ventilating and Air Conditioning

.1 General Requirements: Refer to drawing M-l of the Title I drawings.

.2 Service Buildings MI-10, $-20,-30,-40,-50$

.2A Control Room and Kicker Room:

Temperature: $\quad 68^{\circ} \mathrm{F}$ Heating

$78^{\circ} \mathrm{F}$ Cooling

Rel. Humidity: No Requirements

Air Change/Hr: 2 Minimum 
.2B Power Supply Room and Pump Room:

Temperature: $\quad 68^{\circ} \mathrm{F}$ Heating No Cooling Control

Rel. Humidity: No Requirements

Air Change/Hr: 2 Minimum

.3 Service Building MI-60:

Temperature: $\quad 68^{\circ} \mathrm{F}$ Heating $78^{\circ} \mathrm{F}$ Cooling

Rel. Humidity: No Requirements

Air Change/Hr: 2 Minimum

.4 Kicker Buildings (MI-52, MI-62, and F-17):

.4A Kicker Room:

Temperature: $\quad 68^{\circ} \mathrm{F}$ Heating $78^{\circ} \mathrm{F}$ Cooling

Rel. Humidity: No Requirements

Air Change/Hr: 2 Minimum

.4B Power Supply Room:

Temperature: $\quad 68^{\circ} \mathrm{F}$ Heating No Cooling Control

Rel. Humidity: No Requirements

Air Change/Hr: 2 Minimum

.5 North Hatch Building:

$.5 \mathrm{~A}$ Control Room:

Temperature: $\quad 68^{\circ} \mathrm{F}$ Heating

$78^{\circ} \mathrm{F}$ Cooling

Rel. Humidity: No Requirements

Air Change/Hr: 2 Minimum

.5B Pump Room and Magnet Staging Storage Area:

Temperature: $\quad 68^{\circ} \mathrm{F}$ Heating No Cooling Control

Rel. Humidity: No Requirements

Air Change/Hr: 2 Minimum

\section{I.T Ducts and Trays}

.1 Ducts: $16-5$ " PVC-BB concrete encased power/communication ducts routed along circumference of Main Injector ring.

.2 Trays: 18 " wide power and control cable trays, routed entire length of Main Injector Ring. 


\section{BEAM TRANSPORT ENCLOSURES}

\section{A Location}

.1 Main Injector Enclosure: Beam enclosure approximately 10,900 feet long, (at the beam line), adjacent to TeV Ring F0 section.

$.28 \mathrm{GeV}$ Transport Enclosure: Beam enclosure approximately 2,119 feet long, (at the beam line) connecting the Booster Accelerator to the Main Injector near MI-10.

.3 P-150 and A-150 Injection Enclosures: Beam enclosure each approximately 200 feet long, connecting $\mathrm{MI}$ enclosure to $\mathrm{TeV}$ enclosure.

\section{B Occupancy and Function}

.1 Beam On Conditions: No personnel in enclosures.

.2 Beam Off Conditions: Maximum 24 persons in MI, P-150, and A-150 enclosures. Maximum 4 persons in $8 \mathrm{Gev}$ enclosure.

.3 Function: Enclosures to contain beam transport magnets, vacuum pipe and associated utilities. Enclosure to provide passage and aisle space for installation and maintenance of equipment.

\section{C Enclosure Size and Elevations}

.1 Main Injector Enclosure: Floor elevation level at 713'-6". 10'-0" minimum width. 8'-0" minimum height, 9'-0" at alcoves.

$.28 \mathrm{GeV}$ Transport Enclosure: Floor elevation varies, 722'-6" at Booster, 720'-6" for approximately 200 feet, and 713'-6" to Main Injector. 10'-0" minimum width, 8'-0" minimum height, from MI Enclosure to shielded hatch; 11'-0" minimum width, 8'$0 "$ minimum height from shielded hatch to existing Booster beam enclosure.

$.3 \quad \mathrm{P}-150$ and A-150 Injection Enclosure: Floor elevation level at 713'-6" with stairs to Main Injector. 10'-0" width, 10'-0" height.

.4 F0 Enclosure: Floor elevation varies, 718'-6" on $150 \mathrm{GeV}$ side of enclosure, 722'-6" on Tevatron side. 18'-0" minimum width; 8'-0" minimum height on Tevatron side, $12^{\prime}-0$ " minimum height $150 \mathrm{GeV}$ side.

.5 Beam Elevations: Beam lowers through $8 \mathrm{GeV}$ enclosure from approximately 726'-6" to 715'-9" and levels off. Continues at 715'-9" through MI enclosure. Rises through A-150 and P-150 enclosures from 715'-9" to 723'-4-1/2" (P-150) or 725'-2" (A-150).

\section{D Magnets and Equipment in Enclosures}

.1 Locations: See drawing AS-1 of Title I drawings.

.2 Typical Weights:

1DA (1DB dipoles) $\quad 40,500$

1DC and 1DD dipoles $\quad 28,000$

B1 dipole and B2 dipole (in place) $\quad 25,800$ 
B2 dipole

B3 dipole

SDB dipole

39,300

2XB2 dipole

25,200

$\mathrm{BQA}$ quadrupole

6,000

$\mathrm{BQB}$ quadrupole

9,000

IQC quadrupole

10,700

IQD quadrupole

12,500

Extraction Lambertson (94")

$12,000^{*}$

Extraction Lambertson (189")

$30,000^{*}$

$\mathrm{TeV}$ injection Lambertson

Magnet lifting fixture

$30,000^{*}$

*approximate weights

2,450

\section{E Equipment Access}

.1 Main Injector Enclosure: Equipment is lowered from MI-60 craneway via a 8' wide x 30' long hatchway, elevation 742'-6"; 8'-0" clear ceiling height in connecting labyrinth, with overhead crane coverage.

Service elevator from MI-60 craneway, 8'-6" wide x 10'-0" deep; $5000 \mathrm{lbs}$. capacity. F0 equipment lift, 6'-0" wide x 9'-0" deep; to 7'O" high x 6'-0" wide labyrinth.

$.28 \mathrm{GeV}$ Transport Enclosure: Equipment lowered through hatch in North Hatch building or MI-60 and rolled into enclosure, and through construction hatch 500' southeast of Booster and rolled into higher level enclosure.

.3 A-150 and P-150 Injection Enclosure: Equipment is brought through the existing Tevatron Enclosure and picked up by a bridge crane in the roof of the F0 enclosure. The crane moves the equipment over the Tevatron and $150 \mathrm{GeV}$ beamlines to the $150 \mathrm{GeV}$ side. Equipment can then be transferred by a pair of 10-ton monorail cranes across the step in the $150 \mathrm{GeV}$ enclosure.

\section{F Material Handling}

.1 MI-60: 30-ton hoist capacity; top running, independent hoist, bridge, and trolley movements, with multiple/variable hoist speeds, radio control, operable at craneway floor and beam line level. CMAA Class $\mathrm{C}$.

.2 North Hatch: 30-ton hoist capacity; top running, independent hoist, bridge, and trolley movements, with multiple/variable hoist speeds, radio control, operable at main floor and beam line. CMAA Class $\mathrm{C}$.

.3 Miscellaneous Cranes and Lifts: Two 10-ton monorail hoists on a single monorail beam at intersection of P-150 and A-150 enclosures with F0 enclosure.

Two 10-ton hoist bridge cranes operating over the $150 \mathrm{GeV}$ and Tevatron sides of the F0 enclosure.

One 1-ton jib crane at each intersection of the MI enclosure with the P-150 and A-150 enclosures. 
Two 10-ton monorail hoists at construction hatch, $8 \mathrm{GeV}$ enclosure.

One 1-ton monorail chainfall at each MI-10, MI-40, MI-52 and MI-62.

\section{G Personnel Access and Emergency Exit}

.1 Main Injector Enclosure: Stairway from MI-60 craneway at elevation $742^{\prime} 6^{\prime \prime}$ to labyrinth at MI enclosure, floor at elevation 713'-6" clear ceiling height 8'-0", 4'-0" clear width. Service elevator from MI-60 craneway at elevation 742'-6" to labyrinth at elevation 713-6" for personnel and light equipment; 5,000 lb. capacity; 8'-6" wide x 10'-0" long with 8'-0" x 7'-0" door opening.

MI enclosure exits to MI-60 by stairs or service elevator to floor at grade, adjacent to main entry.

MI enclosure exits from elevation $713^{\prime} 6^{\prime \prime}$ to headhouse at grade at each intersection of the MI enclosure with the P-150 and A-150 enclosures.

Service Buildings MI-10, $-20,-30,-40,-50$ : Utility alcove on MI enclosure connects to service building stairways; elevation 742'-0" (except 748'-6" at MI-20); 4'-0" wide x 8'-0" high.

Fire exits spaced at approximate 600 foot intervals from exits at elevation $713^{\prime}-6^{\prime \prime}$ to headhouse at grade.

.2 F0 Enclosure: F0 enclosure exists from elevation $718^{\prime}-6^{\prime \prime}$ to headhouse at grade at each intersection of the $\mathrm{F} 0$ enclosure with the $\mathrm{P}-150$ and $\mathrm{A}-150$ enclosures.

Existing F0 labyrinth from Kicker Supply Room equipment lift and stairway; floor at 742'-6", clear ceiling height 7'-0", clear width 3'-6".

$.3 \quad$ P-150 and A-150:

Exit stairway at the intersections of the P-150 and A-150 enclosures with the MI and $F 0$ enclosures from enclosure floor at elevation $713^{\prime}-6^{\prime \prime}$ to grade; $3^{\prime}-6^{\prime \prime}$ wide $\mathrm{x}$ 8'-0" high.

$.48 \mathrm{GeV}$ Enclosure: Exit stairway at existing intersection of AP-4 beamline and Booster ring enclosures; from elevation 722'-6" to grade; 4'-0" wide x 8'-0" high.

Exit stairway at construction hatchway, from elevations $720^{\prime}-6^{\prime \prime}$ and $713^{\prime}-6^{\prime \prime}$ to grade; 4'-0" wide x 8'-0" high.

Emergency exit stairway from elevation $713^{\prime}-6^{\prime \prime}$ to headhouse at grade, located between North Hatch labyrinth and construction hatchway exit.

Exit stairway at intersection with MI enclosure, from elevation 713'-6" to grade; 4'-0" wide x 8'-0" high.

North Hatch labyrinth connects $8 \mathrm{GeV}$ enclosure to North Hatch stairway, from elevation 713'-6" to 746'-6"; 7'-0" wide x 8'-0" high.

.5 Proton Abort: Exit stairway from elevation 712'-0" to grade, 4'0" wide x 8'-0" high. 


\section{H Earth Shielding Berms}

.1 Typical MI and $8 \mathrm{GeV}$ enclosure: $24^{\prime}-6$ " earth equivalent combination of earth and enclosure concrete, with steel plate as required, to top of berm.

.2 Service Alcoves: 26'-6" earth equivalent.

.3 F0 Enclosure: 26'-0" earth equivalent.

.4 MI-60 Enclosure: 26'-0" earth equivalent.

.5 P-150 and A-150 Enclosure: 25'-0" earth equivalent.

\section{I Enclosure Services}

.1 Typical Services: Lighting, receptacle power, power cable trays, dc power bus, LCW water headers, signal cable tray.

.2 Ventilation:

$8 \mathrm{GeV}$ Enclosure:

Temperature: $\quad 65^{\circ} \mathrm{F}$ Tempering of Air No Cooling Control

Air Change/Hr: $\quad 2$ Minimum

Main Injector Enclosure:

Temperature: $\quad 65^{\circ} \mathrm{F}$ Tempering of Air No Cooling Control

Air Change/Hr: 2 Minimum

.3 Drainage: Exterior underdrains leading to sumps.

.4 Fire Protection: Detectors in beam line enclosures, automatic sprinklers in alcoves and exitways.

\section{J Utility Connections to Enclosures}

.1 From North Hatch to $8 \mathrm{GeV}$ :

30-6" PVC conduits.

1-3" D.I./C.S. ICW pipes.

1-3" D.I. Sump pump discharge.

See AS-27 and 28 of the Title I drawings.

.2 From MI-10 to Main Injector (Same for MI-20, $-30,-40$, and -50 ):

32-6" PVC conduits.

3-TS $10 \times 6$ conduits.

4 - 6" SS LCW pipes.

1-3" D.I./C.S. ICW pipe

1-3" D.I./Sump pump discharge

See AS-17, 18, and 19 of the Title I drawings. 
.3 From MI-52 to Main Injector (Same for MI-62):

16-6" PVC conduits.

1-3" D.I./C.S. ICW pipe.

1-3" D.I. Sump pump discharge

See AS-20 of the Title I drawings.

.4 From MI-60 Main Injector:

96-6" PVC conduits.

21-TS conduits.

6-6" SS LCW pipes..

1-3" D.I./C.S. ICW pipe.

1-3" D.I. Sump pump discharge.

See AS-22, 25, and 26 of the Title I drawings.

.5 From MI-60 to A-150. (Same for P-150):

8-6" PVC conduits. See AS-22 and 26 of the Title I drawings.

.6 F0 to TeV Enclosure: 46-6" PVC conduits. 2-8" SS He pipes. 2-3" SS N2 pipes.

8-14" steel wave guides. See AS-22, 25, and 26 of the Title I drawings.

$.7 \quad$ F-17

12-6" PVC conduits.

1-3" D.I./C.S. ICW pipe.

See AS-21 of the Title I drawings.

\section{DESIGN CONSTRAINTS - MAIN INJECTOR}

\section{A Shielding During Construction}

.1 Minimum Cover: 21'-0" earth equivalent over and adjacent to the Main Ring enclosure during accelerator operations at $150 \mathrm{GeV}$.

.2 Construction Work: Continuous occupancy allowable for construction personnel in all areas including immediately above minimum cover zones.

.3 Radiation Monitoring: None required.

\section{B F0 Building}

.1 Protection: Preserve structural integrity and function of building during all construction.

.2 Access: Maintain access to building doors from Ring Road.

.3 Buried Utilities: Protect from damage; minimize interruption.

\section{C Cooling Ponds}

.1 Capacity: $18.5 \mathrm{MW}, 8$ ponds. 
.2 Size:

18.8 acres.

11,900 ' aggregate length.

$60^{\prime}$ to $90^{\prime}$ wide.

7'-0" deep.

.3 Elevations:

Varies, $737^{\prime}$ to $741^{\prime}$.

See M3 and M4 of the Title I drawings.

\section{DESIGN CONSTRAINTS - FERMILAB SITE}

\section{A Site Stormwater}

.1 Drainage: No adverse effect on downstream areas beyond Fermi property due to this project. Design basis: 100 year storm.

.2 Erosion Control: Design conforms to Bulletin 70 of the State of Illinois Department of Energy and Natural Resources.

\section{B Subgrade Soil Conditions}

.1 Subgrade Exploration: 31 soil borings have been made at the site. including 7 borings drilled for previous projects.

.2 Bearing Capacities: The allowable in-site soil bearing capacity has been determined to be capable of supporting the expected design pressures.

.3 Slope Stability: .4 Soil Boring Logs: Saturated areas of granular and silty materials dictate a maximum of 3:2 slope at all deep excavations.

.4 Soil Boring Logs: Refer to Drawing C-1 of the Title I drawings for boring locations. 


\section{DESCRIPTION FACILITIES}

\section{Site Characteristics}

The FMI ring enclosure encompasses 440 acres of the southwest corner of the Fermilab site and is located approximately 245 feet from the site boundary. This southwest boundary parallels an abandoned railroad embankment which has been converted to the Illinois Prairie Path. The majority of this area is open cropland, one-third of which has been in recent cultivation with the remainder lying fallow for more than ten years. Indian Creek and small tributary ditches meander through the site from the north to the southwest following the general topography which slopes from elevation $747^{\prime}$ to $731^{\prime}$ within the ring limits. Indian Creek, with its headwaters located on site, drains approximately 1,480 Fermilab acres before leaving the site via a double box culvert under the Prairie Path on a seven mile journey south and west to the Fox River.

The FMI site crosses through the limits of the 100 year floodplain of Indian Creek at two locations (see Drawing C1) where shielding berms, road embankments and cooling ponds will displace 29 acre-feet of storage. The required compensatory storage can be readily accommodated in the FMI infield and has been combined with the wetland mitigation area to provide a total of 40.9 acre-feet as shown on Drawings C2 and C7. The FMI storm drainage system will be designed not to exceed a discharge at the site boundary of 618 c.f.s. or a maximum flood elevation of 734' which represent the historic 100 year flood conditions. Discharge from the site will be controlled by impounding storm water within the FMI infield and designing the culverts through the berm at the southwest quadrant to limit flows for all storms with less than a ten year frequency. A 100 year storm will result in a maximum impoundment of 340 acre-feet and a water level in the infield which will peak at approximately elevation 735.5'. The FMI berm will be designed as a Class III dam in accordance with the Illinois Department of Transportation (IDOT) standards, and relocated Kautz Road as well as the emergency exit stairways on the infield side of the berm will all be located well above this maximum impoundment elevation. All service buildings, except MI-60, are located along the outer perimeter of the berm while service building MI-60 is separated from the infield by relocated Kautz Road, and all road elevations and building floors are above 100 year flood levels.

A wetland survey by Envirodyne Engineers, Inc. in the spring of 1990 identified nine different classifications of wetlands covering a total of 100.4 acres within the environs of the FMI ring which are subject to regulation by Section 404 of the Clean Water Act. By careful design modification, the FMI will only require permanent filling of 5.7 acres of these wetlands. These modifications included altered cooling pond configuration, road alignment changes, relocation of service building MI-40, and minimal construction limits through the major wetland area as demonstrated by cross sections shown on Drawing C- 6 . A wetland mitigation area of 10.3 acres has been planned for the infield area east of and adjacent to Indian Creek exceeding the 
required 1.5 to 1.0 ratio for the mitigation area. Hydric soils from the existing wetland will be transferred to the mitigation area which will be divided into a central sedge meadow with a perimeter forested zone. All work, including erosion control and the five year monitoring plan, will be in accordance with a U.S. Army Corps of Engineers (COE) 404 permit. In addition, Fermilab will attempt to relocate a number of trees and shrubs from the existing wetland to augment the new plantings in the mitigation area.

A three acre great blue heron rookery is located in a stand of dead maple trees within the southern quadrant of the FMI infield. However, as of the spring of 1991, the herons abandoned this nesting site in favor of an area located in the center of the Main Ring infield almost one mile to the northeast. Should the herons return, construction activities within a 200 meter radius would be limited during the nesting season. However, it has been demonstrated that construction can be scheduled around the nesting season without delaying the project completion. Fermilab has employed an ornithologist to observe the movements of the herons and to make recommendations to ensure the birds are protected under the Federal Migratory Bird Treaty Act. Very limited access to the FMI infield after completion of construction will actually provide a higher degree of protection to the rookery site than presently exists.

Three archaeological sites have been identified within the region of the FMI (see Drawing C-2), but all have been classified as not eligible for the National Register of Historic Places. The Lorenz site, located adjacent to the wetland mitigation area in the infield, as well as the Pioneer and Tadpole sites, will be fenced and left undisturbed but accessible. More definitive and extensive information regarding these and other environmental aspects of the FMI site have been addressed in the EA document. The EA was the basis for a FONSI by U.S. Department of Energy (DOE) as published in the Federal Register on July 6, 1992.

The sub-surface characteristics of the FMI site have been thoroughly investigated and conditions are generally consistent with the remainder of the Fermilab site. Seven existing soil borings have been augmented with an additional 32 new borings (see Drawing $\mathrm{C}-1$ ) and a final phase of sub-surface exploration will include borings along the $345 \mathrm{kV}$ transmission line. Typically, the site is overlain with several feet of topsoil, then either a layer of weathered till or an alluvial deposit followed by the unweathered glacial till. This brown-gray clay with traces of sand and gravel has proven to be an excellent foundation strata. The unweathered till is found at depths between $4^{\prime}$ and $22^{\prime}$ on the FMI site and, hence, the entire ring enclosure will be founded on this strata. The glacial till has unconfined compressive strengths ranging from 2.5 to 5.0 tons per square foot which will be adequate for superimposed enclosure and shielding berm loads. Moisture contents range up to $30 \%$ near the surface to $18 \%$ in the till. Predicted long-term settlements for the enclosure base slab are in the range of 0.1 inches to 0.2 inches with the majority occurring soon after construction. Permeability ranges from $10^{-4}$ to $10^{-6} \mathrm{~cm} / \mathrm{sec}$ above 
the till and $10^{-7}$ to $10^{-8} \mathrm{~cm} / \mathrm{sec}$ in the glacial till. Construction dewatering will be required to protect initial cut slopes with ditches, benches and pumped sumps at the excavation base. However, construction experience at the nearby Antiproton Source indicated much of the groundwater was perched and presented no significant problems after initial pumping because of the slow recharge rate. All completed underground enclosures will be protected by perimeter underdrains.

\section{Site Preparation and Utilities}

Site drainage will be controlled by ditches and culverts while preserving the existing watershed characteristics both during construction and subsequent operation. The cooling pond system will generally follow the ground elevations with pumping stations utilized to circulate water "uphill." Culverts passing through the shielding berm over the FMI enclosure will be designed to attenuate radiation by limiting culvert diameter, spacing multiple culverts at least two diameters apart and adding steel shielding above the enclosure roof to provide the equivalent passive protection afforded by the typical berm.

An early subcontract will provide a 30 ' wide crushed stone road base along the Indian Road alignment to serve as a construction access road. Since the principal power and communication duct bank is sited below the road, its construction along with the manholes will be included in this scope and precede the installation of the base course (see Drawings C-3 and C-6). This stone base will be maintained throughout the construction period for all access requirements, including early installation of technical components, until major hauling and earthwork activities are complete. The base will then be cleaned, new stone added where required, recompacted and paved with two 1 1/2-inch courses of bituminous aggregate. The final paved width will be 22 ' with 4 foot aggregate shoulders. The road profile will be designed with a maximum grade of $3 \%$ with all areas above the 100 year floodplain elevation.

Another early subcontract will provide a temporary overhead power line at $13.8 \mathrm{kV}$. The power source will be an existing $34.5 \mathrm{kV}$ Commonwealth Edison pole line along Giese Road located approximately 1,000 feet northwest of the FMI ring. A leased transformer with a capacity of at least 7.5 MVA will be located at Giese Road, temporary poles installed along Indian and Kautz Roads (except through the wetland borrow area) and drops terminating with fused disconnects provided at intervals for the subcontractor's use. (See Drawing E-3.) There will be sufficient temporary power available to operate pumping stations, subcontractor's equipment, and the initial power requirements for the early occupancy of the MI-60 service building.

Underground utility systems include ICW, domestic water (DWS), sanitary sewer, chilled water supply (CHWS) and chilled water return (CHWR) all connected to or extensions of existing site-wide systems (see Drawing C-5). The cooling water piping system and the power and communication duct bank system are described elsewhere in this report. An ICW loop 
consisting of 12 inch ductile iron pipe will be located along Indian Road and relocated Kautz Road with connections at two locations to the existing ICW site system. The ICW system is the water source for the fire protection system located in all service buildings and the major alcoves of the FMI ring enclosure. The new system will include draft hydrants located near the service buildings.

Domestic water and sanitary sewer services are required for toilets located at the MI-60 service building and the North Hatch building. The DWS will be extended from the Antiproton Source near service building AP-10. The sanitary sewer will be a combination gravity sewer/force main with a lift station located near the North Hatch building and the tie-in to the existing sewer in the Antiproton area near Well Pond Road (see Drawing C-5). Chilled water requirements are limited to the MI-60 service building and will be furnished by extending supply and return piping from the utility corridor located along the Main Ring Road.

\section{Ring Enclosure}

The MI ring enclosure (WBS 1.2.2.1 and 1.2.2.2) is an oval-shaped, below-grade enclosure approximately 10,900 ' in length, with a rectangular cross-section typically $10^{\prime}-0$ " wide by $8^{\prime}-0$ " high. At utility alcoves opposite the five typical service buildings and the two kicker buildings, the enclosure height is increased to 9'-0" and widths are increased to accommodate utility penetrations, sump pumps, dehumidifiers, electrical panels, dry-type transformers, LCW expansion loops and services crossing the enclosure width along the ceiling. Four additional utility alcoves will be provided midway between service buildings MI-10 through MI-50 as illustrated on Drawing AS-3. Alcove lengths are nominally $16^{\prime}$ but the total length of this CIP concrete varies to match the placing pattern of the adjacent precast concrete elements typical for the majority of the ring enclosure. The enclosure plan and sections are shown on Drawings AS-2 through AS-8. The floor of the ring enclosure is at a constant (locally defined) elevation of 713'6" or between 18' and 33' below existing grade. The MI technical components for the circulating beam are in a true plane nominally centered at elevation 715'-9" (or more precisely at 715.724'), approximately 2'-3" above the enclosure floor and nominally positioned 2'-3" from the inside face of the outer enclosure wall.

Several segments of the MI enclosure vary from the typical configuration to accommodate injection, extraction and acceleration functions of the FMI. The width at the $8 \mathrm{GeV}$ injection area, shown on Drawing AS-14, varies from 15' to $24^{\prime}$. At the proton abort region, which may also be utilized as an extraction point for future experimental areas, the enclosure width varies from $15^{\prime}$ to $22^{\prime}$ while the base slab is stepped with the outer region (extracted beam area) at elevation 712'-0" as illustrated on Drawing AS-4. The MI-60 region, which houses the MI rf accelerating and coalescing cavities, will be approximately $460^{\prime}$ long with a cross section $15^{\prime}-0$ " wide by 9'-0" high. The $150 \mathrm{GeV}$ transition regions for the proton and antiproton injection, 
which intersect the MI ring enclosure to either side of station MI-60, will be $10^{\prime}-0^{\prime \prime}$ high enclosures with widths varying from the typical $10^{\prime}-0^{\prime \prime}$ to a maximum of $26^{\prime}-0^{\prime \prime}$. Drawing AS-3 shows a plan of the MI- 60 enclosure region plus the $150 \mathrm{GeV}$ transitions and includes references to both transverse and longitudinal sections shown on other drawings.

The MI ring enclosure is divided into two principal regions - injector enclosure at MI-60 (WBS 1.2.2.1) and the remainder of the ring, injector enclosure between MI-62 and MI-52 (WBS 1.2.2.2). The MI-60 enclosure is planned as the first major construction effort for several reasons. Most importantly, the MI-60 enclosure plus service building will be the hub of FMI functions and activities during both installation and operation phases. All magnets and beamline equipment will be installed into the MI enclosure via an elevator or crane-covered vertical shaft extending from the high bay space of the MI-60 service building to the MI-60 enclosure. The MI-60 enclosure houses atypical functional components such as the rf accelerating and coalescing cavities and, at regions to either side of MI-60, the extraction systems for the $150 \mathrm{GeV}$ beamlines which will require more time to install and test. There are over 200 utility penetrations between the MI-60 enclosure and its service building including waveguides, power bus or cables, controls, diagnostics, and three LCW systems. The MI-60 service building, which will closely follow the MI-60 enclosure construction, houses assembly areas and will be utilized for initial installation and testing of power supplies, $\mathrm{rf}$ components and controls. The MI-60 enclosure and service building can be used to temporarily store delivered magnets and equipment prior to final testing and installation. Hence, the early occupancy of the MI-60 enclosure and service building are critical to the project schedule.

There is also a basic construction scheduling logic for starting the enclosure work at MI60. The majority of the MI enclosure (exclusive of the MI-60 region) will be constructed using precast concrete inverted U-shaped elements for the walls and roof. Use of these elements makes the below grade work more independent of weather conditions, provides a drier enclosure with a better interior surface finish and minimizes the construction schedule by eliminating form work and concrete curing time. However, because more than 1,900 of these elements will be required and because steel forms must be fabricated first, some lead time will be necessary before these elements are available for installation. Consequently, the CIP MI-60 enclosure with its larger atypical cross section is the logical initial on-site construction project while a separate concurrent procurement of the elements commences at an off-site concrete precasting plant.

One of the basic design parameters of the FMI was to place the new facility as close to the existing Main Ring enclosure as possible to minimize the length of the transfer beamlines between the FMI and the Tevatron, as well as maximizing the distance to the site boundary at the opposite side of the new machine. Since the construction must proceed while the existing accelerator remains operational, the minimum distance between the old and new ring enclosures 
is determined by radiation shielding requirements. Hence, the MI-60 enclosure work area will be separated from the existing F0 enclosure by a minimum of 21' of earth shielding. It is also an economical and functional expedient to locate grade-level service buildings as close to their associated underground enclosures as feasible without actually placing the service building directly above the enclosure. This latter procedure restricts the ability to increase the shielding between the two structures when regulations become more conservative and new penetrations, enclosure improvements, and construction on backfill with the probability of increased settlements all pose potential future problems. In order to place the MI-60 enclosure close to the Tevatron and, later, construct the MI-60 service building with minimal penetration and access lengths, two parallel lines of steel sheet piling with walers and cross lot bracing will be utilized to form an earth retention system both southwest and northeast of the MI-60 enclosure. This procedure provides the required 21' of earth shielding to the existing F0 region of the Tevatron, locates the MI beamline only 38'-9" from the parallel Tevatron beamline and places the near wall of the MI-60 service building slightly more than 28 ' horizontally from the MI beamline while still providing $26^{\prime}$ of shielding. The retention wall configuration is shown in plan on Drawing AS-3 while Drawings AS-25 and AS-26 show several transverse cross sections. The final relationship of the MI-60 enclosure and service building in plan view as well as a tabulation of the utility penetrations is shown on Drawing AS-22. A detailed cross-section of the MI-60 enclosure is shown on Drawing AS-7.

Earth berms over the FMI ring enclosure typically provide the required $24^{\prime}-6$ " earth equivalent radiation shielding for unlimited occupancy resulting in a normal top of berm elevation of $747^{\prime}-0^{\prime \prime}$. The extraction regions are shielded with $25^{\prime}-0^{\prime \prime}$ of earth equivalent. Areas where future accessibility for increasing the shielding will be restricted, such as between the MI60 and F0 service buildings or directly behind typical service buildings at the service corridor, will be shielded with 26'-0" of earth. Shielding throughout the project will be augmented by the use of steel plate where physical limitations preclude "all earth" berms. A foot of steel nominally replaces three feet of earth. Steel will be added at culvert crossings over the enclosure (see Section through Indian Creek Outfall on Drawing C-6) or where the passageway between the MI-60 and F0 service buildings passes over the MI enclosure (Section A on Drawing AS-25).

The base for the FMI ring enclosure will be a CIP concrete slab over a 3" thick lean concrete "mud slab" located on undisturbed glacial till. The mud slab is placed immediately after the excavation is completed to minimize disturbance of the bearing strata and to provide an allweather work surface for placing the base slab. The majority (approximately 9,500 1.f.) of the walls and roof of the ring enclosure with a typical cross-section 10'-0" wide by 8'-0" high will consist of precast reinforced concrete inverted U-shaped elements averaging approximately 7 ' in length. These precast elements will be cast off site under a separate subcontract and delivered to 
the site for installation by the erecting subcontractor. The elements, weighing up to 20 tons, are lowered onto the base slab and held in place by welded anchors in four locations. The joints between units are made watertight with sealant applied over a backer rod. This underground enclosure construction system is a proven procedure at Fermilab with nearly 26,000 feet of this general type of precast element placed during the last 20 years. Drawing AS-8 illustrates the typical precast element details and placing plan while the typical precast section for the MI enclosure is shown on Drawing AS-7. Segments of the enclosure requiring varying widths or special configurations, such as the injection or extraction regions, the alcoves, intersections of the ring enclosure with access labyrinths or exit stairs or the MI-60 region with a larger crosssection, will be constructed of CIP concrete walls and roof as illustrated on Drawings AS-4, AS7, AS-18 and AS-19. The exterior walls and roof of the entire ring enclosure will be dampproofed with continuous underdrains along both sides of the base slab and granular backfill at enclosure walls to ensure a dry interior.

Equipment access to the FMI ring enclosure is provided at the MI-60 region via the adjacent MI-60 service building. An 8'-0"x30'-0" floor hatch and shaft connect the high bay area of the service building with a $10^{\prime}-0^{\prime \prime}$ wide by $8^{\prime}-0^{\prime \prime}$ high curved labyrinth illustrated on Drawing AS-3. A 5,000 pound capacity hydraulic elevator also provides equipment access via the same labyrinth. Hence, all major equipment for the FMI ring enclosure, including magnets, magnet stands, cable, beam pipe, vacuum pumps and LCW piping, will be delivered to the MI- 60 service building and installed via crane through the hatch or via elevator connected by labyrinth to the MI-60 region of the enclosure.

Personnel access from grade level to the FMI ring enclosure is provided at the five typical service buildings and the MI-60 service building via CIP concrete stairs and labyrinths. Exiting from the ring enclosure is provided by these six stairways plus an additional 18 stairs/labyrinths insuring that the maximum distance to an exit is no more than 300 ' in accordance with the classification of the enclosure as a Special Industrial Occupancy under the NFPA 101 Life Safety Code. All stair labyrinths will include a rated door at the ring enclosure with a direct outside exit at grade level. The 18 designated exit stairs will generally be located on the infield side of the berm and there will be no exterior door hardware so they will function solely as emergency exits. The location of access and egress stairs is indicated as part of the enclosure criteria shown on Drawing AS-2.

Cable trays, power bus, LCW piping, lighting, convenience power and other services are ceiling- or wall-mounted facilitated by channel inserts embedded in the enclosure walls and ceilings at regular intervals. Numerous penetrations located at the alcoves or the atypical enclosure segments connect to the above-ground service buildings. All penetrations are designed 
to eliminate any "line-of-sight" configurations between the technical components and the service buildings above to maximize radiation protection

Ventilation for the FMI enclosure is provided by above-ground pad-mounted air-handling units connected via buried steel ducts. Supply units with heating coils will be located at typical service buildings and the MI-60 service building with exhaust fans located between typical service buildings and at the Kicker service building as shown on Drawing M-1.

The MI abort is located near service building MI-40. The divergence of the abort line from the MI beamline requires a widened CIP concrete enclosure as shown on Drawing AS-4. Since the abort line is extracted vertically downward, the enclosure floor is stepped 1'-6" down to accommodate the abort line components. A separate stair labyrinth (not included in the earlier exit summary) provides a grade level exit from the downstream end of the abort line enclosure. The beam dump is located approximately 100 ' beyond the end of the abort enclosure connected by a buried 12" diameter steel beam pipe with cathodic protection. The central feature of the dump is a graphite core surrounded by aluminum cooling channels in a "box" measuring approximately 18 " square by $16^{\prime}$ long. The core box will be fabricated by Fermilab and furnished to the construction subcontractor for connection to the beam pipe and installation in the beam dump. The dump will consist of a block of steel plates measuring approximately 7 ' square by $26^{\prime}$ long which surround the core. The foundation for the dump consists of a concrete base slab topped with a 1' thick steel layer. The entire dump will be encased in a concrete "shell" approximately 1' thick with all surfaces covered with a waterproof membrane. The dump site will be over-excavated, lined with a waterproof membrane, backfilled to the dump foundation level with granular material and a 4" diameter sampling underdrain located below the longitudinal axis of the dump. A 6" diameter perimeter underdrain will be located around the foundation. The core will be water cooled with two separate sets of supply and return pipes routed from the top of the dump to an abort service alcove located along the nearby MI enclosure. The 6" underdrain and the 4" sampling pipe will also be routed under the MI enclosure to this service alcove. The alcove will be a CIP concrete structure similar to other MI alcoves except the floor will be depressed below the 713'-6" MI floor level. The abort service alcove will house a sump for the 6" underdrain with radiation monitors to control the discharge of the pump. The capped 4 " sampling drain will extend vertically above the alcove floor to provide a means of sampling ground water directly below the dump. The alcove will also house a cooling system circulating pump plus a frame and plate type heat exchanger connected to the MI LCW system on one side and the two dump cooling circuits on the other. The depressed alcove floor assures that no leaks or inadvertent water spills associated with the dump will spread beyond the alcove. Refer to Drawing AS-4 for abort enclosure and dump cross-sections. 
The abort beamline will be designed to accommodate an extracted proton beam for future experiments including long baseline neutrino oscillations. Space will be provided along the abort beamline for additional magnets and equipment, the buried beam pipe will be large enough to accommodate two separate beam alignments and a bypass will be provided through the dump itself. The beam pipe for a future external beamline will be extended far enough beyond the downstream end of the dump to ensure that future excavations will be outside the radiation shielding limits of the MI enclosure and the dump. Thus a future extension of the extracted beamline will not interfere with FMI operation.

\section{Beam Transport Enclosures.}

Although there are six functionally different beam transport lines (listed earlier in the Overview), only three distinct new beam enclosures are required due to the use of shared beam elements and common enclosures. The civil work therefore includes the $8 \mathrm{GeV}$ beam enclosure and the two $150 \mathrm{GeV}$ transport enclosures. Drawing AS-1 illustrates the various beamlines, their direction and a general geometric layout.

The $8 \mathrm{GeV}$ beam enclosure, connecting the existing Booster enclosure with the FMI ring enclosure, requires the construction of a 2,190' long below-grade structure with a majority of its length composed of a 10'-0" wide by 8'-0" high cross-section identical to the MI ring enclosure (see Drawing AS-14). The $8 \mathrm{GeV}$ enclosure is presently conceived as four separate segments because some construction will be restricted by on-going accelerator operations. The segment which connects to the Booster enclosure (WBS 1.2.3.2) and the segment which passes below the antiproton transport enclosure housing beamlines AP2 and AP3 (WBS 1.2.3.3) must be constructed during the accelerator shutdown. The other two segments, totaling approximately 1,865 1.f., (WBS 1.2.2.7), will be constructed while the present accelerator is operational.

The $8 \mathrm{GeV}$ beamline slopes downward from elevation $726.552^{\prime}$ at the Booster to elevation 715.724' at the FMI so the $8 \mathrm{GeV}$ enclosure will be constructed in stepped segments with level base slabs. Beginning at the Booster, the $8 \mathrm{GeV}$ enclosure will match the Booster enclosure floor elevation at $722^{\prime}-6^{\prime \prime}$ for $80^{\prime}$, then drop $2^{\prime}-0^{\prime \prime}$ to elevation $720^{\prime}-6^{\prime \prime}$ for approximately $210^{\prime}$ and finally step down $7^{\prime}-0^{\prime \prime}$ to elevation $713^{\prime}-6^{\prime \prime}$ for the remaining length to match the FMI ring enclosure floor elevation. The 7'-0" vertical transition area (see Drawing AS-10) is the location for a personnel access stair labyrinth from grade to both levels, a ceiling mounted monorail with two 10 -ton hoists to provide equipment access between levels and a vertical access hatch to grade. This enclosure segment will be as wide as $16^{\prime}-0^{\prime \prime}$ to accommodate the hatch and to facilitate the change in the $8 \mathrm{GeV}$ beamline location relative to the enclosure wall. Components are centered $2^{\prime}-10^{\prime \prime}$ from the inside face of the west wall at the 11'-0" wide upper level (elevation 720'-6") and 2'-3" from the inside face of the east wall at the 10'-0' wide lower level (elevation $\left.713^{\prime}-6^{\prime \prime}\right)$. The enclosure height also varies in this region to accommodate the 
sloping beamline components and to provide a horizontal surface for mounting the monorail with the maximum height at $15^{\prime}-0^{\prime \prime}$. The $7^{\prime}-0^{\prime \prime}$ wide by $24^{\prime}-0$ " long hatch provides early temporary equipment access to the $8 \mathrm{GeV}$ enclosure between its initial (Phase 2) termination point approximately 380' from the Booster and the opposite initial (Phase 2) termination point at the antiproton crossing. The permanent equipment access via the North Hatch Building must await the accelerator shutdown period before the $8 \mathrm{GeV}$ connecting enclosure segment can be constructed below the antiproton AP2 and AP3 beamline enclosure. See Drawings AS-12 and AS-15 for details of this connecting segment. Once technical components for the northern portion of the $8 \mathrm{GeV}$ enclosure have been installed via the temporary hatch, it will be plugged with precast concrete shielding blocks, capped with a water-tight cover and topped with earth to provide the required shielding.

The $8 \mathrm{GeV}$ enclosure will be constructed using the identical methods described for the MI ring enclosure. Approximately 1,660 1.f. will consist of $10^{\prime}-0^{\prime \prime}$ wide by $8^{\prime}-0$ " high precast elements, 155 l.f. of $11^{\prime}-0$ " wide by $8^{\prime}-0$ " high precast elements and the remaining 375 l.f. as CIP concrete. In addition to the 90 l.f. of CIP concrete at the aforementioned hatch area, there will be a 40' alcove and 50' transition at the equipment access both located opposite the North Hatch Building (Drawing AS-13), three short segments of enclosure at exit stair intersections, 72 ' at the segment below the antiproton transport enclosure and the remaining 103 l.f. at the Booster connection including 80 l.f. of existing enclosure to be demolished and reconstructed to support the greater shielding load (Drawing AS-9). Earth berms or a combination of earth and steel plate over the $8 \mathrm{GeV}$ enclosure will typically provide $24^{\prime}-6^{\prime \prime}$ of radiation shielding required for unlimited occupancy.

The $8 \mathrm{GeV}$ enclosure Booster connection (WBS 1.2.3.2) includes approximately 173 1.f. of new enclosure plus 80 1.f. of demolished and rebuilt enclosure which must be constructed during the Phase 3 accelerator shutdown period. This portion of the $8 \mathrm{GeV}$ enclosure traverses an area with several active underground utilities including domestic water, sanitary force main , natural gas, two sets of chilled water supply and return, industrial cold water, power and communication ducts, storm sewer, pump discharge and a cooling water return pipe to the Booster bond. The enclosure also passes below Well Pond and South Booster Roads, the parking lot for the Southwest Booster Lab office building and a portion of the building itself. Because the $8 \mathrm{GeV}$ enclosure at this location is at a relatively shallow depth (to accommodate the extracted beam at the Booster elevation), the shielding equivalent of $24^{\prime}-6$ " of earth will require significant quantities of steel shielding to maintain roads at existing elevations and to minimize interference with existing facilities. In addition, sheet piling, steel H-piles with timber lagging, underpinning techniques and retaining walls will be required to protect existing utilities and structures. Approximately 80 l.f. of the existing Booster extension enclosure will be demolished and 
reconstructed to support the heavier shielding load. Portions of the existing Booster enclosure will be reinforced with additional concrete or straddled with a separate support structure to carry the added shielding weight. A limited area of the Southwest Booster Lab office building will require modifications including underpinning, replacing windows with a concrete retaining wall and small quantities of interior shielding. While the means of achieving the most cost effective shielding will continue to be studied, the Title I concepts illustrated on Drawings AS-9 and AS16 demonstrate a conservative, feasible method for a totally passive radiation shielding scheme. Work under WBS 1.2.3.2 will include a new personnel exit stair connecting with the Booster enclosure downstream of the existing beam dump and the rebuilt portion of the Booster extension will preserve the required equipment space for the existing $8 \mathrm{GeV}$ beam transport to the Antiproton Source (AP4 beamline).

The other segment of the $8 \mathrm{GeV}$ enclosure to be constructed during the shutdown is the connecting link below the antiproton enclosure housing the AP2 and AP3 beamlines (WBS 1.2.3.3) shown on Drawings AS-12 and AS-15. This work requires relocation of equipment for the AP2 and AP3 beamlines (by Fermilab) for a length of approximately 75 feet, removal of nine existing precast concrete antiproton enclosure elements and demolition of the CIP concrete base slab to provide access for construction of the $8 \mathrm{GeV}$ connecting enclosure. The connecting segment will be CIP concrete to support the atypical load of the antiproton enclosure plus its higher shielding berm. Once the $8 \mathrm{GeV}$ enclosure connection is completed and backfilled to elevation 725'-0", the antiproton base slab will be replaced, the precast elements reinstalled and dampproofed, underdrains reconnected and the shielding berm completed. Fermilab will then reinstall the AP2 and AP3 beamline components and related equipment.

The Phase 2 portions of the $8 \mathrm{GeV}$ enclosure (WBS 1.2.2.7), comprising the majority of the work, are typically identical to the precast element construction for the MI enclosure. There are two significant areas of CIP concrete enclosure. The temporary hatch area with monorail hoists, access stair and the 7' vertical step in the floor elevation has already been described. The other area of CIP concrete is located opposite the North Hatch Building and includes an alcove for utility penetrations and the intersection region of the equipment-personnel access labyrinth from the North Hatch Building with the $8 \mathrm{GeV}$ enclosure (see Drawing AS-13).

In addition to the stairs at the North Hatch Building, the temporary hatch location and the Booster connection, there are three more exit stair labyrinths located along the length of the 8 $\mathrm{GeV}$ enclosure. The six exits ensure no deadends longer than 50' and no exit distance greater than $300^{\prime}$. As noted earlier, the primary equipment access will be via a $7^{\prime}-8^{\prime \prime}$ by $30^{\prime}-2^{\prime \prime}$ covered hatch at the North Hatch Building connecting to a $10^{\prime}-0^{\prime \prime}$ wide by $8^{\prime}-0^{\prime \prime}$ high curved labyrinth at floor elevation 713'-6". 
The other two beam transport enclosures are the nearly symmetrical structures connecting the MI and Tevatron enclosures. Identified by their major functions as the $150 \mathrm{GeV}$ proton injection (P-150 GeV) and $150 \mathrm{GeV}$ antiproton injection (A-150 GeV) enclosures, the plan is shown on Drawing AS-3 with longitudinal sections on Drawings AS-5 and AS-6, and the transverse section on Drawing AS-7. In addition to the $150 \mathrm{GeV}$ proton injection beamline, the southeastern enclosure also houses the $120 \mathrm{GeV}$ proton beam from the FMI to the antiproton production target and the $120 \mathrm{GeV}$ extracted proton test beam to the fixed target areas. These beams travel to the Tevatron enclosure at $\mathrm{F} 0$ where both beams are injected into a beamline arc composed of the former Main Ring accelerator components as far as either F-17 in the case of the antiproton production, or the A0 Transfer Hall and the start of the Switchyard for fixed target beams in the case of the test beam. The $8 \mathrm{GeV}$ antiprotons are transported to the FMI following the $120 \mathrm{GeV}$ antiproton production line in reverse from F-17 to F0 and back to the FMI. While the injector beam lines are approximately $900^{\prime}$ in length, a significant portion of their components are housed in widened portions of the Injector enclosure and the F0 sector of the Tevatron enclosure leaving only $135^{\prime}$ long segments as $10^{\prime}-0^{\prime \prime}$ wide by $10^{\prime}-0^{\prime \prime}$ high precast element enclosures with a floor elevation at 713'-6". Because the $150 \mathrm{Gev}$ enclosure physically connect the early Phase 2 MI enclosure work with the Phase 3 shutdown work at the F0 enclosure, they must necessarily be constructed in two phases. Drawing AS-3 shows the interface between these construction phases as a line of sheet piling transverse to the $150 \mathrm{GeV}$ enclosures and clearly demonstrates why a portion of each enclosure is part of the injector enclosure between MI-62 and MI-52 (WBS 1.2.2.2) with the remaining segments are included with the F0 enclosure (WBS 1.2.3.1).

The transfer beams must transition from the MI beamline at elevation 715'-9" to meet either the Tevatron or remnant Main Ring at elevations $723^{\prime}-41 / 2^{\prime \prime}$ and $725^{\prime}-6^{\prime \prime}$ respectively. Provisions must also be made to install (or later replace) magnets and other equipment along these several beamlines. With the floor of the MI enclosure at 713'-6" or 9'-0" below the Main Ring enclosure floor elevation of $722^{\prime}-6$ ", one possible solution was holding the transition enclosures and one side of the F0 enclosure at the MI floor elevation of 713'-6". This configuration allows the magnet mover a level access floor throughout but requires mounting magnets $12^{\prime}$ above the floor. It also requires the MI side of the F0 enclosure to be 17'-0" high - a very large expensive structure. The Title I solution is a compromise providing a 5'-0" vertical step from the $150 \mathrm{GeV}$ enclosures to the F0 enclosure with a floor elevation of $718^{\prime \prime}-6 "$ ". The majority of the transfer line magnets can be installed from elevation 713'-6" with the magnet mover but hoists and rigging are required to install equipment for the MI components in the F0 enclosure. Longitudinal sections of the two $150 \mathrm{GeV}$ enclosures shown on Drawings AS-5 and AS-6 show the beamlines in relation to the enclosure elevation. 
The plan of the enclosures and beamlines in this area, shown on Drawing AS-3, indicates that a $60^{\prime}$ long segment of main injector components must be moved laterally toward a pocket along the inside wall to provide access for the magnet mover to travel from the MI aisle to the $150 \mathrm{GeV}$ enclosure. A one ton $\mathrm{jib}$ crane is located at the bifurcation of the two enclosures so that smaller components can be moved over the MI beamline into the $150 \mathrm{GeV}$ enclosure without moving magnets. Note also an exit stair from the $150 \mathrm{GeV}$ enclosure near the jib crane location. This stair labyrinth passes over the beam enclosures to connect with the exit stair from the MI enclosure. Hence exiting is provided without crossing under or over beamlines. The Phase 3 region of the $150 \mathrm{GeV}$ enclosures will be included in the description of the F0 enclosure later in this report.

\section{Service Buildings}

Ten above grade service buildings in five size configurations house equipment, services and utilities for the FMI and the beam transport lines. The locations of the ten service buildings are shown on the site plan Drawing C3 and the site criteria plan Drawing C4.

Typical service buildings MI-10, MI-20, MI-30, MI-40 and MI-50 (WBS 1.2.2.3) are identical in every respect except floor elevation. Drawing AS-17 shows the floor plan and Drawing AS-19 includes two sections through the typical service building. These buildings are located outside the FMI shielding berm approximately 1,800' apart. Since the buildings contain the magnet power supplies, the locations correspond to equal strings of magnets or approximately one-sixth of the dipoles in the beam enclosure below. The buildings also contain control racks, cable trays, pumps, two heat exchangers, deionizing bottles and controls for the LCW system, power distribution equipment and an air compressor. At two buildings, MI-10 and MI-40, power supplies and controls for kicker magnets ( $8 \mathrm{GeV}$ injection and $150 \mathrm{GeV}$ proton abort respectively) are also housed in a separate room with a depressed floor to retain oil spills. Each typical service building provides a direct personnel access via a CIP concrete service corridor over the berm to a stair and labyrinth connecting to an alcove area of the injector enclosure below. The stair and labyrinth contain no utilities, cable trays or ventilation air for the enclosure. Supply or return air to the FMI enclosure alcove below is directed via a vertical duct to an outdoor air handling unit. A rated door at the base of the stairs and an outside door at the top of the berm provide an emergency exit from the FMI enclosure at each typical service building. The service corridor between the back of the service building and the interlocked doors at the head of the stairway provide three functions other than personnel access to the FMI enclosure. The 6'-0" width permits a 2'-6" wide utility aisle for dc bus in a protective enclosure, power, controls and LCW piping to extend from the building to penetrations which connect with the alcove below. The penetrations consist of steel tubes, PVC ducts, or piping which are vertically offset or shaped in a reverse curve to avoid any line-of-sight penetrations through the 
shielding berm. A door to the outside just before reaching the interlocked doors provides a second exit from the service building. And since the corridor is constructed of reinforced concrete and the aforementioned outside door will be protected against flying projectiles by a concrete retaining wall, the service corridor also serves as a tornado shelter.

The five typical service buildings are nominally 50'-0" square in plan with a clear interior height of 10'-0". The foundation consists of concrete spread footings extending to an undisturbed bearing strata, concrete foundation walls, grade beams and floors, insulated metal siding erected on a structural steel frame and a built-up roofing membrane with insulation on a metal deck. Equipment access is provided by a 10'-0" wide by $8^{\prime}-0$ " high roll-up door and two sets of double doors. A 1-ton monorail with chain fall will be provided in the kicker room at service buildings MI-10 and MI-40. Kicker room floor elevations are dropped 3" below the general service building floor level to retain any potential oil spills from the kicker supplies. A transformer yard will typically be located immediately outside the power supply room of each building. Outdoor equipment will include pad-mounted transformers for the dipole and quadrupole power supplies, conventional power transformers, vacuum circuit breakers and switchgear. Below grade concrete retaining walls filled with stone will be provided around the perimeter of all equipment using oil coolants to serve as a secondary containment basin. Because the proximity of the transformers to the power supplies significantly reduces power costs, the distance will be minimized and the service building will be protected by an 8 " concrete block fire-rated wall adjacent to the transformer yard. All interior partitions will be concrete masonry units (CMU) with hollow metal doors and frames. The electrical and mechanical systems for these buildings are described in detail in subsequent sections of this report.

Service buildings will typically be located $25^{\prime}-6^{\prime \prime}$ from the FMI beam centerline at a floor elevation slightly above the surrounding existing grade. This siting arrangement provides a minimum of $26^{\prime}$ of equivalent earth shielding between the service building and the FMI enclosure. Where possible, Indian Road will be located far enough from the service buildings to permit easy access for turning trucks. A hardstand area for vehicular parking will be provided on the side of the service building opposite the transformer yard.

Two kicker service buildings, MI-52 and MI-62 (WBS 1.2.2.4), are located to either side of the MI-60 service building. These smaller buildings house power supplies and controls required for the kicker magnets in the $150 \mathrm{GeV}$ enclosures below grade. The building plan and section are shown on Drawing AS-20. These service buildings are nominally $25^{\prime}$ wide by $44^{\prime}$ long with a 10'-3" inside clear height. No personnel access to the FMI enclosure is provided at the kicker service buildings and, hence, there is no service corridor tornado shelter. Other features of the typical service building construction are incorporated in these buildings. 
Kicker Service Building F17 (WBS 1.2.3.1) is located adjacent to the Main Ring berm between existing service buildings F1 and F2. The power supplies and controls in this building are required by the kicker magnets to be installed in the existing Main Ring enclosure to insert the $150 \mathrm{GeV}$ protons into the Tevatron. The complementary function for the $150 \mathrm{GeV}$ antiproton insertion at $\mathrm{E} 48$ will be powered from a room in the remodeled F0 building above Tevatron location E48. No new kicker building is required at that location. The F17 kicker building, shown on Drawing AS-21, is nominally $20^{\prime}$ wide by $35^{\prime}$ long with a $10^{\prime}-3^{\prime \prime}$ inside clear height and the same features described for the other two kicker buildings except for the utility penetrations. The MI-52 and MI-62 kicker buildings are connected to the uncommissioned MI enclosure while F17 services the Tevatron enclosure. Hence, construction of its utility penetrations must await the Phase 3 shutdown period and will require temporary support of helium lines on the berm, excavation to the existing enclosure and core drilling through one or more of the precast hoopshaped Main Ring enclosure elements to install the penetrations.

The North Hatch building (WBS 1.2.2.8) is sited along the $8 \mathrm{GeV}$ beamline near the intersection of Kautz and Indian Roads. A plan of the building is shown on Drawing AS-27 with typical sections shown on the following drawing. The North Hatch building is composed of a nominally $50^{\prime}$ square low bay area with a $10^{\prime}-0^{\prime \prime}$ clear height plus a $40^{\prime}$ wide by $75^{\prime}$ long high bay area with $28^{\prime}$ clear height. Functionally, the low bay area mimics the typical service building except the kicker room has been replaced with a toilet area. The stair and labyrinth access to the $8 \mathrm{GeV}$ enclosure is also of a different configuration but serves the same functions of an exit from the below grade enclosure to a direct outside egress, tornado shelter and second exit from the service building. Power supplies, controls, LCW cooling equipment, and penetrations service the dipole and quadruple magnets of the $8 \mathrm{GeV}$ beam line.

The high bay of the North Hatch building primarily provides equipment access to the same $8 \mathrm{GeV}$ beam enclosure. A $7^{\prime}-8^{\prime \prime} \times 30^{\prime}-2^{\prime \prime}$ hatch is located at one end of the high bay connecting directly with a semi-circular 10' wide by $8^{\prime}$ high labyrinth at elevation $713^{\prime}-6^{\prime \prime}$. The hatch will be covered with 1'-6" thick precast concrete blocks as additional shielding whenever the $8 \mathrm{GeV}$ beamline is operational. A $12^{\prime}$ wide by $13^{\prime}$ high roll-up door provides truck access to the high bay which is serviced by a 30 -ton bridge crane with an $18^{\prime}$ hook height. The high bay will also serve as a magnet storage and staging area for the $8 \mathrm{GeV}$ beam line. Other features, including utility penetrations to an enclosure alcove, earth shielding parameters, transformer yard, hardstand and all construction features, are similar to those described for the typical service building.

The largest of the new service buildings will be located parallel to and southwest of the MI-60 segment of the FMI enclosure directly across the berm from the existing F0 service building. The MI-60 Service Building (WBS 1.2.2.8), as shown in plan view on Drawing AS-22 
and AS-23 with elevations shown on Drawing AS-24 and sections illustrated on Drawing AS-26, houses a number of functions, including two power supply areas at opposite ends of the building for dipole and quadrupole magnets, all power supply and control requirements for the FMI rf cavities, a pump room and deionizing facility for $\mathrm{LCW}$, technician space, $\mathrm{rf}$ development and assembly spaces, magnet test area, the FMI control room, and toilet facilities all located in a $22,500 \mathrm{sq} f \mathrm{ft}$ low bay area. An adjacent 5,000 sq ft high bay features an open $8^{\prime}-0^{\prime \prime}$ by $30^{\prime}-0^{\prime \prime}$ long hatch connecting directly with a curving $10^{\prime}$ wide by $8^{\prime}$ high labyrinth at elevation $713^{\prime}-6^{\prime \prime}$ which is the equipment access for the entire FMI ring enclosure as well as the $150 \mathrm{GeV}$ FMI enclosures. A 12 ' wide by $13^{\prime}$ high roll-up door provides truck access to the high bay which is serviced by a 30 -ton bridge crane with an $18^{\prime}$ hook height. A 5,000 pound capacity hydraulic freight elevator and a stairway located immediately adjacent to the high bay area provide additional access to the FMI enclosure below. The stair and adjoining labyrinth provide a rated exit for the MI-60 enclosure and the lower elevator lobby and hatch area serve as a tornado shelter. The high bay space will also serve as a staging and storage area for the FMI magnets and other beam line components.

The MI-60 Service Building will be $450^{\prime}$ long with a low bay width of $50^{\prime}$ while the high bay measures $50^{\prime}$ by $100^{\prime}$. As indicated on the building sections shown on Drawing AS-25, the floor elevation of the MI-60 Service Building is set at elevation 742'-6" to match the existing F0 service building floor and the clear interior heights are $12^{\prime}$ for the low bay and approximately $28^{\prime}$ for the high bay. The majority of the low bay area will be provided with a continuous floor trench located along the northeast wall which will provide access to the numerous utility penetrations leading to the MI-60 Enclosure. The MI-60 Service Building will be positioned far enough from the MI-60 Enclosure to provide 26' of equivalent earth shielding to the lower outer corner of the aforementioned cable trench.

Transformer yards will be located at either end of the MI-60 Service Building as well as directly southwest of the LCW pump room. Anode power transformers will be housed in special enclosures connecting to the rf gallery and because the entire service building is air conditioned, two 150-ton pad-mounted chillers will also be located southwest of the building. In addition to the high bay area, equipment access via roll-up doors will be provided at each beamline power supply room at the ends of the building. Construction features generally will be identical with those outlined for the typical service buildings. Some departures include CMU walls at the anode power supply enclosures, horizontal strip windows at occupied areas such as the high bay, tech area and if development lab and a CIP concrete wall adjacent to the berm.

The existing F0(RF) Service Building will undergo several modifications as part of the FMI project. These changes are required because the underground F0 Enclosure, which lies directly below the southwest half of the F0 Service Building must be demolished and 
reconstructed to accommodate the expanded beamline functions. Consequently, the overlying portion of the service building must be vacated of equipment and demolished. Additionally, a significant area of the remaining service building will require interior shielding - removing more functional space from service. These steps take place during the Phase 3 shutdown and will be described in the following section of this report. They are mentioned here to explain the ultimate need to replace space in the F0 (rf) Service Building.

Since equipment must be relocated before demolition can commence, the substitute space will be created before the shutdown. The scope of Service Building F0 North Addition (WBS 1.2.2.6) accomplishes this work. Conceived as a concurrent project with the MI-60 Service Building, the north addition will be constructed without disturbing the ongoing functions within the F0 Service Building. Drawing AS-22 shows the plan view of the addition while the section is shown as Stage 2, Section A on Drawing AS-26. Construction will first require the relocation of approximately $650^{\prime}$ of the Main Ring Road away from the present F0 service building to the far side of the transformers. Some relocation of underground utilities will also be required involving short duration shutdowns for reconnection. The 20'-0" wide addition will consist of the same structural and architectural details as the typical MI service buildings. The existing northeast wall of the F0 Service Building will remain in place except for small cut-outs required to connect new roof beams to existing columns. The existing foundation wall has been shown to have adequate strength and bearing to support its share of the new addition. The North Addition will be approximately $215^{\prime}$ long and enclose a floor area of $4,345 \mathrm{sq} \mathrm{ft}$. Once the addition is complete, the existing (former exterior) wall can be removed resulting in a 45' wide general space. After the shutdown commences, Tevatron of power supplies and controls, beamline power supplies and the control room will be relocated into the addition. Exterior transformers, anode power transformers and chillers will be provided to augment existing equipment.

\section{FOEnclosure}

The F0 Enclosure (WBS 1.2.3.1) construction as shown on Drawing AS-3, encompasses a region slightly longer than the long straight section of the existing Tevatron enclosure and connects with the $150 \mathrm{GeV}$ transition enclosures. This region will house rf accelerating and coalescing cavities reinstalled from the existing Tevatron, the remnant Main Ring elements and components of the several transport beamlines. Functionally, these are elements of the $150 \mathrm{GeV}$ proton injection line, the $150 \mathrm{GeV}$ antiproton injection line, the $120 \mathrm{GeV}$ antiproton production line, the $8 \mathrm{GeV}$ antiproton accumulator to the FMI, and the $120 \mathrm{GeV}$ extracted test beam line. As noted above, some of these lines share common elements or share common enclosures. But the existing F0 long straight section has insufficient space for the new transport beams to be included in addition to space required for the existing Tevatron rf cavities and beamline components. Hence, except for the equipment access labyrinth at the south end, 532' of the existing Tevatron 
enclosure, including all of the F0 long straight section, must be demolished and a new larger enclosure rebuilt with all work to be accomplished during the seven month Phase 3 shutdown. The sequence of construction in the F0/MI-60 area is illustrated by several cross-sections shown on Drawing AS-26. Stages 1 and 2 show the completion of the MI-60 Enclosure, MI-60 Service Building and the North Addition to the F0 Service Building - all completed while the Tevatron remains in operation. Note that the two initial lines of sheet piling remain in place. The southwestern line has been used to support utility penetrations and allow an early start of the MI60 Service Building construction. The second or middle line of piling remains in place to be used again during the Phase 3 work. The walers and horizontal cross lot bracing have been removed.

Once the shutdown of the Tevatron operation commences, equipment will be relocated (by Fermilab) from the southwest portion of the existing F0 Service Building to the New Addition and demolition will begin from the southeast. Fortuitously, the section of the service building to be demolished is actually a former building addition and the demarcation line is a full-height concrete wall which will function well in the remodeled configuration. Concurrently with the removal of equipment from the service building, beamline components will be removed from the underground F0 enclosure by Fermilab. Equipment, such as the Tevatron rf cavities which must be reinstalled later, will be stored in the E-sector of the Tevatron enclosure. Removal will be sequenced to provide early access to the 200' long CIP concrete section between stations E-49 and F-11 so that transverse saw cutting of the concrete can commence from inside the enclosure. After the above-grade service building is removed along with helium transfer lines and the upper portion of the waveguide and utility penetrations, the third (northeast) line of sheet piling, approximately 600 ' long, will be driven between the remaining section of the F0 Service Building and the northeast side of the underground Tevatron Enclosure at F0. This condition is depicted as Stage 3 on Drawing AS-26. The sheet piling, like the service building demolition will move from the southeast toward the northwest. Interior saw cutting will be similarly sequenced so no piling is driven above occupied areas of the F0 Enclosure. Excavation between the new piling line and the existing middle line will follow the sheet piling operation with walers and crosslot bracing installed as the excavation proceeds.

As the existing Tevatron enclosure is exposed by the excavation work, demolition will proceed in earnest. There are three types of demolition or removal operations planned. The central 200' of F0 Enclosure walls and roof are CIP concrete approximately 20" thick. This area will be saw cut transversely at approximately 6 ' intervals and then saw cut horizontally at the base of the walls to free the inverted U-shapes in 25 ton units. The 31 units will then be removed from the excavation and hauled to the railhead storage area on the Fermilab site for future use. The majority of the remaining F0 Enclosure is composed of $12^{\prime}$ diameter (188') and 10' diameter (112') hoop-shaped precast concrete elements each approximately 10' long. Experience has 
shown that these elements, with a maximum weight of 16 tons, are readily broken free of the base slab and easily removed to be stored at the railhead. The CIP concrete enclosure at the equipment access to the F0 Service Building and the entire 532' long concrete base slab, with a maximum thickness of 18 ", will be saw cut into manageable pieces, removed and deposited in the excavation along the middle line of sheet piling as shown in Stage 4, Section A on Drawing AS-26.

The reconstructed F0 enclosure will have a floor slab at two different elevations. The southwest or MI portion of the floor will be at elevation 718'-6" while the northeast side will match the Tevatron enclosure floor at elevation 722'-6" as shown in Section D on Drawing AS-7. The beamline components will be mounted on stands fixed to the lower floor but both levels will include an aisle space to permit magnets and equipment to be moved longitudinally along both sides of the enclosure. In particular, the upper level at elevation 722'-6" will allow the magnet mover to travel through the F0 enclosure providing continuous access around the Tevatron ring. The enclosure width will vary in steps from the typical $18^{\prime}-0^{\prime \prime}$ minimum to a maximum of $24^{\prime}-0^{\prime \prime}$ to meet the requirements of the diverging beamlines as indicated on Drawing AS-3. The ceiling elevation of $730^{\prime}-6^{\prime \prime}$ provides a minimum clear height of $8^{\prime}-0^{\prime \prime}$ on the Tevatron side and $12^{\prime}-0^{\prime \prime}$ on the MI side. The F0 enclosure will be a CIP concrete enclosure except for precast concrete roof beams. These roof beams will be utilized as a composite roof element to speed the construction by eliminating the need for interior shoring. The precast beams will be designed to carry the weight of the CIP roof concrete with provision to tie the two elements structurally so that the composite roof can support the full shielding loads. The existing curved access labyrinth leading to the stair and hydraulic freight elevator at the F0 Service Building will be reconnected to the new F0 enclosure. As noted earlier, this enclosure will also connect with the two $150-\mathrm{GeV}$ injection enclosures but a physical barrier with an air-tight door in both injection enclosures will be required to isolate the ODH possibility of the Tevatron enclosure from the FMI enclosure. Construction will require utility penetrations including right-angle type conduits for the eight Tevatron waveguide penetrations. The latter group will require a vertical concrete manhole at each waveguide for installation access which will later be plugged by steel and concrete and covered by a hatch as shown in Stage 4, Section A on Drawing AS-26.

The F0 enclosure connection to the $150 \mathrm{GeV}$ enclosures at each end will have nearly symmetrical features. The $150 \mathrm{GeV}$ enclosure floor elevation at 713'-6" will meet the F0 enclosure floor at $718^{\prime}-6^{\prime \prime}$ at a single $5^{\prime}-0^{\prime \prime}$ step approximately $250^{\prime}$ from station MI-60. A combined stairway will be located at this step providing personnel access from both levels of the $150 \mathrm{GeV}$ enclosure and also from the adjacent MI-60 enclosure to a common exit stair labyrinth leading to grade level. The step area is also the location of a ceiling mounted monorail with two 10 ton hoists which provide a means of transferring beamline equipment from the magnet mover 
on the 713'-6" level to the 718'-6" level of the MI F0 enclosure. The hoist area includes a shallow alcove area for storing rigging equipment and locating power panels and a sump. The hoist enclosure will be $17^{\prime}-0^{\prime \prime}$ high, a maximum of $18^{\prime}-0^{\prime \prime}$ wide and extend $30^{\prime}-0^{\prime \prime}$ beyond the step to meet the 10'-0" wide by 10'-0" high $150 \mathrm{GeV}$ precast concrete enclosure. The hoist area is shown in plan view on Drawing AS-3 and as longitudinal sections on Drawings AS-5 and AS-6.

Equipment can also be moved from the Tevatron side of the F0 enclosure to the MI side via another hoist area located between stations F0 and MI-60. A bridge crane with two 10-ton hoists will be located in an alcove with a width and length measuring 22'-6" and a ceiling height of 17'-0". As shown in the aforementioned plan and the longitudinal section on Drawing AS-5, this hoist area is located at beamline segments without magnets to provide maximum vertical clearance for material handling.

Shielding for the F0 enclosure has been established at 26' primarily because the ground level area between the MI-60 and F0 service building will be difficult to access in the future. As shown on the cross-section on Drawing AS-26, the final berm over the F0 enclosure will be at elevation $756^{\prime}-6$ " or 8 ' -0 " higher than the adjacent berm over the MI-60 enclosure. Areas with atypical ceiling heights such as the hoist alcove near the center of the F0 enclosure will require some steel shielding to maintain a uniform top of berm elevation. The $26^{\prime}$ shielding requirement between the F0 enclosure and the remaining portion of the F0 service building will require some special shielding configurations. Referring again to Stage 4, Section A on Drawing AS-26, it will be necessary to abandon the existing utility trench and a portion of the interior floor area along the southwest wall in order to construct an earth embankment inside the existing building. Lshaped precast concrete retaining walls will be used to minimize the earth encroachment and the earth will be capped with a concrete slab. The existing southwest wall is constructed of CIP concrete which will permit earth backfill placement on both sides. For those limited areas of the F0 service building where function or space requirements preclude the interior earth shield, exterior steel shielding will be added as the excavation is backfilled. The limits of the interior earth fill are shown on the building plan on Drawing AS-22 and the areas of steel shielding are shown on Drawing AS-3. Steel shielding may also be required above the hoist areas at either end of the F0 enclosure where it meets the $150 \mathrm{GeV}$ enclosure. A full height earth berm at these locations may impose an excessive shielding load on the adjacent existing Tevatron precast concrete enclosure. Local steel shielding above the hoist area will permit a reduced berm height matching the existing Tevatron berm.

Once the majority of the backfill between the MI-60 and F0 service buildings is complete, an 8'-0" wide by 8'-0" high connecting passageway of CIP concrete will be constructed between the buildings for personnel and control cabling access. As shown in sections on both 
Drawings AS-5 and AS-25, steel shielding will be required below the passageway as it passes over both the F0 and MI-60 enclosures.

The middle line of sheet piling plus the walers and braces will be salvaged from the earth retention system. The outer two lines of sheet piling will remain in place. The helium transfer lines will be reinstalled along the top of the completed berm. Underdrains, dampproofing and granular backfill at the walls will be used to insure a dry enclosure. Cable trays, power bus, conventional power and lighting, LCW piping and other utilities will be installed as shown on Section D of Drawing AS-7.

\section{Foundation Systems, Earth Retention and Active Soil Control}

All base slabs for the FMI ring and transport beam enclosures will be founded on unweathered glacial till with high bearing capacities. Soil boring locations, elevations of the glacial till and unconfined compressive strengths are shown on Drawing $\mathrm{C}-1$. Foundations for the service buildings will generally consist of spread footings located below frost level with perimeter foundation walls. Where foundations are located within the limits of the enclosure excavation, the footing elevation will be dropped to bear an undisturbed material and the load carried by concrete piers and grade beams. The service corridors passing over the berm between the service buildings and the stair to the enclosure will be supported by three concrete piers bearing on the alcove structure below. Because the corridors are constructed of CIP concrete, there will be adequate structural stiffness to bridge between the deep and shallow foundations. The pier supports at the service corridor also eliminate differential settlements between the structure and utility penetrations.

The portion of the MI-60 service building located above the personnel and equipment access labyrinth presents a special problem. The earth retention system proposed for the MI-60 enclosure assumes equal earth loads on both sides of the excavation so the MI-60 labyrinths cannot be excavated after the MI-60 enclosure sheet piling has been driven and the space between fully excavated. However, if the labyrinth area is constructed first, using normal cut and cover methods, almost half of the MI-60 service building will bear on compacted fill presenting potential differential settlement problems.

After studying several alternatives, it has been proposed to construct the labyrinths, stair enclosure and elevator shaft prior to the adjacent section of the MI-60 enclosure. To reduce the volume of excavation required, sheet piling will be driven around the perimeter of the labyrinths within the limits of the MI-60 service building as indicated on Drawing AS-3. A combination of crosslot bracing and deadmen will be utilized to support the piling horizontally. After the labyrinths and shafts are constructed to grade level, the space between pilings will be backfilled with compacted granular material and the sheet piling pulled to be reused for the MI-60 enclosure. The combination of reduced backfill volume plus ample time for settlement before 
starting the service building footings should reduce potential settlement problems. Additionally, the high bay columns, which carry the reactions of the 30 -ton bridge crane, will be supported by belled caissons extending into the glacial till.

Earth retention systems will be used during the various construction phases in order to retain foundations of existing beam enclosure or service building structures. In addition, the retention systems will contain and confine much of the active soil adjacent to these existing beam enclosures. With these methods, the FMI ring enclosure and much of the beam transport enclosures will be built during normal accelerator operations.

Sheet piling, driven beside the existing Tevatron F0 enclosure and F0 service building will allow construction of the FMI ring enclosure and MI-60 service building during accelerator operations. This sheet piling will be driven parallel to and 21' beyond the Tevatron enclosure to an approximate depth of $42^{\prime}$ for a length of 940 '. Refer to Drawing AS-3.

A second row of parallel sheet piling approximately $650^{\prime}$ long will be driven along the southwest side of the proposed FMI MI-60 enclosure to be supported by walers and crosslot (horizontal) bracing or walers and prestressed tie-backs. After the MI-60 enclosure is completed and partially backfilled, the walers and bracing will be removed and reused. Both lines of sheet piling will remain in place.

After the Tevatron accelerator shutdown commences and the demolition of a portion of the existing F0 service building is complete, a third line of sheet piling will be driven between the remaining F0 service building and the Tevatron F0 enclosure for a length of approximately 610'. Two short (100') segments of sheet piling will also be required between the Tevatron and $150 \mathrm{GeV}$ enclosures to maintain balanced earth loads over the Tevatron enclosure. Horizontal bracing will be modified and reinstalled between the first and third piling rows. After excavation between the sheet piling, the Tevatron F0 enclosure will be demolished and rebuilt and the connecting portions of the $150 \mathrm{GeV}$ injection enclosures will be completed.

Soils excavated from areas adjacent to existing Tevatron enclosures that exhibit low levels of activity will be carefully segregated, controlled and subsequently backfilled into areas adjacent to the reconstructed enclosures. Soil storage pits next to required excavations will be dug as a repository for all active soils removed during construction. The active soil bulk will be covered with an umbrella of clay soil for temporary protection and containment during the construction period. Surface water will be controlled and diverted away from these storage pits. Demolished concrete from the base slab of the Tevatron F0 enclosure will be left in the bottom of the excavation at documented locations and backfilled.

\section{Kautz Road Master Substation and Power Distributions}

Power for the FMI project will be provided via a new $345 \mathrm{kV}$ overhead transmission line, a new $345 \mathrm{kV}$ substation and a $13.8 \mathrm{kV}$ secondary distribution system in underground ductbanks 
to various substations for three FMI power systems. These systems, as discussed in Volume 1 of this Title I report, are the pulsed power system, the conventional power system and the beamline power system.

A new $345 \mathrm{kV}$ switching station will be installed at the southeast corner of the Fermilab site along the Commonwealth Edison Co. transmission line corridor paralleling the EJ\&E railroad tracks as indicated on Drawing C-1. Two manually operated 1,600 amp, $345 \mathrm{kV}$ switches will connect the new transmission line to Commonwealth Edison transmission lines No. 11119 and No 11120.

A new overhead transmission line, approximately $13,200^{\prime}$ long will be installed parallel to the southern boundary within the Fermilab site, at least 500' from Illinois Highway 56, Butterfield Road. The line will bend northward along Kautz Road and will terminate at the New Kautz Road Master Substation (KMS). Double arm steel poles at an average span of 750' will carry a single $345 \mathrm{kV}$ circuit with static shield wires above.

The new KMS will be located east of Kautz Road approximately 900' from nearest arc of the FMI, 0.5 miles from the south site boundary and 1.6 miles from the existing Master Substation (MSS) at the intersection of Roads A-1 and B. The new substation area is well drained and lies east of the wooded areas that abut the Tevatron ring between service buildings E-3 and E-4.

The new KMS will consist of an 188,000 sq ft rock base enclosed within a security fence with an access gate to Kautz Road. Within this area will be the $345 \mathrm{kV}$ dead-end structures, aluminum tubular bus and insulators, motor operated $345 \mathrm{kV}$ switches, SF6 main circuit breaker, four transformers, and a walk-in structure for secondary equipment. Foundation pads and vaults, oil containment sumps, lightning and ground grids are also included.

Two new transformers and two existing transformers from the present MSS will be installed in the new KMS. Refer to Drawing E-1. The new transformers will be 40 MVA capacity (40/53/66.6 MVA-OA/FA/FOA), 345/13.8 kV, 3-phase, $60 \mathrm{~Hz}$ oil filled and will be used for the FMI pulsed power supply and beamline power systems. An existing 60 MVA transformer 82B, that will be retired from Main Ring pulsed power supply service, will be used for the FMI conventional power system. Another existing 40 MVA transformer 84A, currently an MSS on-line spare, will be moved and reinstalled in the new KMS.

The secondary sides of the four transformers will be connected by $3,000 \mathrm{amp}, 13.8 \mathrm{kV}$ non-segregated outdoor bus to $13.8 \mathrm{kV}, \mathrm{SF}-6$ type main and feeder breaker with sufficient interrupting capacity for the available short circuit currents. These breakers, together with metering, relaying and communication equipment are all housed in an enclosed metal walk-in structure. 
Underground concrete-encased ductbanks with precast concrete manholes will route the $13.8 \mathrm{kV}$ feeders from vaults under the switchgear equipment at the new KMS to the various FMI power systems. Refer to Drawings E-1 and E-2. Other ductbanks will connect back to the existing Main Ring ductbank between service buildings E-2 and E-3. With these connections and the use of six existing but unused Main Ring feeders, approximately 40 MVA of primary power may be back-fed to the MSS to provide limited standby power at a future date.

The Pulsed Power Supply System will be fed from the new 40 MVA transformers in the KMS through four $13.8 \mathrm{kV}$ feeders for FMI ring pulsed power and one $13.8 \mathrm{kV}$ feeder for FMI beamline power. The FMI ring will use three loop feeders carried through an underground ductbank, the ends of which connect through switchgear at the KMS and near service building MI-50. At each service building, there will be a disconnect switch to supply power to the power supplies. This routing is shown in Drawing E-2. A paralleling switch at MI-30 will enable uneven loading of each segment without overloading the feeders. This switch can also be used for feeder isolation for maintenance purposes. The power for the beamlines will require one feeder with two 1,500 kVA substations at MI-60 and one 1,500 kVA substation at the North Hatch Building.

The Conventional Power System will be fed from the relocated transformer 82B and will consist of one $13.8 \mathrm{kV}$ feeder around the FMI ring, with a $500 \mathrm{kVA}$ transformer at each of the principal ring service buildings and a $750 \mathrm{kVA}$ at the North Hatch Building. The conventional power will be used for building power, lights, pumps, heating and air conditioning. At each service building there will be a disconnect switch with a ductbank connection to the conventional power transformer. Conventional power will be connected to power distribution panelboards in each service building. Power for the water pumps, heating and ventilating equipment, control racks and service outlets will be provided by 480/277 volt, 3-phase branch circuits. Step-down transformers and panelboards provide 208/120 volt power for lighting and outlets. Separate panelboards for isolating beam equipment at $480 / 277$ volt and 208/120 volt are provided. Drawing E-4 summarizes the criteria used for determining general lighting levels and convenience power distribution.

\section{Primary Cooling and Mechanical Systems}

The primary heat rejection medium for the $18.5 \mathrm{MW}$ water-cooled load generated by the FMI is cooling pond water (PW). Drawings M-3 and M-4 show the eight new interconnected cooling ponds ( $\mathrm{A}$ through $\mathrm{H}$ ) that roughly follow the MI ring perimeter and provide 18.8 acres of cooling surface. The ponds total $11,900^{\prime}$ in length, range from $60^{\prime}$ to $90^{\prime}$ in width and generally have a depth range of from 4'-6" to 7'-0". A transverse concrete dam near service building MI-30 permits a change in water level between ponds $\mathrm{D}$ and $\mathrm{E}$. Generally, the pond water levels vary from elevation $741^{\prime}$ to $737^{\prime}$ following the general site topography with ponds $\mathrm{A}, \mathrm{B}$, and $\mathrm{H}$ at 
elevation 739' to match the Main Ring pond elevations at the F0 area. Transfer piping between the FMI ponds and the existing Main Ring ponds allow for make-up and temperature control.

As described in Chapter 3.9 of Volume 1 of this Title I report, the LCW system consists of parallel supply and return loops exchanging heat from the FMI beamline magnets, if components and power supplies to the pond water. Much of the equipment now in use in the present Main Ring service buildings will be relocated to the new FMI service buildings and perform in a similar capacity. New LCW piping will be installed in the FMI beamline enclosures. Primary deionized water will be supplied to the FMI LCW system along piping in the $8 \mathrm{GeV}$ enclosure from existing Main Ring columns at the Central Utility Building. This building will also be fitted with 3,000 gallons of LCW tanked storage for make-up use in the FMI similar to the existing Main Ring system. An additional 3,000 gallon storage tank will be located at the MI60 service building. Continuous slip-stream deionizing bottles will be located at the five typical FMI service buildings, the MI-60 service building and the North Hatch Building.

The civil construction scope (WBS 1.2.1.2) includes the pond excavation and berm construction, dams between ponds, interconnecting underground piping, pond liners, rip-rap slope protection, and pond overflow structures. The pond water system included as WBS 1.2.1.11 includes the pond water intake and discharge pipes, pump vaults, pond water pumps, level control system and supply and return piping to the service building as shown schematically on Drawing M-3. For purposes of this Title I report, the installation of heat exchangers, LCW pumps, LCW piping and related work is included in the technical scope of work.

An existing chilled water (CW) system at the F0 service building, which originates at the Central Utility Building, will be retained and extended to the pump room of the new MI-60 service building to cool the LCW for the MI rf system. The new combined loads on the CW system will be comparable to the present loads.

An underdrain system, typically consisting of 6 " perforated pipe surrounded by a granular filter media and covered by a geotextile fabric, will be installed along both sides of the base slab for all underground enclosures. Similar underdrain systems are typically used for all Fermilab beam enclosures. Sump basins with alternating duplex pumps will be located in alcoves or stairway cul-de-sacs along the enclosures to collect the underdrain flow and discharge it into surface ditches as indicated on Drawing M-3. Based upon the Main Ring experience, the average MI ring underdrain flow is anticipated to be $200 \mathrm{gpm}$.

A slurry wall or similar barrier will be constructed on either side of the MI enclosure as it passes through the wetland area along Indian Creek at the south quadrant of the ring. The cutoff wall will extend through the alluvial soil and 5 ' into the glacial till to seal off any wetland groundwater flow into the underdrain system. A cross-section of the proposed slurry (cutoff) wall is shown on Drawing C-6. 
Moderate ventilation rates with dehumidification will be used in the FMI enclosures. Drawing M-1 presents a general layout of this arrangement. Ventilation supply fans with filters and electric heat are located at each service building with exhaust fans at intermediate points between, all connected by underground ducts to alcove areas of the FMI enclosures. Two air changes per hour will be provided when needed during non-operating periods. Ventilation systems will be manually controlled. Dehumidification units will be located periodically along the beam enclosures at the ceiling in alcoves or opposite exit stairways where sump basins are available to receive condensate. Small fans in the units will afford some circulation as a further aid in controlling humidity. Both the ventilation and dehumidification systems are patterned after the existing Main Ring systems.

The FMI service buildings are equipped with a variety of HVAC systems to accommodate the required occupancy, as outlined on Drawings M-1 and M-2. Local split-system air conditioning units with electric heat will provide temperature control in all kicker rooms and control rooms in the FMI North Hatch, kicker and typical service buildings. Electric unit heaters and filtered ventilative cooling supply fans with interlocked relief louvers will serve pump rooms, power supply rooms and magnet staging and storage areas in these same buildings. Temperature control at the F0/MI-60 service building will be provided by HVAC units with electric heat and fed from local central air-cooled chillers totaling about 425 tons capacity. All of the above buildings will be equipped with required ventilation provisions.

\section{Fire Protection and Life Safety}

All FMI structures will be provided with fire protection systems as scoped on Drawing M-1. Automatic sprinkler systems will be supplied from a direct buried 12" diameter ICW loop encircling the FMI and tied into the existing site ICW fire protection system in two places, just north of the F0 area and just south of the existing Antiproton Target Hall. Hydrants provided at each kicker and service building will be of the draft type, fed from the FMI cooling water ponds. All areas will be provided with code-required signage and local alarms and will be connected to the existing site-wide FIRUS monitoring system for reporting alarms and trouble conditions. Beamline enclosures will have combination fixed temperature/rate-of-use heat detectors and manual pull stations. Enclosure alcoves at the typical MI service buildings, MI-60 service building and North Hatch Building will have quick response sprinklers and standpipes in exit enclosures. All above-grade service buildings will have ordinary hazard wet type sprinklers with manual pull stations and smoke detectors.

The ten service buildings range in area from $700 \mathrm{sq} \mathrm{ft}$ at the F17 Kicker building to $27,500 \mathrm{sq} \mathrm{ft}$ at the MI-60 service building. All service buildings are Type II (000) construction consisting primarily of insulated metal siding and built-up roofing on steel frames. Where transformers are in close proximity to a service building, the adjacent wall will include two-hour 
fire rated masonry construction with a metal siding facing. All exit enclosures including stair labyrinths will include 11/2-hour rated door assemblies. Penetrations between enclosures and service buildings for cabling and other services will be sealed with fire stopping materials. Exits will be provided in accordance with the criteria of NFPA 101, the Life Safety Code. For this purpose, DOE- $\mathrm{CH}$ has classified the underground beamline enclosures as a "Special Purpose Industrial Occupancy" under Subsection 28-2.6.3 which requires the maximum travel distance for emergency egress not to exceed 300 feet. The addition of the exit stair labyrinths combined with access stairs at the service buildings results in intervals between exits at less than 600' at all locations. Additionally, where beamline components present a barrier to an aisle, such as diverging beams at the abort, $8 \mathrm{GeV}$ injection or the $150 \mathrm{GeV}$ extraction regions, exits are provided on both sides of the beamline. Wherever possible, dead end enclosures have been limited to $50^{\prime}$ and stairways between enclosure levels are enclosed. Handrails, railings around equipment hatches, stair configurations, aisle widths and vertical headroom have been designed in accordance with recognized standards - most notably OSHA standards. Emergency lighting is provided throughout the FMI facility and all electrical work will be in conformance with the National Electric Code and Underwriters Laboratory. Refer to the FMI Preliminary Safety Analysis Report for details of the fire protection and life safety provisions.

\section{Environmental Concerns and Actions}

Detailed and specific definitions of the wetland areas, floodplain and storm water management, archaeological concerns and ecological resources have been identified by environmental consultants resulting in the preparation, submittal and approval of a Floodplain/Wetland Assessment Report and an EA. As a result of these efforts, the following approvals/permits have been obtained:

As this Title I is issued, only two environmental-related issues remain unresolved. As explained in the EA, a great blue heron rookery exists inside the FMI ring. While the herons abandoned this rookery in 1991 to take residence near the center of the Main Ring, it is conceivable they may return while the FMI is under construction. It is recognized that limits must be imposed on construction proximity during the heron nesting season. However, the buffer zone radius, which is dependent upon noise levels, is not a well-defined value. Therefore, noise tolerance levels have been under study since 1991 at Fermilab and the results will be used to derive the construction activity limits. Secondly, Fermilab is preparing and will submit an application for a NPDES stormwater permit for the construction of the FMI. 


\section{AGENCY}

Division of Air Pollution Control

Illinois Environmental Protection

Agency

Springfield, Illinois

U.S. Environmental Protection Agency

Region V (SAC-26)

Chicago, Illinois
ACTION REOUESTED

Application for Permit

to Construct

Il. Adm. Code 201.142

NESHAP

ID \#0438 07AA1

Application for Permit

to Construct

40 CFR Part 61.07

Radionuclides National Emission

Standards for Hazardous Air Pollutions

(NESHAP)

REF: 5AT-26

Clean Water Act

Section 401,

Water Quality Certification

Clean Water Act

Section 404, Nationwide 26

Permit Application

No. 3499102

Farmland Conversion

Impact Rating

Springfield, Illinois

Department of the Army

Chicago District U.S.Corps of

Engineers

Chicago, Illinois

U.S.Department of Argiculture

Soil Conservation Service

Champaign, Illinois

U.S.Department of Energy
June 4, 1991

ISSUED

April 1, 1991

May 9, 1991

June 26, 1991

Sept. 18, 1991

July 6, 1992
Finding of No Significant Impact (FONSI)

In addition, other environmental agencies have been consulted resulting in the following accords:

\section{AGENCY}

U.S. Fish \& Wildlife Service

Rock Island, Illinois

Illinois Department of Conservation Springfield, Illinois

State Historical Preservation Officer Illinois Historic Preservation Agency Springfield, Illinois
CONSULTATION REQUESTED ISSUED

Consultation in Accordance

With Fish \&Wildlife Coordination

April 30, 1991

Act

48 Stat. 401

16 U.S.C. 661

Endangered Species Act

Consultation in Accordance with Fish \& Wildlife Coordination Act

106 Determination of No Effect 36 CFR 800
June 20, 1991

July 22, 1991 
As a result of the Fermilab environmental efforts, the FMI design and construction will incorporate the following features:

a. Modifications of the original FMI plan have avoided wetland impact so that the current design will require permanent filling of only 5.70 acres. This area represents less than $6 \%$ of the wetlands located within the immediate environs of the FMI project.

b. Pursuant to COE standards, at least 8.6 acres of mitigation area, representing a 1.5 to 1.0 ratio of filled wetlands, will be constructed near Indian Creek within the limits of the FMI berm. The mitigation area will be divided into sedge meadow and a forested area to mimic the existing W4 wetland habitat.

c. While the FMI project is located within the Indian Creek floodplain, the design will insure no increase in the high water elevation or total discharge flow for a 100 year storm at the Fermilab site boundary. A compensatory storage area of at least 29 acre-feet will be constructed within the floodplain to offset the FMI construction. Stormwater flows through the wetland areas will be designed to insure adequate supplies.

d. Three archaeological areas have been identified in the vicinity of the FMI but none will be disturbed by construction activities. The Tadpole, Pioneer and Lorenz sites will be permanently fenced to preclude any interference.

e. Ecologically, the FMI proposed construction affects less than $4 \%$ of the undeveloped areas of the Fermilab site and, hence, will have no significant effect on Fermilab's biological communities or the Laboratory's status as a NERP. No federal- or state-protected species were identified within the FMI construction area. The proposed measures for avoiding impacts to the heron rookery have been sanctioned by the U.S. Fish and Wildlife Service.

\section{Energy Conservation}

Energy conservation practice, requiring consideration of total energy consumption for both the materials of construction as well as operation of the FMI facility for its projected lifetime, is not applicable to accelerator facilities with their inherent heavy electric power requirements. Environmental requirements for heating, ventilating, lighting, humidity control and air conditioning are driven by the essential needs of the technical equipment in a generally uninhabited facility. Where personnel are present, the environmental requirements relate to conditions necessary for effective operations. The service buildings are occupied during brief shutdown periods and they have been designed in accordance with DOE standards relative to material selection, thermal insulation and minimal fenestration. Energy conservation features related to efficiencies of mechanical equipment and the capability of remotely turning off 
enclosure lighting systems have been incorporated in the design. Consideration of alternate energy sources such as solar, wind or natural gas require that such sources compete against the heavy electrical service required by the accelerator facility. When generation equipment and utility extension costs are considered, these alternatives are not competitive with electrical service. 


\section{OUTLINE SPECIFICATIONS AND SYSTEM DESCRIPTIONS}

\section{SITE PREPARATION}

\section{I.A Site Layout and Site Limits}

.1 Monuments and Benchmarks: Primary control points furnished by Fermilab.

.2 Lines and Grades: Extend from primary control points for all work as required.

.3 Construction Limit Fencing: Standard 48" wood slat snow fencing with studded T-posts.

.4 Traffic Barricades: Furnish as required with flasher lights.

\section{B F0 and MI-60 Enclosure Construction Protection}

.1 System: Driven steel sheeting with two lines of walers and either crosslot bracing, drilled and grouted soil anchors, or tiebacks to concrete deadmen.

.2 Steel Sheeting: Rolled steel sheeting, interlocking joint, standard strength, ASTM A-328.

.3 Walers: Channel shaped and wide flange structural steel, ASTM A-36.

.4 Crosslot Bracing: Structural steel members, ASTM A-36; or hollow structural sections, ASTM A-500 Grade B or ASTM A-53 Grade B; or pipe sections, ASTM A-501.

.5 Soil Anchors: Grouted soil anchor tie rods of hi-tensile $150 \mathrm{ksi}$ steel, "Dywidag" or equal, ASTM A-722.

.6 Tie Backs: Steel rods, ASTM A-36 or A-572.

.7 Concrete: 4,000 psi Class "X" concrete, IDOT Standard Specification Section 504.

\section{C Existing Construction Protection}

.1 Included: Sheet piling near intersection of $8 \mathrm{GeV}$ enclosure and booster to protect power and control ducts (two locations). Temporary supports at cryo line crossing. Removal and reinstallation of AP beamline enclosure above $8 \mathrm{GeV}$ enclosure. Temporary support of helium lines at F-17 Kicker building.

.2 Specifications: Similar to 1.B, F0 and MI-60 enclosure construction protection above.

\section{D Construction Roads and Hardstands}

.1 Included: Rough grading, subbase, and culverts for construction roads and hardstands.

.2 System: Remove topsoil and unsuitable material; provide rough grading, pit run gravel embankment, 12" subbase, 6" base, culverts. Provide geotextile mat at wetland areas.

.3 Aggregates: Per IDOT specifications; Subbase: 12" CA-1; base, 6" CA-6. 
.4 Geotextile: Inorganic, non-woven, heavy fabric, $300 \mathrm{lb}$. tensile strength per ASTM D-1682.

.5 Culverts: Galvanized corrugated steel pipe, with end sections and bituminous coating; or reinforced concrete pipe with concrete end sections.

\section{I.E Erosion Control}

.1 Included: Silt fences, dikes, swales, sediment traps, and stabilized construction entrances. Conform to Illinois Environmental Protection Agency, "Standards and Specifications for Soil Erosion and Sediment Control," IEPA/WPC/87-012.

\section{SITE WORK AND EARTHWORK}

\section{A Site Work}

.1 Included: Clearing, grubbing, demolition, excavation and backfilling; for enclosure, cooling ponds, and buildings.

.2 Demolition: Sawcut and break out existing concrete. Blasting not permitted. Stockpile and segregate rubble during construction and place contaminated material in designated backfill areas. Non-contaminated materials to be placed in designated locations on Fermilab site.

.3 Excavation: Excavate to required bearing strata. Segregate and stockpile topsoil, radiated soil, suitable backfill, and unsuitable material. Radiated soil to be used in designated backfill areas.

.4 Excess Material: Remove to designated areas on site.

.5 Dewatering: As required to provide firm, dry subbase. Discharge into sedimentation basins.

.6 Fill Material: Suitable excavated material or sound bank run sand and gravel, granular material, free of vegetable matter, wood, debris and stones larger than 4". Minimum 6" compacted granular fill under slabs on grade and within 24" minimum of enclosure walls. Fill to be placed in maximum 8" loose lifts.

.7 Compaction: Structural backfill to be compacted to $95 \%$ of the maximum dry density per ASTM D-1557, Modified Proctor. Nonstructural fill to be compacted to 95\% of the maximum dry density per ASTM D-698, Standard Proctor.

\section{B Road and Parking}

.1 Included: Regrade construction roads, add additional aggregate as required, and 3" bituminous topping.

.2 Aggregates: Per IDOT Specifications; Subbase: CA-1; base, CA-6.

.3 Bituminous Pavement: $3^{\prime \prime}$ bituminous concrete binder and surface course conforming to IDOT Standard Specification 406. 


\section{D Site Concrete}

.1 Included: Headwalls, spillways, dams, thrust blocks, curbs, exterior concrete aprons, pads, sidewalks, duct banks and deadmen.

.2 Material: 4,000 psi Class "X" concrete, IDOT Standard Specification Section 504.

.3 Reinforcing: Grade 60, ASTM A-615.

\section{E ICW (Industrial Cold Water) Piping}

.1 Included: Material, labor and equipment to extend and connect to existing ICW system.

.2 Material: Ductile-iron pipe, Class 52, AWWA C151, with cement lining AWWA C104.

.3 Valves: Gate valves, with non-rising stem, inside screw, $175 \mathrm{psi}$, mechanical joint, NFPA 24.

.4 Indicators: Post indicators, Class 150,175 psi, flanged connections, indicator, wrench and locking device, per Factory Mutual or Underwriters Laboratories.

.5 Fittings: Mechanical joint type, cast iron, cement lined AWWA C110.

.6 Bedding: 1'-0" minimum compacted fine aggregate under piping and along side for full width of trench.

\section{F DWS (Domestic Water System) Piping}

.1 Included: Material, labor and equipment to extend and connect to existing DWS.

.2 Material: Ductile-iron pipe, Class 52, AWWA C151, with cement lining to AWWA C104; 2" and less, copper Type K, ASTM B 88

.3 Valves: Gate valves, AWWA C500.

.4 Fittings: Cast iron, cement lined, AWWA C110, with rubber gasket joints, AWWA C111; 2" and less, copper sweat fittings.

.5 Bedding: 1'-0" minimum compacted fine aggregate under piping and along side for full width of trench.

\section{G Storm Water Drainage Piping}

.1 Included: Material, labor and equipment to extend above ground and below ground piping from roof drains to storm sewers and/or ditches.

.2 Pipe and Fittings: Reinforced concrete pipe, ASTM C-76 Class 3 with joints per ASTM C-443 or C-361; or 16 gauge galvanized corrugated steel pipe, AASHTO M-36, with asphalt coating AASHTO M-190.

.3 Manholes, Frames, and Covers: Precast reinforced concrete, Illinois Standard Specification Section 612. Frames, grates, and lids, Section 614.

\section{H Sanitary Sewer System}

.1 Included: Installation of lift station manholes and piping. 
.2 Pipe and Fittings: Gravity flow sewer, Class 52 ductile iron cement lined and asphalt coated conforming to AWWA C-151/ANSI A21.5186 with mechanical joints.

.3 Lift Station: Prefabricated assembly including chamber area, pump, controls and alarm system. Frames, grates and lids, Section 614.

.4 Manholes, Frames, and Covers: Precast reinforced concrete, IDOT Standard Specification Section 612. Frames, grates, and lids, Section 614.

\section{K Cooling Ponds}

.1 Included: Clearing, grubbing, and topsoil removal; bulk excavation, dewatering, grading, proof-rolling; installing pond lining, rip-rap, and pond perimeter berms; reinstalling top soil and finish grading.

.2 Material:

Earthwork: IDOT Standard Specification Section 200.

Rip-rap: IDOT Standard Specification Section 600.

Liner: Natural in-situ clay and/or a geosynthetic clay liner, or a geomembrane liner.

.3 Overflow Piping: Corrugated steel pipe, galvanized, with bituminous coating; or reinforced concrete pipe.

.4 Dams: Reinforced concrete.

\section{L PW (Pond Water) Piping}

.1 Included: Installation of new pump vaults, circulating pumps and piping to service buildings MI-10, $-20,-30,-40,-50,-60$, and North Hatch, and overflow piping.

.2 Materials: Ductile iron, Class 52, with external asphaltic coating, ANSI/AWWA Cl51/A21.51-86, with mechanical joints.

.3 Valves: Wafer-type butterfly valves and flanged iron swing check valves.

.4 Fittings: Mechanical joint ductile iron fittings.

.5 Pumps: Each pump vault contains two redundant alternating circulating pond water pumps installed in parallel. The pumps shall be Gould's vertical industrial can-type pumps with iron casing and bronze fitted. The temperature of the pond water for all pumps is between $90^{\circ} \mathrm{F}$. and $100^{\circ} \mathrm{F}$.

MI-60:

Two 2,400 gpm @ 200' TDH Model VIC-L 14" HMO - 3 stage 150 hp, 1,770 rpm.

Two 1,600 gpm @ 185' TDH Model VIC-L 16" BLC - 2 stage 100 hp, 1,770 rpm. 
Service Buildings: MI-10, -20, $-30,-40, \&-50$ :

Two at each building, total of 10 pumps - 1,600 gpm @ 185' TDH Model

VIC-L 16" BLC - 2 stage $100 \mathrm{hp}, 1,770 \mathrm{rpm}$.

North Hatch Building:

Two 500 gpm @ 240' TDH Model VIC-L 9LC - 2 stage 75 hp, 3,600 rpm.

.6 Strainers: Mueller iron body simplex basket strainers, Model \#165 for 6", 12", and 14 " with $125 \mathrm{lb}$. flange connections.

.7 Bedding: 1'-0" minimum compacted fine aggregate under piping and along sides for full width of trench.

\section{M Pond Make-up Water Lift Station}

.1 Included: $300 \mathrm{gpm}$ lift station consisting of two submersible redundant $300 \mathrm{gpm} @$ $25^{\prime}$ TDH pumps, concrete encased prefabricated fiberglass sump basin, and required controls.

\section{N CW (Chilled Water) System}

.1 Include: Installation of new piping.

.2 Material: Class 52 ductile iron with external asphaltic coating conforming to ANSI/AWWA C151/A21.51-86 with mechanical joints for underground piping. Schedule 40 carbon steel conforming to ASTM A53 - Type E, Grade B piping inside service building. All carbon steel piping shall be painted.

.3 Valves: Wafer-type butterfly valve.

.4 Fittings: Mechanical joint ductile iron fittings below grade and carbon steel buttweld fittings inside the service building.

\section{P Underground Electrical and Communication Ducts}

.1 Included: Extension and connection of existing duct system.

.2 Duct: Polyvinyl chloride, plastic duct and fittings, type EB, for concrete encasement, per NEMA Standards TC-6, UL 615A, and ANSI/ASTM F-512.

.3 Stub-ups: Rigid galvanized steel, long sweep, $90^{\circ}$ bends.

.4 Duct Encasement: Minimum 2" space between conduits, 3" all around, 2,000 psi concrete fill, steel reinforced, red colorant spread across fresh concrete, clean backfill

.5 Fish Wire: Pull and leave 1/4" nylon rope in each duct.

\section{V Underdrain Piping}

.1 Included: Installation of underdrain pipe, filter media, deep sumps and pump discharge piping along enclosure foundations. 
.2 Perforated Pipe and Fittings: Helically corrugated steel pipe, 16 gage, with 1/4" perforations, galvanized, AASHTO M-36, Type III Class I, with asphalt coating AASHTO M-190.

.3 Filter Media: Pipe surrounded by 6" blanket of coarse aggregate or pea gravel, CA8. Aggregate surrounded by geotextile filter fabric with perforations of 70 to 140 , USACOE-CW02215 EOS-US sleeve size opening, and strength characteristics according to ASTM D-3887 and ASTM D-2263.

.4 Sumps: CIP concrete or precast concrete basin; Illinois Standard Specification Section 612 (see Section 15I).

\section{Y Fencing}

.1 Included: Installation of fencing and gates at switchyard.

.2 Posts and Framing: Line posts to be 2" Schedule 40 galvanized steel pipe, ASTM A-120. Terminal posts to be 2-1/2" Schedule 40 galvanized steel pipe, ASTM A120. Rails to be $1-1 / 4 "$ Schedule 40 galvanized steel pipe, ASTM A-120. Truss rods to be $3 / 8$ " diameter galvanized steel rods, ASTM A-123. Stretcher bars to be 3/16" x 3/4" galvanized steel bars, ASTM A-123. Fence fittings shall conform to ASTM F-626.

.3 Gates: Welded frame, 1-1/2" Schedule 40 galvanized steel pipe, ASTM A-120. Gate posts to be $2-1 / 2^{\prime \prime}$ up to $6^{\prime}-0^{\prime \prime}$ leaves, 3-1/2" for 6'-0" to 13'-0" leaves, and 6" for 13'$0 "$ to $18 \sim-0 "$ leaves; Schedule 40 galvanized steel pipe, ASTM A-120.

.4 Fabric: 8'-0" high galvanized steel fabric conforming to ASTM A-392, \#9 wire in 2" diamond mesh, top selvage twisted and barbed, bottom selvage knuckled. Barbed wire to be double strand, 12-1/2 gauge wire with 14 gauge, round, 4 point barbs, ASTM A-585 Type II, Class II.

\section{REINFORCED CONCRETE}

\section{A Formwork}

.1 Included: All formwork required for cast-in-place and precast concrete.

.2 Materials: Clean, straight rough lumber for below grade or concealed work. Grade "C" plywood or approved commercial forming system for exposed work.

.3 Standards: Conform to ACI Standard "Recommended Practice for Concrete Formwork" (ACI 347).

\section{B Reinforcing}

.1 Included: Reinforcing bars, welded wire fabric, mechanical splices, and bar supports.

.2 Materials: Reinforcing bars, Grade 60, ASTM A-615. Welded wire fabric, ASTM A-185. 
.3 Standards: Conform to ACI Standard "Manual of Standard Practice for Detailing Concrete Structures" (ACI 315).

\section{C Concrete Materials}

.1 Included: Mud slabs, base mat, grade beams, slabs-on-grade, walls, columns, roof slabs, precast roof slabs, precast tunnel sections, and shield blocks.

.2 Design Mix: 4,000 psi at 28 days for CIP concrete and 6,000 psi at 28 days for precast concrete.

.3 Cement: Type I ASTM C-150; or Type III, ASTM C-150, for precast units.

.4 Aggregates: Clean graded aggregates, ASTM C-33.

.5 Admixtures: Air entraining per ASTM C-260. Water reducing per ASTM C-494, type A or D.

.6 Water: Clean, potable.

.7 Standards: ACI 301, Specifications for Structural Concrete for Buildings; ACI 318, Building Code Requirements for Reinforced Concrete.

\section{D Concrete Finishes}

.1 Floors: Steel trowel finish with two coat acrylic curing and sealing compound; ASTM C-309 and Federal Specification TT-C-800A.

.2 Enclosure Roof Slab: Broom finish.

.3 Stairs and Ramps: Non-slip finish.

.4 Exposed Walls: Form ties and fins removed, holes patched or plugged.

.5 Backfilled Walls: Form ties removed, holes patched and fins removed where dampproofing is required.

\section{MASONRY}

\section{A Concrete Unit Masonry}

.1 Included: Concrete masonry materials, reinforcing and miscellaneous anchoring devices required to lay-up all concrete block walls as detailed on the drawings.

.2 Blocks: Normal weight, hollow units, Type 1, Grade N, ASTM C-90.

.3 Mortar: ASTM C-270, Type $\mathrm{M}$ in contact with ground and Type $\mathrm{S}$ elsewhere.

.4 Grout: ASTM C-476, minimum compressive strength of 2,500 psi in 28 days.

.5 Aggregates: For mortar, sand, ASTM C-144; for grout, ASTM C-404.

.6 Bonding and Joints: Running bond, $3 / 8^{\prime \prime}$ concave tooled joints.

.7 Horizontal Joint Reinforcement: Truss type, "Dur-O-Wal," 9 gage galvanized steel wire, ASTM A-82.

.8 Lintels: Precast concrete or lintel block with steel reinforcing and concrete or grout fill.

.9 Reinforcing Bars: ASTM A615, Grade 60 . 
.10 Masonry Ties and Anchors: Galvanized steel, as manufactured by Dur-O-Wal, Hohmann-Barnard, or AA Wire Products.

\section{METAL}

\section{A Structural Steel}

.1 Included: Base plates, anchor bolts, columns, beams, anchorage items, purlins, bracing members, connections and other items required for steel frame structures.

.2 Materials: Structural shapes, plates, and bars, ASTM A-36; structural tubing, ASTM A-500 Grade B; Structural pipe, ASTM A-53 Grade B or ASTM A-501; High strength structural bolts, ASTM A-325; common bolts and anchor bolts, ASTM A-307 or A-36; nuts for high strength bolts, ASTM A-563 DH; welding electrodes $\mathrm{E} 7018$.

.3 Standards: AISC "Specifications for the Design, Fabrication and Erection of Structural Steel for Buildings," Ninth Edition. AWS D1.1, 1990, "Structural Welding Code."

.4 Paint: Rust inhibitor lead-free shop primer; touch up primer in field after erection, field finish paint, two coats alkyd enamel.

\section{C Metal Decking}

.1 Included: Galvanized steel roof decking, sheet metal edgings and all miscellaneous cover plates required for complete installation.

.2 Roof Deck: Intermediate rib, 1-1/2", minimum 20 gauge, ASTM A-446 for Class I roof construction, Factory Mutual Loss Prevention Data Sheet 1-28 and standard I90.

.3 Finish: Galvanized per ASTM A525, G-90; field finish paint, two coats alkyd enamel.

\section{D Miscellaneous}

$.1 \quad$ Metal Included: Non-structural supports and clips, expansion bolts, concrete edge angles and plates, welded stud anchors, pipe sleeves, and other items not required for the steel frame structure.

.2 Material: As listed in Section 5A, above.

.3 Removable and Stationary Guard Rails: Clear plastic panel mounted to a welded steel angle frame with all joints ground smooth; vehicular guards, 6" diameter concrete filled galvanized steel pipe, 3'-6" embedment in concrete.

.4 Handrails: 1-1/2" o.d. Schedule 40 pipe, welded and ground smooth.

.5 Finish: As listed in Section 5A above. 


\section{MOISTURE CONTROL}

\section{A Built-up Roofing}

.1 Included: Roof insulation, tapered insulation saddles, fasteners, four ply bituminous roof covering and associated flashings required for a weathertight roof installation.

.2 Roof Class: Class I-90, Factory Mutual Loss Prevention Data Sheet 128 for deck and 1-29 for membrane.

.3 Insulation: Rigid 2-1/4" Isocyanurate and 3/4" expanded perlite recovery board; tapered expanded perlite saddles and crickets; $R=14.7$.

\section{B Dampproofing and Waterproofing}

.1 Included: Spray-on and membrane type moisture barriers required for the protection of below-grade concrete walls and roof slabs.

.2 Dampproofing: Sprayed two-coat bituminous coating, with chopped fibers.

.3 Waterproof Membrane: Plain neoprene sheets over primed surfaces.

\section{D Caulking and Sealants}

.1 Included: Sealant and pre-formed filler materials required for weatherproofing, materials separation, maintenance of fire ratings at penetrations through rated slabs and partitions, sound control and general aesthetic considerations.

.2 Joint Filler: Closed cell, synthetic foam sheet, strip or backer rod.

.3 Caulking: Silicone, polysulfide, or polyurethane, color matched. Fire safing and intumescent sealant at penetrations through fire rated floors and partitions.

\section{F Louvers}

.1 Included: Stormproof aluminum louver assemblies installed in exterior walls, as required for proper operation of building mechanical systems.

.2 Materials: Aluminum alloys, 6061-T6, 6063-TS or 6063-T6; fasteners, Type 302 stainless steel.

.3 Assembly: Standard 4" deep frames with mitered and welded comers, $45^{\circ}$ stormproof blades and interior mounted bird screens.

\section{G Insulated Metal Siding}

.1 Included: Pre-finished, field assembled metal wall panels, roof parapet coping sections, rigid insulation, all fastening devices and miscellaneous trim and closure pieces required for a complete weathertight wall system.

.2 Materials: Exterior face 20 gage, galvanized, embossed steel, with Kynar 500 (fluoropolymer enamel) coil coating, interior face, 20 gage, galvanized steel, with white polyester coil coating; insulation, high density fiberglass; steel ASTM A-446; ASTM A-525 G-90 galvanizing. 
.3 Assembly: Flush face, interlocking panels with an R-value of 14, wind load design of 25 psf with deflection limit of L/180. Maximum flame spread rating of 25 and maximum smoke developed rating of 50 when tested in compliance with ASTM E-84. Air infiltration per NAAMM TM-1-68T: .12 cfm at 1" water pressure. Water penetration per ASTM E-331.

\section{H Roof Accessories}

.1 Included: Installation of prefabricated roof curbs for exhaust fans, ready for final flashing by roofing subcontractor.

.2 Roof Curb: Fully welded and insulated galvanized steel prefabricated assembly with treated wood nailer and metal cant.

\section{DOORS, WINDOWS AND GLASS}

\section{A Hollow Metal Doors and Frames}

.1 Included: All flush panel, fire rated and non-rated metal personnel doors and door frames.

.2 Door Frames: Combination buck and jamb with integral stop, 16 gage; exterior galvanized.

.3 Doors: Flush design, 1-3/4" thick, 18 gage interior, 16 gage galvanized and insulated exterior, fire labels as required, ASTM E-152; and Steel Door Institute SDI-100.

.4 Finish: Rust inhibitor lead-free primer over phosphate treatment, with two finish coats, alkyd enamel.

\section{B Overhead Sectional Doors}

.1 Included: Installation of insulated steel, sectional, overhead type truck access doors, including motor operator, controls, safety devices and complete weatherstripping accessory package.

.2 Door: Engineered, standard lift with heavy duty 3" rollers and thermally broken, insulated, galvanized steel panels fully weatherstripped at head, jambs and sill.

.3 Track: 3" heavy duty, galvanized steel.

.4 Operator: Electric motor operated with wall mounted push button control, safety stop and automatic reversing function.

.5 Finish: Rust inhibitor, lead-free primer over zinc coated steel; field applied topcoat.

\section{C Roll-up Doors}

.1 Included: Installation of insulated steel roll-up type truck access door, including motor operator, controls, safety devices, and complete weatherstripping accessory package at MI-60 craneway. 
.2 Door: Engineered, thermally broken, insulated, galvanized, steel interlocking panels, with weather stripping at roll-up baffle, jambs and sill.

.3 Operator: Electric motor operated with wall mounted pushbutton control, safety stops, and automatic reversing function.

.4 Finish: Rust inhibitor, lead free primer over zinc coated steel; field applied topcoat.

\section{D Aluminum Doors and Frames}

.1 Included: Aluminum entrance doors and all related finish hardware required for entrance vestibule.

.2 Doors: Heavy duty series, complete with: weatherstripping, closer, mortise deadbolt with panic hardware, and exterior lever handles.

.3 Finish: Duranodic; match windows.

\section{E Aluminum Windows}

.1 Included: Aluminum windows for tech area craneway, if development and vestibule.

.2 Windows: Thermally broken 2-1/4" x 2-1/4" 6063-TS aluminum extrusions, with receptors; for l" gazing; duranodic finish, color by Fermilab.

\section{G Finish Hardware}

.1 Included: Complete fire rated, non-rated and security hardware sets required for proper operation and code compliance of all flush panel metal personnel doors.

.2 Hardware Sets: Ball bearing and plain bearing hinges, mortise locksets, cylindrical latchsets, closures, coordinators and stops, including thresholds and weatherstripping on exterior doors. Low opening force closures for accessibility requirements.

.3 Finish: BHMA 630 satin stainless; 626 satin chrome where stainless is not available; and aluminum for non-ferrous parts.

.4 Locksets: Mortise type with automatic deadlocking plunger. Furnished less cylinder cores. Lever handles and panic hardware for accessibility requirements.

.5 Keying System: Match existing Fermilab system, Best mortise latchsets for lockable doors and cylinder latchsets for passage doors.

\section{H Glass and Glazing}

.1 Included: Single and double pane, interior and exterior glazing, setting blocks and all accessories required for complete installation in compliance with safety glazing standards.

.2 Door Lights: Interior, $1 / 4^{\prime \prime}$ clear safety glass. Tinted $1 / 4$ " safety glass at aluminum entrance doors.

.3 Windows: 1" tinted double pane glass, with Low-E coating 
.4 Setting Material: Neoprene setting blocks, gaskets, pre-shimmed tape and metal stops.

\section{FINISHES}

\section{C Tile Work}

.1 Included: Installation of ceramic wall and floor tile set in thin-set Portland Cement mortar in all toilet rooms.

.2 Ceramic Wall Tile: Standard grade, glazed ceramic tile conforming to ANSI 137-1, installed per Ceramic Tile Installation Handbook Method W-212, utilizing coved base and standard trim tiles where required.

.3 Ceramic Floor Tile: Standard grade, unglazed ceramic mosaic tile conforming to ANSI 137-1, installed per Ceramic Tile Installation Handbook Method F-113.

\section{F Acoustical Panel Ceiling}

.1 Included: Installation of acoustical ceiling panels, grid suspension system, and related trim and accessories.

.2 Acoustical Panels: 2' $\times$ 4' $\times$ 5/8" fissured lay-in with plastic coating; flame spread 25 or less.

.3 Suspension System: Intermediate duty, 15/16" exposed tee, per ASTM A-366 and C-635; white backed enamel finish. Complete with 12 gage hanger wire, edge and end moldings, and miscellaneous trim.

\section{J Painting}

.1 Included: All interior exposed concrete except floors, all exterior and interior exposed steel, galvanized steel and sheet metal except stainless steel or aluminum, all interior masonry.

.2 Colors: As selected by Fermilab, standard colors.

.3 Materials: Approved lead-free primers, fillers and finish coats of reputable manufacturers.

.4 Finish Schedule: Primer and two finish coats on concrete, block filler and two coats on concrete masonry, primer touch-up and two finish coats on shop primed steel, primer and two finish coats on unprimed and galvanized steel.

\section{SPECIALTIES}

\section{A Toilet Partitions}

.1 Included: Pre-finished metal toilet partitions, urinal screens and privacy screens designed and installed in compliance with requirements for the handicapped.

.2 Assembly: All steel shell construction with mitered, welded and smooth finished corners and edges, encasing a rigid honeycomb core. Compartment and door widths and door swings to comply with requirements for handicapped accessibility. 
.3 Attachments and Accessories: Type 302 or 304 stainless steel, or chrome plated brass.

.4 Finish: Lead-free rust inhibitor primer and baked enamel, colors selected from manufacturer's standards.

\section{B Toilet Room Accessories}

.1 Included: Coat hook, grab bar, toilet tissue dispenser, waste receptacle, feminine napkin dispenser and disposal, mirror, soap dispenser, paper towel dispenser, and shelf.

.2 Finish: Satin No. 4 stainless steel.

\section{CONVEYING SYSTEMS}

\section{A Service Elevator}

.1 Included: One oil hydraulic, service elevator, single entrance, microprocessor control and low oil safety control. Complete assembly and installation to be in compliance with the National Electric Code and the American National Standard Safety Code for Elevators, Dumbwaiters and Escalators.

.2 Capacity and Travel: 5,000 lb., 29 feet vertical, 2 stops.

.3 Type and Speed: Hydraulic, $100 \mathrm{fpm}$.

.4 Doors: Top opening.

.5 Handicapped Provisions: None required.

.6 Hydraulic Ram Cylinder: Installed with multiple steel casings, welded watertight to prevent hydraulic oil seepage into aquifer.

\section{B Bridge Crane}

.1 Included: Erection, installation and testing of two top running bridge cranes furnished with runway conductors and safety switches.

.2 Type: Interior, three motor, top running bridge crane.

Capacities

Capacity

Hoist Speed

Hoist Control

Hoist Lift

Trolley Speed

Trolley Control

Trolley Limits

Bridge Speed

Bridge Control

Bridge Travel

CMAA Class

\section{MI-60}

30 ton

$12 \mathrm{fpm}$

5 point

$47 \mathrm{ft}$

$50 \mathrm{fpm}$

3 point

$39 \mathrm{ft}$

$70 \mathrm{fpm}$

5 point

$100 \mathrm{ft}$

C
No. Hatch

30 ton

$12 \mathrm{fpm}$

5 point

$51 \mathrm{ft}$

$50 \mathrm{fpm}$

3 point

$29 \mathrm{ft}$

$70 \mathrm{fpm}$

5 point

$75 \mathrm{ft}$

$\mathrm{C}$ 
.4 Control: Radio control.

.5 Overload Capacity: Overload lifting and holding capacity of $125 \%$ above rated capacity with load at midspan.

\section{C Miscellaneous Hoists and Trolleys}

.1 Type: Over 2 ton: motor operated, pendant control, trolley mount, electromechanical brakes. Two ton and below: manually operated, chain, trolley mount, mechanical load brakes.

.2 Capacities: A-150/P-150: 10 ton, 2 speed.

$8 \mathrm{GeV}$ Enclosure 10 ton, 2 speed.

MI-10, 40, 52, 62: 1 ton.

F0 Enclosure: Bridge type, (2) 10 ton, 2 speed hoists.

\section{MECHANICAL}

\section{A Interior Potable Water System}

.1 Included: Installation of water supply system to toilet facilities in MI-60, North Hatch and F0 building, supply to building provided as part of site civil work.

.2 Pipe Materials: Copper tubing, 1/2" and larger - hard drawn; less than 1/2" - soft tubing.

.3 Fittings: Sweat type lead free solder; less than $1 / 2$ " compression couplings.

.4 Water Closets: Wall hung, handicap style, vitreous china, carrier mount, flush valve and seat.

.5 Urinals: Wall hung, washout type, vitreous china with extended shields. Carrier mounted with flush valve.

.6 Lavatory: Wall hung, vitreous china, single bowl.

.7 Service Sink: Floor mount, cast iron with rim guard.

.8 Electric Water Cooler: Wall mounted, semi-recessed, lead free refrigerant coil and tank package.

.9 Water Heater: Electric, glass lined, quick recovery.

\section{B Sanitary Drainage System}

.1 Included: Installation of underfloor drainage for toilet fixtures and floor drains in MI-60 and North Hatch toilets and pump rooms. System will be connected to existing plant services for MI-60 and North Hatch; F0 building will remain connected to existing F0 septic system.

.2 Pipe: Underslab: Cast iron cement lined and asphaltic coated AWWA-C157 standard weight hub and spigot.

Above Grade: PVC drainage piping Schedule 80; PVC vent piping. 
.3 Fittings: Cast iron pipe: hub and spigot and mechanical joint. PVC: solvent weld joints.

.4 Floor Drains: Cast iron loose trap with sediment bucket. Brass finish in toilets.

\section{C Industrial Cold Water System - Fire Loop}

.1 Included: Installation of piping and connections for a new 12" supply loop around the main injector loop. Two connection points to the existing ICW supply.

.2 Material: Ductile iron, Class 52, AWWA C151, with cement lining AWWA C104.

.3 Valves: Gate valves, with non-rising stem, 175 psi cast iron mechanical joint, post indicator stems.

.4 Hydrants: Dry barrel type with two 2-1/2" hose connections and one 4" hose connection with roadbox key operated isolation valves.

.5 Fittings: Mechanical joint cast iron, cement lined AWWA C110.

.6 Bedding; 1'-0" minimum compacted fine aggregate under piping and along side for full width of trench.

\section{D Interior Fire Sprinkler Systems}

.1 Included: All buildings fully automatic sprinklered and designed in accordance with NFPA-13. Wet system including 2-1/2" hose valve connection at stairways and a building fire department connection. System design for ordinary hazard Group 1 occupancy, compressor room Ordinary Hazard Group 2. All ring exit alcoves sprinklered. Separate zone, fire department connection, and supply for alcove system.

.2 Materials: Carbon steel piping 2" and under Schedule 40 ASTM A795; 2-1/2" and larger Schedule 10 ASTM A-135 with rolled groove.

.3 Valves: Iron body wedge disc OS\&Y gate with bronze trim, wafer check valves, $2-1 / 2$ " brass hose valves.

.4 Sprinkler Heads: $1 / 2$ " orifice brass finish pendent type head.

.5 Fittings: Cast iron threaded, 2" and under; 2-1/2" and larger victaulic style grooved coupling.

.6 Smoke Detector: Ionization type.

.7 Heat Detector: Fixed temperature and rate of rise.

.8 Fire Extinguishers: $A B C$-rating $20 \mathrm{lb}$. capacity dry chemical type. Located in accordance with NFPA 10 ; tunnel spacing 300 feet.

.9 Manual Pull Stations: Located at all building exits. Interior horn and lights. Alarms provided in tunnel, spacing is 300 feet. All alarms connect to fire system. 


\section{F Low Conductivity Water (LCW) Cooling System}

.1 Included: Piping, fittings, water/water heat exchanger, LCW pumps, expansion tank, deionizer station, control valves, strainers, filters and control panels.

.2 Temperature Range: $95^{\circ} \mathrm{F}$ supply to $115^{\circ} \mathrm{F}$ return.

.3 Conductivity: 1 microhm.

.4 Piping Materials: 4" diameter and larger, Schedule 40, Type 304 stainless steel, welded; 3" diameter and smaller, Type $\mathrm{K}$ copper water tube, brazed.

.5 Component Materials: Wetted surfaces, Type 316 stainless steel, copper or brass.

\section{G Chilled Water (CHW) Cooling System}

.1 Included: Piping from LCW heat exchanger in MI-60 to existing chilled water mains in TeV in enclosure. Mains connect to existing Central Utility Plant CHWS and CHWR.

.2 Temperature: $45^{\circ} \mathrm{F}$.

.3 Piping Materials: 2" diameter and larger, Schedule 40, black, steel, welded; 1-1/2" diameter and smaller, Schedule 40, black, steel, threaded.

\section{H Pond Water (PCW) Cooling System (Interior)}

.1 Included: Piping, fittings, strainers, control valves, bypass connection and control panel inside the service buildings.

.2 Temperature Range: $85^{\circ} \mathrm{F}$ supply to $95^{\circ} \mathrm{F}$ return.

.3 Piping Materials:

Above ground: Schedule 40, carbon steel conforming to ASTM A-53, Type E, Grade B; painted.

Below ground: Ductile Iron, Class 52, cement lined, AWWA C104.

.4 Valves: Wafer-type butterfly valve and flanged iron body swing check valves.

Above ground: Carbon steel butt-weld fittings.

Below ground: Mechanical joint, cement lined, AWWA C-110.

\section{I Drainage Sump Pumps In Alcoves and Exit Stairs}

.1 Included: Installation of sump pumps and piping.

.2 Materials: Class 52 ductile iron and asphaltic coated conforming to AWWA C-1S1/ANSI A21.51-86 with mechanical joints for underground piping.

.3 Pumps: Weil Series 2500, Model C-250214, rated at $125 \mathrm{gpm}$ and $40 \mathrm{ft}$ total dynamic head. \#8230 mercury float switches with $20 \mathrm{ft}$ cables and mounting hardware, NEMA-l, wall mounted duplex control panel having wired therein, NEMA-1, wall mounted high water alarm panel with warning light and test button; requiring separate $110 \mathrm{~V}$ power supply, and 53" o.d. duplex steel cover with (2) 
pump access plates having 4" discharge flanges and inspection manhole for 48 " i.d. basin, and a 48" i.d. $x 6 \mathrm{ft}$ deep fiberglass pump basin.

\section{J Heating. Ventilating and Air Conditioning}

.1 Included: Air handling units, supply/exhaust fans, ducts, diffuser, louvers, fan coil units, grilles, controls, chillers, ventilation units, split air conditioning units, unit heaters, dehumidifiers and dampers.

.2 Air Handling Units: Belt drive with guards, V-belt, adjustable drives, chilled water cooling coils, electric heating coils, economizer controls and vibration isolators.

.3 Supply/Exhaust Fans: In-line centrifugal type with automatic backdraft dampers.

.4 Ductwork: Galvanized steel, SMACNA Duct Construction Manual.

.5 Diffusers and Grilles: Factory fabricated steel or aluminum.

.6 Louvers: Factory fabricated aluminum.

.7 Fan Coil Units: Exposed, ceiling mounted with direct drive motor-blower assemblies, chilled water coil, and electric heating coil.

.8 Controls: Direct digital control tied-in with existing plant system.

.9 Chillers: Air cooled packaged chillers, nominal capacity of 175 tons. Includes pumps, expansion tanks and schedule 40 black steel piping with insulation.

.10 Ventilation Units: Belt drive with guards, V-belt, adjustable drives, filters, economizer controls and vibration isolators.

.11 Split Air Conditioning Units: Indoor fan coil section with electric reheat coils and air cooled packaged condensing unit. Fan coil capacity to be 7-1/2 ton and condenser unit to be either $7-1 / 2$ or 15 tons.

.12 Electric Unit Heaters: Wall mounted with bracket with $7.5 \mathrm{~kW}$ nominal capacity.

.13 Dehumidifiers: Heavy duty, industrial, self contained unit precharged with R-22 refrigerant.

.14 Dampers: Motor operated, interlocked with ventilation unit.

16. ELECTRICAL

\section{A Disconnect Switch}

.1 Ratings: $345 \mathrm{kV}, 1,600 \mathrm{~A}$.

.2 Type: Motor operated.

\section{B Circuit Breaker}

.1 Ratings: $345 \mathrm{kV}, 2,000 \mathrm{~A}, 2,500 \mathrm{MVA}$.

.2 Type: SF6, Live Tank, $-40^{\circ} \mathrm{C}$.

16.C Oil Filled Substation Transformer

1 Ratings: 60/79.5/99.9 MVA, OA,FA,FOA, $345 \mathrm{kV}, 3$ wire delta, $13.8 \mathrm{kV}, 4$ wire wye, 3 phase, 60 hertz, solid ground. 
.2 Type: Oil filled, substation class.

.3 Features: Relocated 82B.

16.D Oil Filled Substation Transformer

.1 Ratings: 40/53/66 MVA, OA, FA, FOA, $345 \mathrm{kV}, 3$ wire delta, $13.8 \mathrm{kV}, 4$ wire wye, 3 phase, 60 hertz, solid ground.

.2 Type: Oil filled, substation class.

.3 Features: Relocated 84A.

16.E Oil Filled Substation Transformer

.1 Ratings: 40/53/66 MVA, OA, FA, FOA, $345 \mathrm{kV}, 3$ wire delta, $13.8 \mathrm{k} \mathrm{V}, 4$ wire wye, 3 phase, 60 hertz, solid ground.

.2 Type: Oil filled, substation class.

.3 Features: Pulsed power.

16.F Oil Filled Padmount Transformer

.1 Ratings: $500 \mathrm{kVA}, \mathrm{OA}, 13.8 \mathrm{kV}, 3$ wire delta, 480/277V, 4 wire wye, 3 phase, 60 hertz, solid ground.

.2 Type: Oil filled, pad mount.

.3 Taps: $2-1 / 2 \%$ above and below.

16.G Oil Filled Padmount Transformer

.1 Ratings: $750 \mathrm{kVA}, \mathrm{OA}, 13.8 \mathrm{kV}, 3$ wire delta, $480 / 277 \mathrm{~V}, 4$ wire wye, 3 phase, 60 hertz, solid ground.

.2 Type: Oil filled, pad mount.

.3 Taps: $2-1 / 2 \%$ above and below.

16.H Oil Filled Padmount Transformer

.1 Ratings: $1,500 \mathrm{kVA}, \mathrm{OA}, 13.8 \mathrm{kV}, 3$ wire delta, $480 / 277 \mathrm{~V}, 4$ wire wye, 3 phase, 60 hertz, solid ground.

.2 Type: Oil filled, pad mount.

.3 Taps: $2-1 / 2 \%$ above and below.

\section{I Bus Duct}

.1 Ratings: $15 \mathrm{kV}, 4,000 \mathrm{~A}, 3$ phase, 4 wire.

.2 Type: Nonsegregated.

.3 Features: Outdoor.

16.J Switchgear

.1 Ratings: $15 \mathrm{kV}, 4,000 \mathrm{~A}, 500 \mathrm{MVA}$.

.2 Type: Vacuum Breaker.

.3 Features: 3,000A Mains and ties, 1,200A feeders. 


\section{K Switchgear Building}

.1 Type: Powerhouse assembly for walk through, Weatherproof service in nonhazardous area.

.2 Features: Complete pre-fabricated insulated structure with equipment doors, lighting system, heating and ventilating system, and convenience receptacles.

\section{L Medium Voltage Air Switch MI-30, MI-50}

.1 Ratings: $15 \mathrm{kV}, 600 \mathrm{~A}$, interrupting capacity as required.

.2 Function: Four-way, manually operated, quick make-quick break, fused disconnect switch.

.3 Mounting: Free standing, NEMA 3R, bottom entry.

\section{M Medium Voltage Air Switch MI-50}

.1 Ratings: $15 \mathrm{kV}, 3,000 \mathrm{~A}, 40,000 \mathrm{~A}$ rms asymmetric.

.2 Function: 13 switch links ( 4 main incoming, 1 bus tie, 8 feeder), manually operated, quick make-quick break, disconnect switch.

.3 Mounting: Free standing, NEMA 3R, bottom entry.

\section{N Medium Voltage Air Switch}

.1 Ratings: $15 \mathrm{kV}, 600 \mathrm{~A}$, interrupting capacity as required.

.2 Function: Duplex switch, manually operated, quick make-quick break, fused disconnect switch.

.3 Mounting: Free standing, NEMA 3R, bottom entry.

\section{0 $15 \mathrm{kV}$ Cable}

.1 Construction: $750 \mathrm{MCM}, 15 \mathrm{kV}$, aluminum, cross-linked polyethylene, 1/3 concentric neutral, overall jacket, triplexed.

\section{P Grounding}

.1 Features: \#500 MCM Bare ground cable. l" diameter, 10'-0" long Copper-clad, solid ground rods. Cadweld connections, per NEC.

\section{Q Switchboards}

.1 Ratings: $480 / 277 \mathrm{~V}, 800 \mathrm{~A}, 3$ phase, 4 wire, 60 hertz, interrupting capacity as required.

.2 Breakers: Molded case, bolt on.

.3 Construction: Switchboard, Class II, indoor.

\section{R Switchboards}

.1 Ratings: $480 / 277 \mathrm{~V}, 2,000 \mathrm{~A}, 3$ phase, 4 wire, 60 hertz.

.2 Breakers: Molded case, bolt on.

.3 Construction: Switchboard, Class II, indoor. 


\section{S Panelboards}

.1 Ratings: $480 / 277 \mathrm{~V}, 3$ phase, 4 wire, 60 hertz, interrupting capacity as required.

.2 Features: Flush doors, locks, screw terminals, NEMA PB-1, WP-115a, UL 67 and UL 50.

\section{T Motor Starters}

.1 Type: Combination full voltage, non-reversing, single speed, wall mounted/equipment mounted.

.2 Features: 120 volt control transformer, red indicating light, HOA selector switch or start-stop pushbuttons, 1 N.0. and 1 N.C. auxiliary contact; per IEEE, NEMA, and NEC standards.

\section{U Raceways and Wiring}

.1 Buried Conduit: Galvanized heavy wall.

.2 Surface Conduit: Intermediate metal conduit (IMC).

.3 Wire and Cable: Soft copper, solid \#10 AWG and smaller, stranded \#8 AWG and larger, minimum size \#12 AWG, Type THHN insulation.

\section{V Cable Tray}

.1 Construction: Pre-galvanized steel.

.2 Fabrication: 18 " wide, 9 " rung spacing.

\section{W Dry Type Transformer}

.1 Voltage: $480 \mathrm{~V}, 3$ phase, 60 hertz, 120/208, 3 phase, 4 wire, taps $2-1 / 2 \%$ above and below.

.2 Rating: As required.

.3 Construction: Class $\mathrm{H}$ insulation, indoor cases, for floor or wall mounting.

\section{X Lighting Luminaries}

.1 High Bay Area: High intensity discharge, aluminum reflector, integral ballast.

.2 Service Buildings, Beam Enclosures, Stairs. Walkways, Aisles: Surface mounted, fluorescent.

.3 Exit: LED. type.

.4 Exterior: Mercury vapor, aluminum housing, photocell operation.

\section{Y Emergency Lighting}

.1 Tvpe: Dual lamp, recharable, 6 volt, nickel cadmium battery.

.2 Capacity: 40 Ampere-hour, 4 hour duration. 


\section{METHOD OF ACCOMPLISHING THE WORK}

Title II engineering and design work will be accomplished by the consultant architectengineering (AE) firm of Fluor Daniel, Inc. (FD), Chicago, Illinois under a negotiated fixed price contract.

All drawings will be CADD-produced using AutoCAD Release 11 software.

Deliverables from the $\mathrm{AE}$ will be structured to reflect the anticipated scope of 12 to 15 bid packages in sequence with the FMI project schedule.

Construction milestone schedules will be prepared jointly by FD and the MI Civil Construction Manager (MICCM). Bid package estimates will be prepared by FD.

Bid packages will be assembled by Fermilab with FD furnishing drawings and technical specifications. Fermilab will be responsible for special conditions, including the construction schedule and all general conditions. Bid packages for fixed-price lump sum construction subcontracts will be issued and administered by the Contracts Department of the Fermilab Business Services Section.

Long-lead procurements, including $15 \mathrm{kV}$ cable, major transformers, switchgear, overhead bridge cranes, shielding steel, and precast concrete enclosure elements, will be assembled and administered in a similar fashion resulting in Fermilab procurement subcontracts.

Title III construction management will be performed by the MICCM with some shop drawing review and field inspection assistance from FD on an hourly cost plus basis. The MICCM will provide construction coordination (field inspection), construction safety overview, scheduling and contract administration. Prebid and preconstruction conferences, change orders, update meetings, payouts, shop drawing and material reviews, reports, field inspections, environment, safety and health (ES\&H) and quality assurance programs (QAP) will be in accordance with existing Fermilab procedures for construction subcontracts.

Construction testing including soils, concrete, and welding will be conducted by independent laboratories engaged and directed by the MICCM.

Acceptance inspections for beneficial occupancy or final completion will include representatives from FD, the MI Department, Fermilab and DOE-BAO conducted under the direction of the MICCM.

As-built drawings will be compiled by FD and all documentation will be turned over to Fermilab records.

Refer to the FMI Project Management Plan for specifics regarding the MI organization, civil construction management, the QAP or ES\&H compliance. 


\section{CONSTRUCTION SCHEDULE}

The FMI project master schedule and principal milestone dates are listed in Chapter 5, Volume 1 of this report. As noted in the accompanying discussion, the schedule is funding driven except for the seven month period when accelerator operations will cease in order to permit construction of the required interfaces of the FMI with the existing facilities. While obviously necessary, the shutdown represents a curtailment of high energy physics research, Fermilab's dedicated purpose, and, hence, every effort will be made to minimize this duration. The shutdown period, referred to in Phase 3 in the civil construction WBS, involves several work packages including the F0 enclosure demolition and reconstruction, modifications to the F0 service building, the F-17 Kicker Building, the $8 \mathrm{GeV}$ enclosure link at the Antiproton and the 8 $\mathrm{GeV}$ enclosure connection at the Booster. The first and last listed projects are the most expensive and complex and therefore, present the greatest challenge for maintaining the minimum shutdown schedule.

In order to verify the assumed shutdown schedule before issuing the Title I Report, Fermilab and Fluor Daniel constructibility and scheduling personnel worked jointly to establish a detailed scenario for the construction of both the F0 enclosure and the $8 \mathrm{GeV}$ Booster connections. This effort included meetings with specialty contractors in areas such as sheet piling, saw cutting and earth retention wall systems to establish reasonable schedule durations. The F0 enclosure emerged as the most critical shutdown activity because of the confined work area (between the F0 and MI-60 service buildings), the restraint of sequential efforts (equipment removal, service building demolition, driving sheet piling, excavation, F0 enclosure demolition, etc.), and the requirement to remove technical equipment from both the F0 enclosure and service building and then reinstall the equipment before accelerator operations can resume. The proposed schedule countered the sequential restraints with parallel efforts such as Fermilab removing equipment simultaneously from both the enclosure and the service building or starting transverse saw cutting of the CIP concrete F0 enclosure from inside while the service building above was being demolished. Where practical, multiple crews have been assumed and, once critical operations were identified, some double shift work is forecast, especially for early activities such as demolition. Some special techniques have been included in the Title I design, including the use of precast roof beams over the F0 enclosure to eliminate internal shoring and to accelerate beneficial occupancy. Five day work weeks were assumed with weekends reserved to compensate for weather days. The analysis assumed a shutdown commencing in January to maximize weather impact. The resultant construction schedule made allowances for Fermilab activities including ten days for equipment removal at the commencement of work and four weeks for reinstallation, alignment and testing at the end of the construction period. 
The result of this constructibility analysis is a confirmation that each of the civil construction Phase 3 projects can, in fact, be completed as separate subcontracts in a 30 week shutdown period. The scheduling logic for the F0 enclosure has been documented as a fairly detailed CPM diagram (400 activities) as well as a preliminary FD report with bar chart schedules for the F0 enclosure and the two $8 \mathrm{GeV}$ enclosure connections. Note that the cost of assumed overtime or double shift work has not been included in the Title I civil cost estimate because the time of year (currently scheduled for May) for the shutdown may change and additional design or construction techniques for improving the schedule remain to be studied. But the main thrust of this analysis verifies the seven month shutdown schedule as tight but achievable. 


\section{COST ESTIMATE}

The cost estimate for the entire FMI project is summarized in Chapter 4, Volume 1 of this report. The civil construction cost estimate, to the fourth WBS level, is summarized on the following page. The detailed "bottoms up" civil estimate is available for review as a separate volume with a limited controlled distribution. All costs are listed in 1991 dollars.

The cost estimate methodology is typical for civil construction. Detailed quantity takeoffs are based upon the Title I drawings, preliminary design calculations and outline specifications. Unit prices are determined from published construction cost data such as Means or Richardson, quotations from vendors, the AE's cost data book and the experience of recent construction projects on the Fermilab site. Line item listings in the detailed estimate include material, labor and subcontract costs with appropriate mark-ups.

The ED\&I for the civil construction is currently estimated at $\$ 6,504 \mathrm{~K}$ or $9.8 \%$ of the estimated construction cost with a contingency of $\$ 12,800,000$ or $17.5 \%$ of the civil cost. 


\section{CIVIL CONSTRUCTION COST ESTIMATE (1991\$) WBS SUMMARY EXCLUSIVE OF ED\&I}

\section{PHASE 1}

WBS 1.2.1.1

WBS 1.2.1.2

WBS 1.2.1.3
Wetland Mitigation

Site Preparation

Roads and Utilities
$\$ 590,595$

$3,448,887$

$5,826,296$

$\$ 7,863,179$

$17,930,717$

$2,290,543$

511,494

$3,265,271$

765,503

$4,406,868$

846,384

$1,627,984$

$4,212,457$

$1,528,955$

$5,924,013$

$4,697,109$

263,538
$8 \mathrm{GeV}$ Enclosure at Antiproton

F0 Enclosure, F0, Service Building Modifications and F17
WBS 1.2.3.2

WBS 1.2.3.3

$8 \mathrm{GeV}$ Enclosure at Booster

\section{PHASE 4}

WBS 1.2.4.1
Landscaping and Paving
$\$ 538,085$

$\$ 66,537,878$ 


\section{APPENDIX A}

\section{CIVIL CONSTRUCTION DRAWINGS}




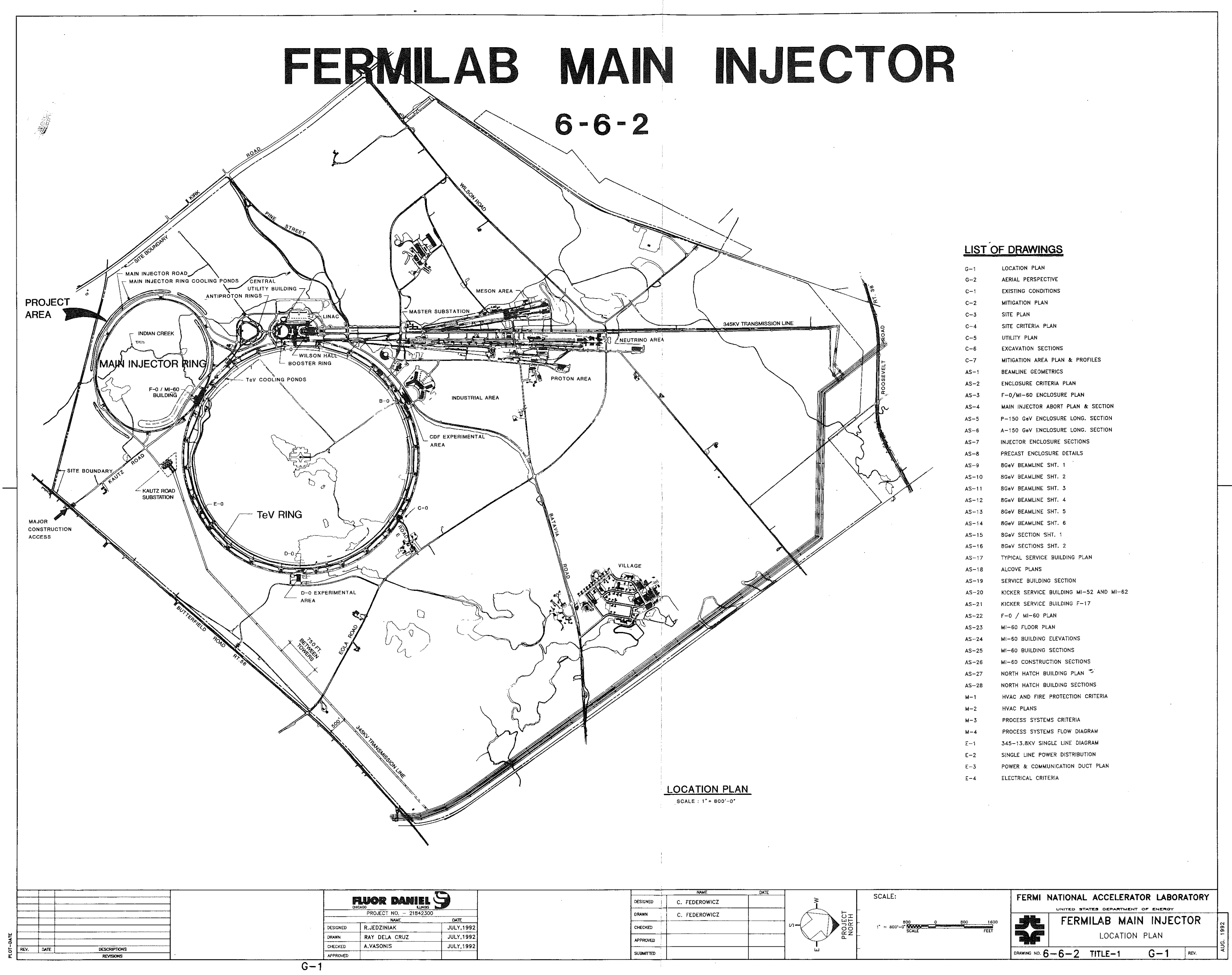




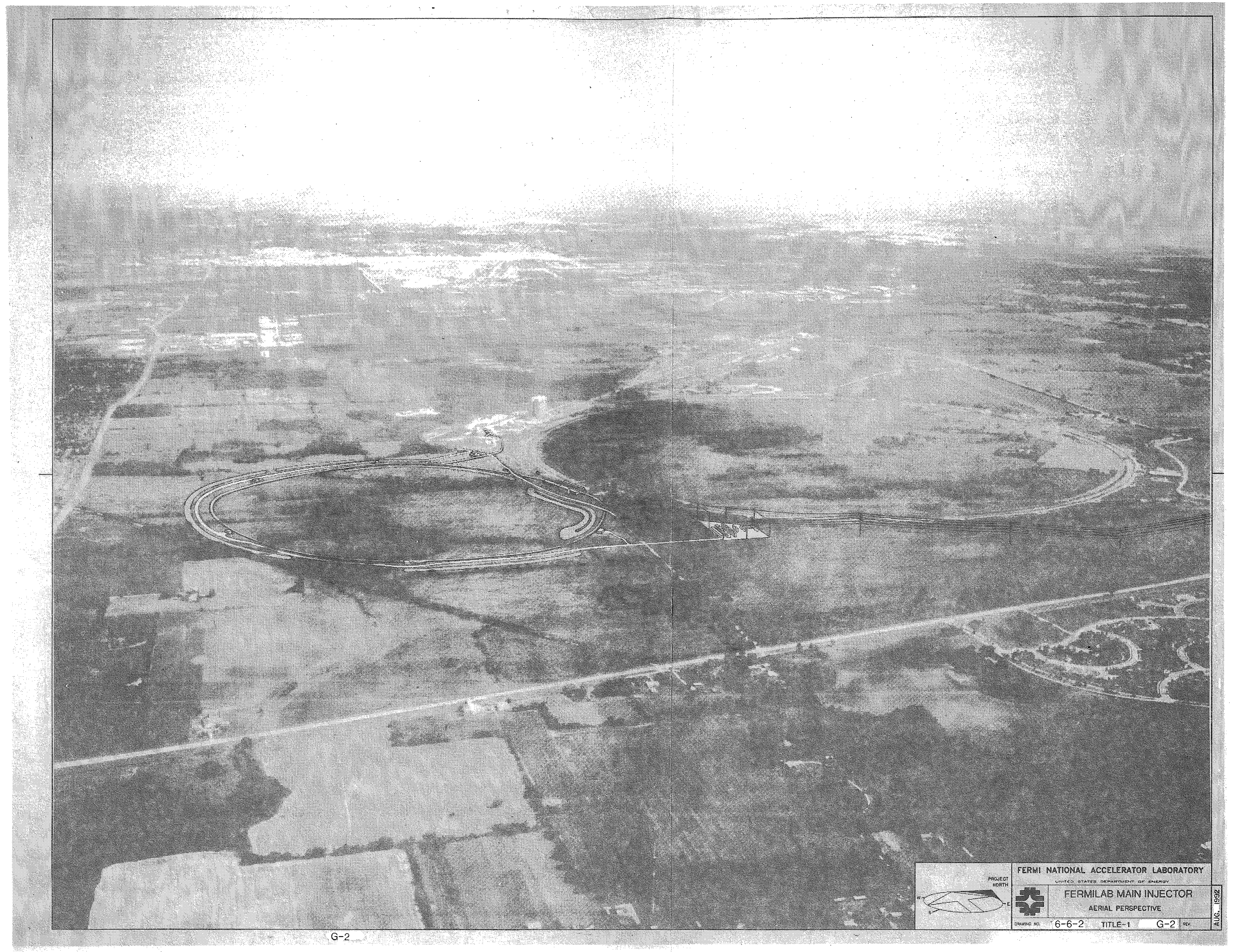




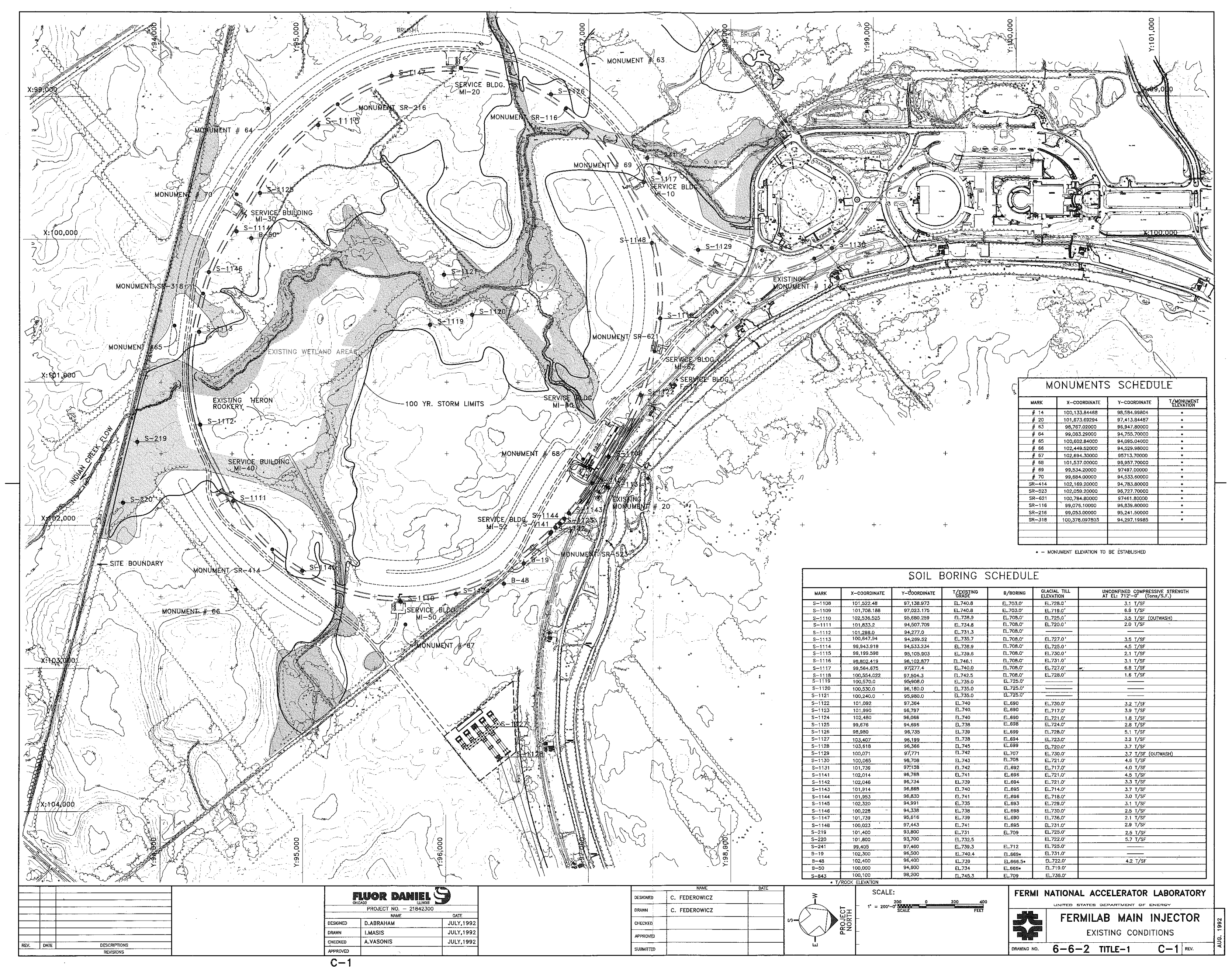




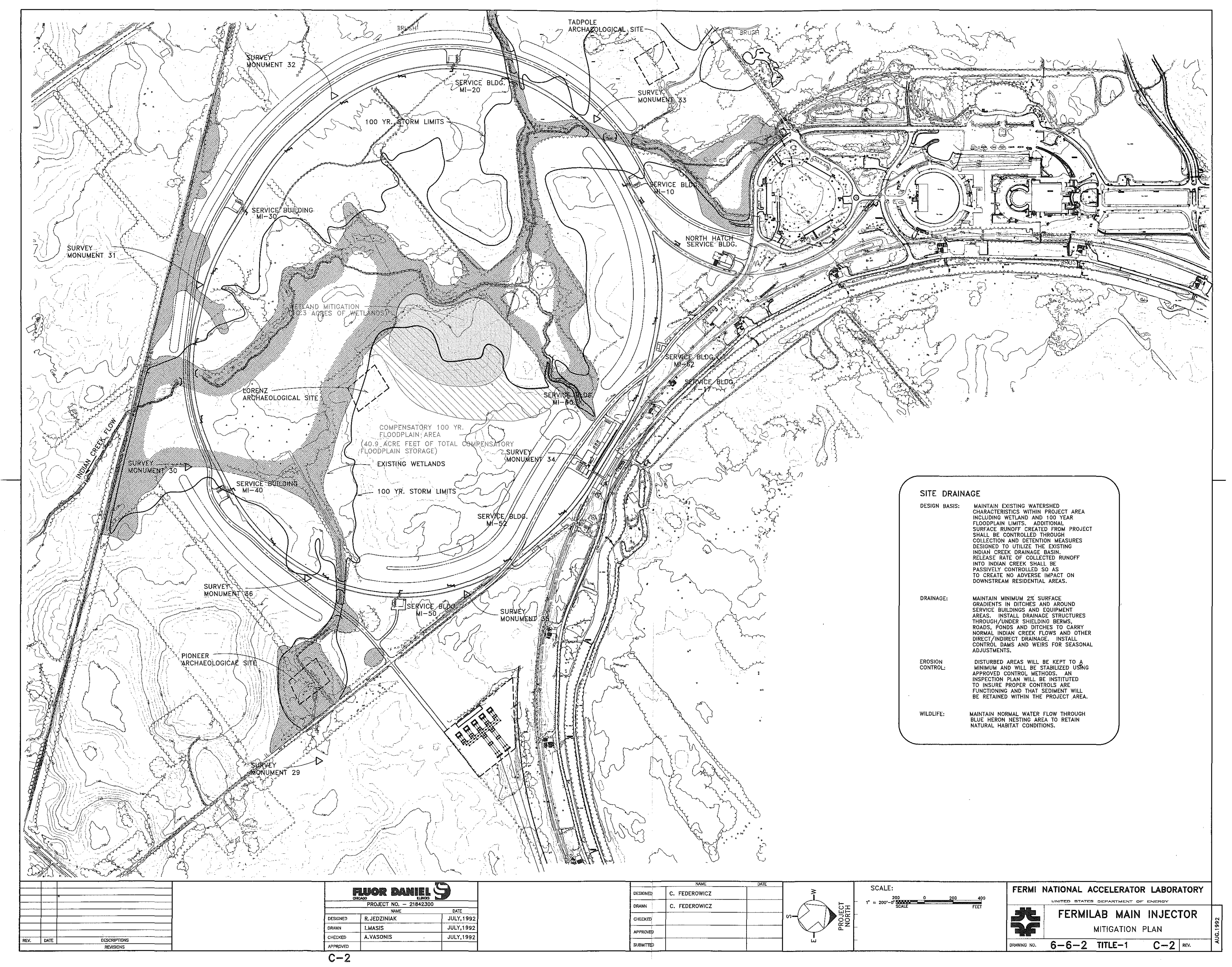




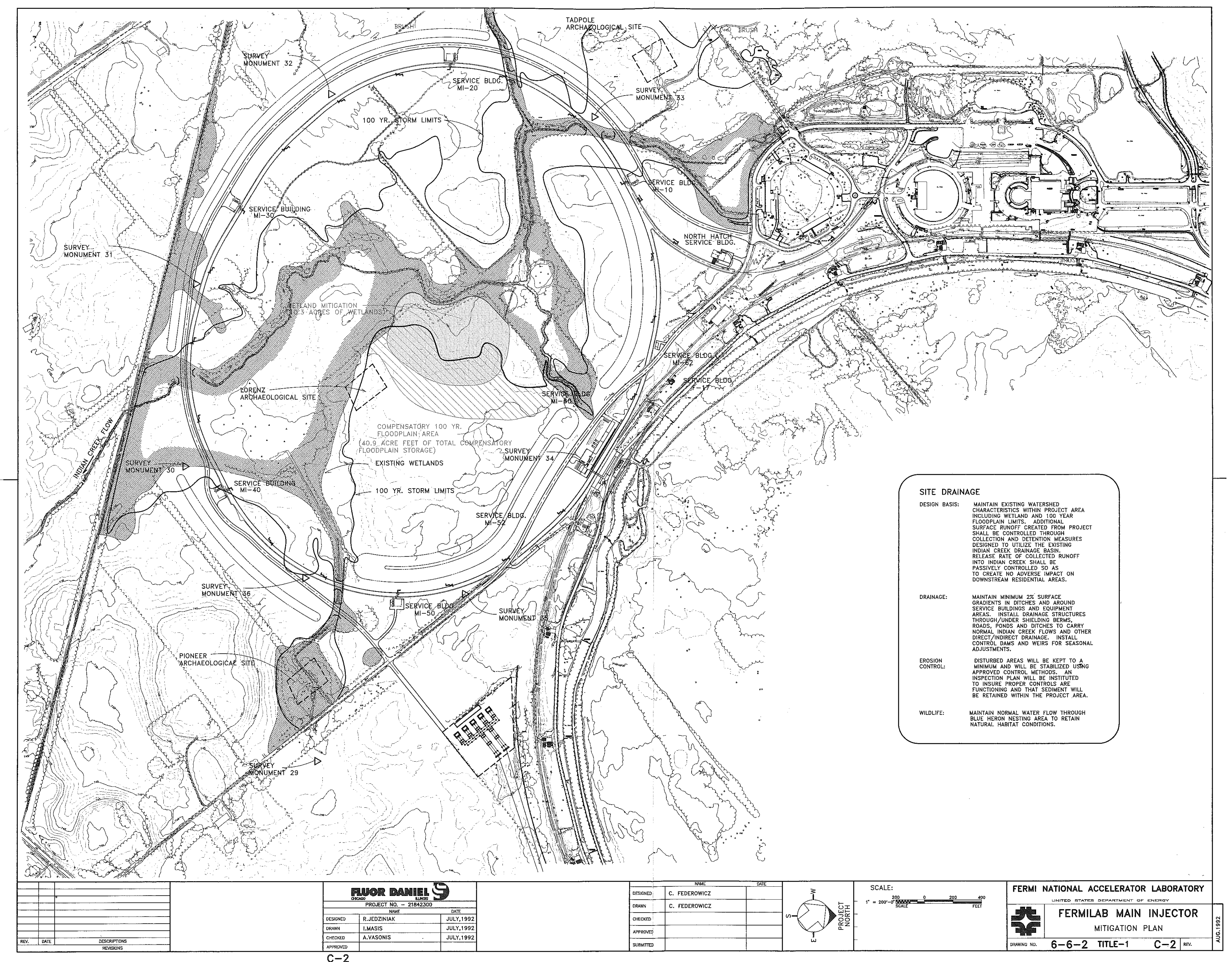




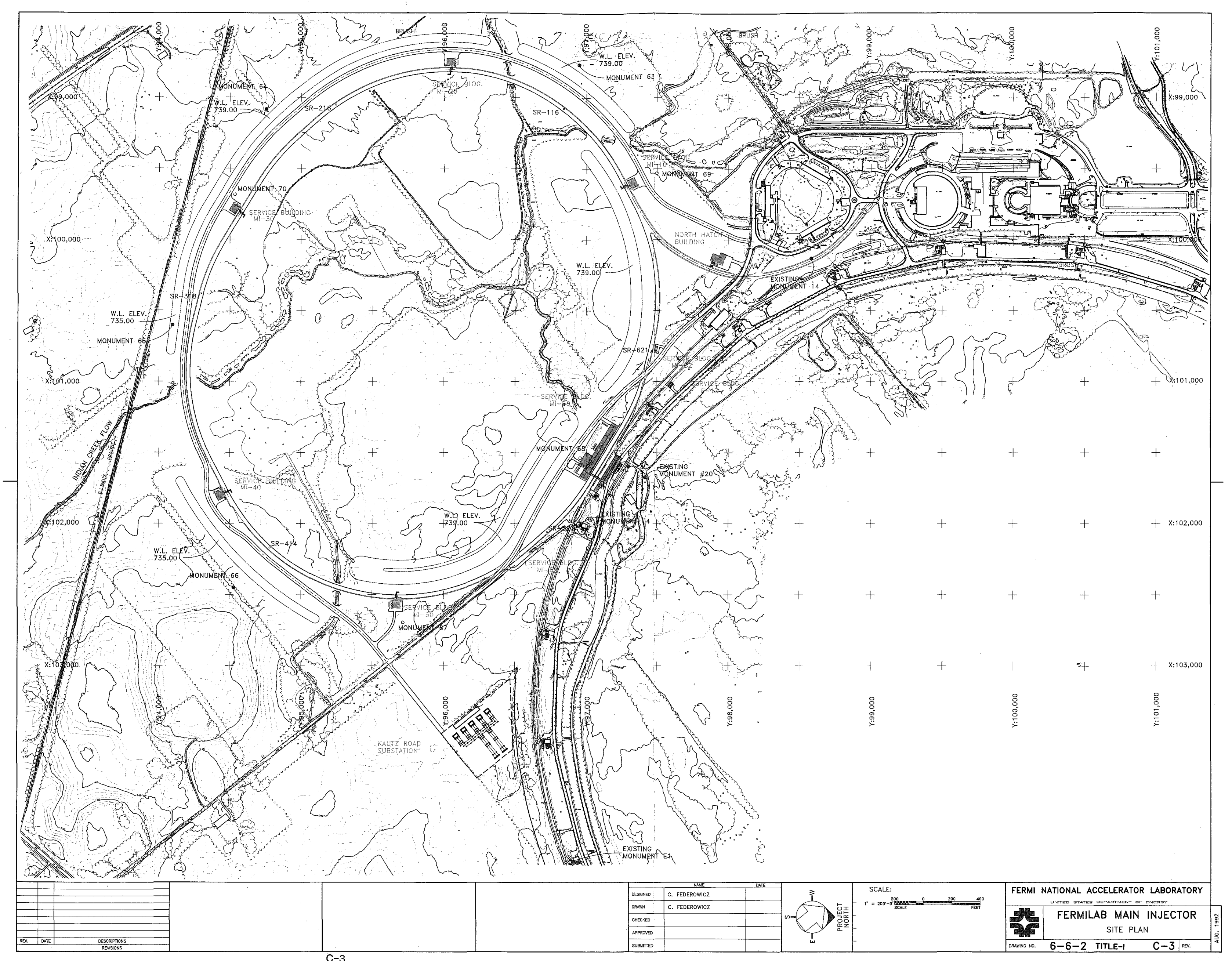




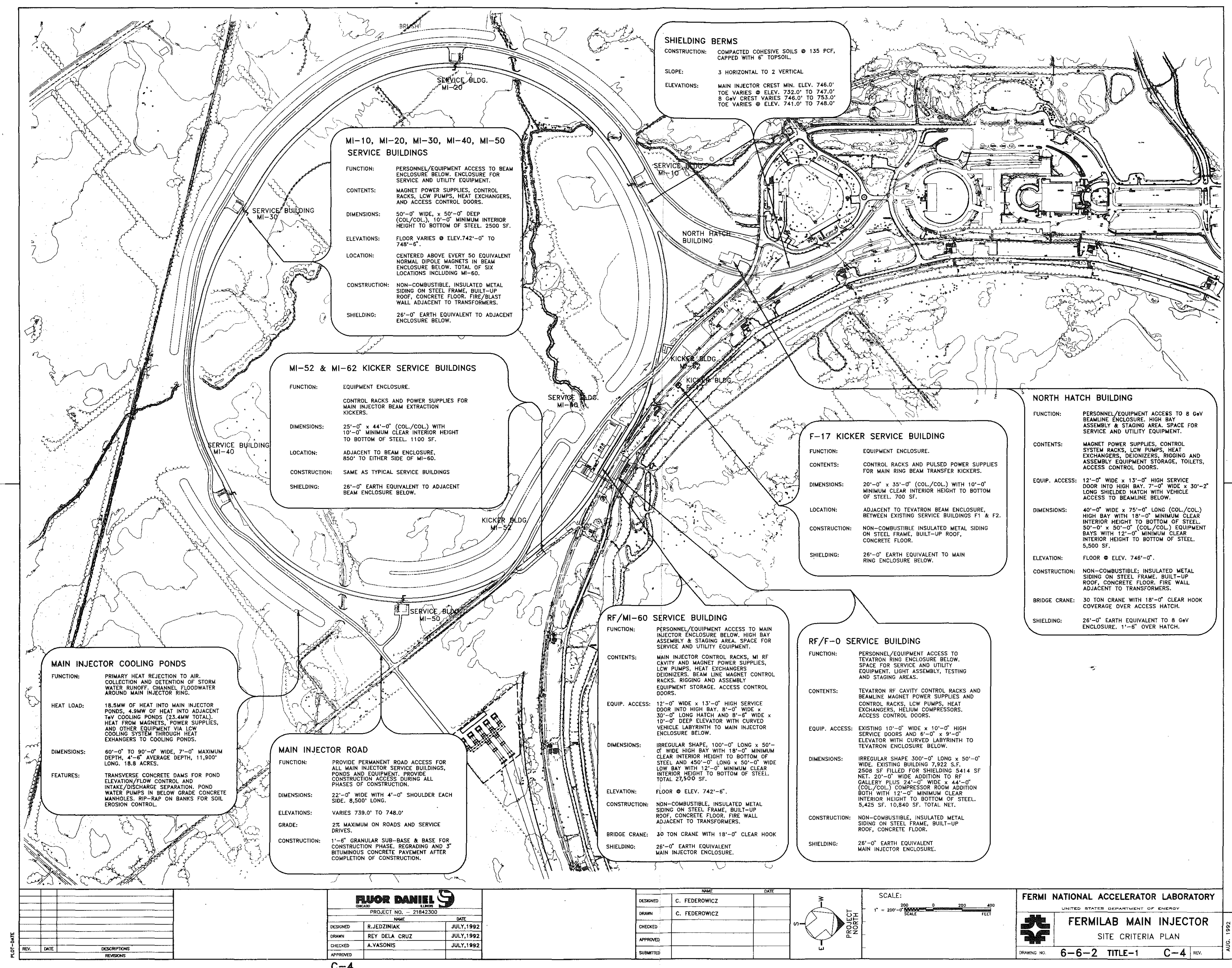




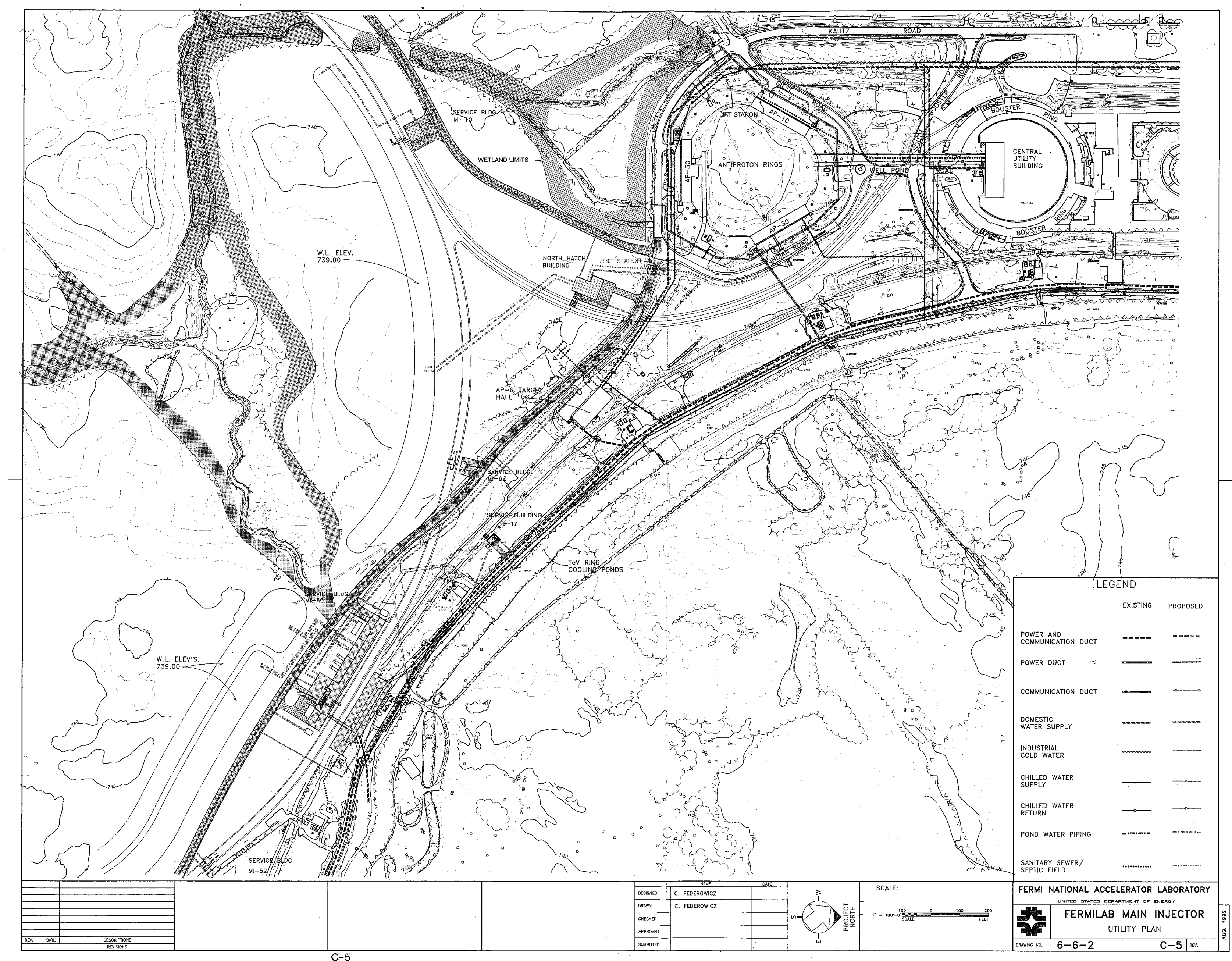




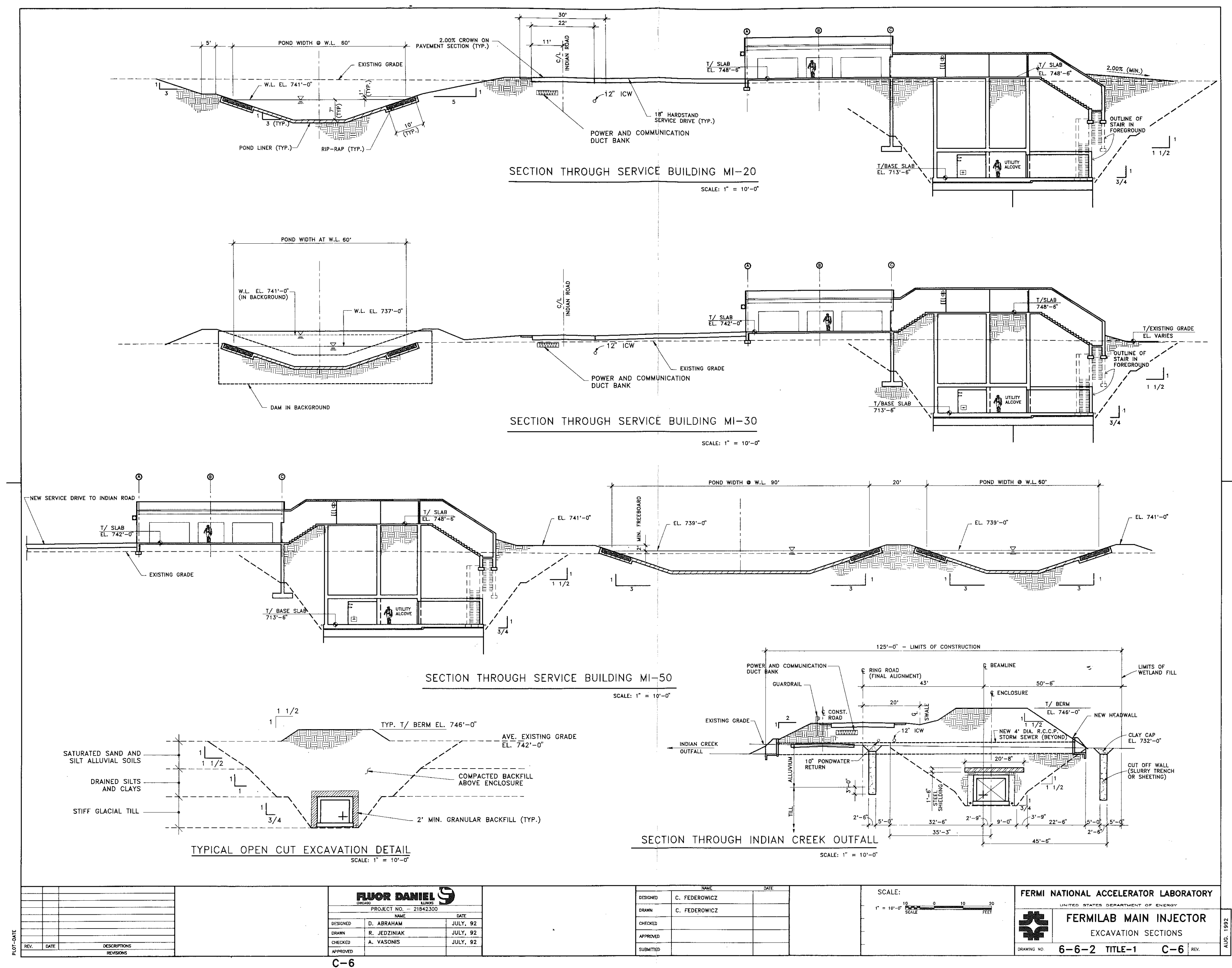




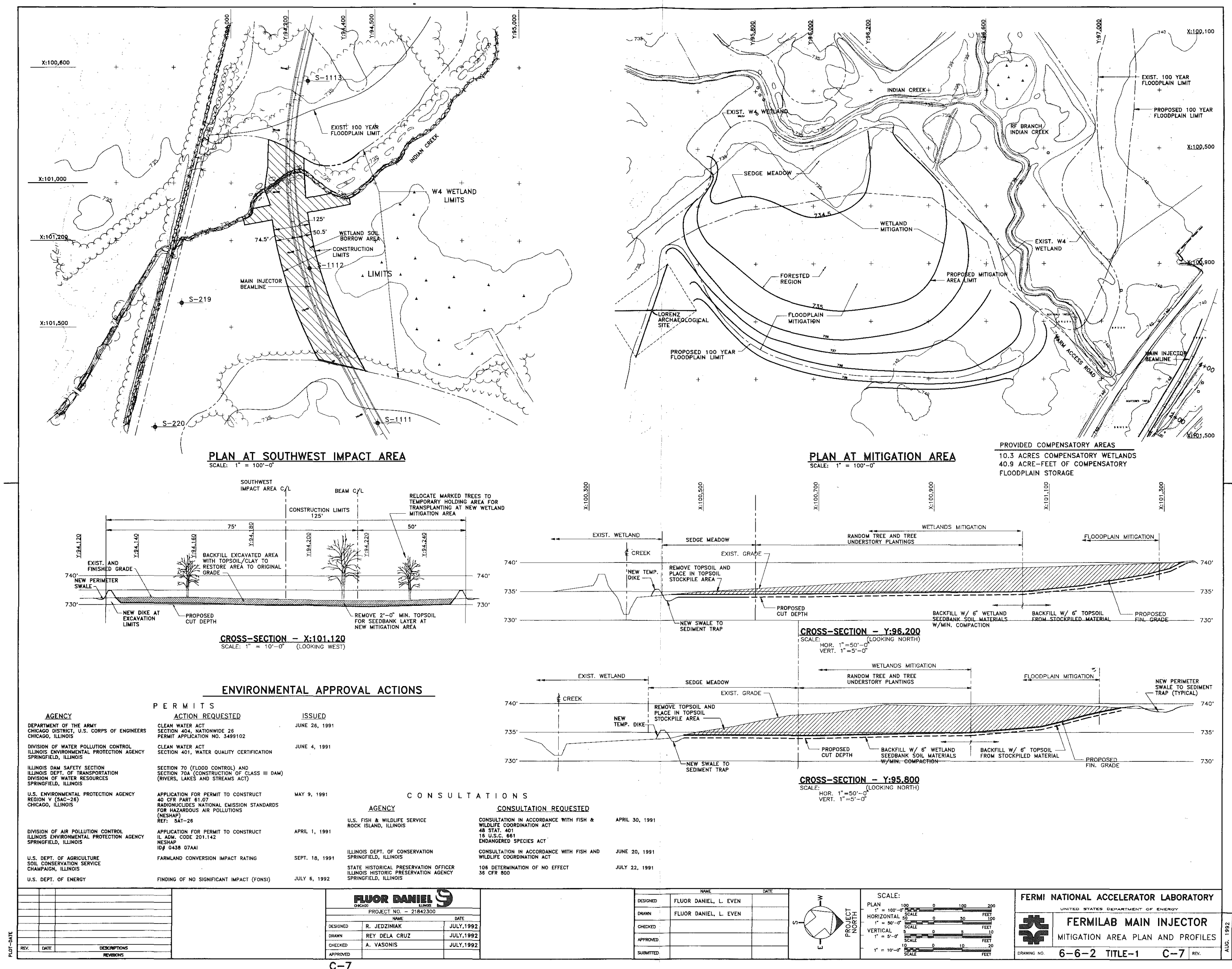




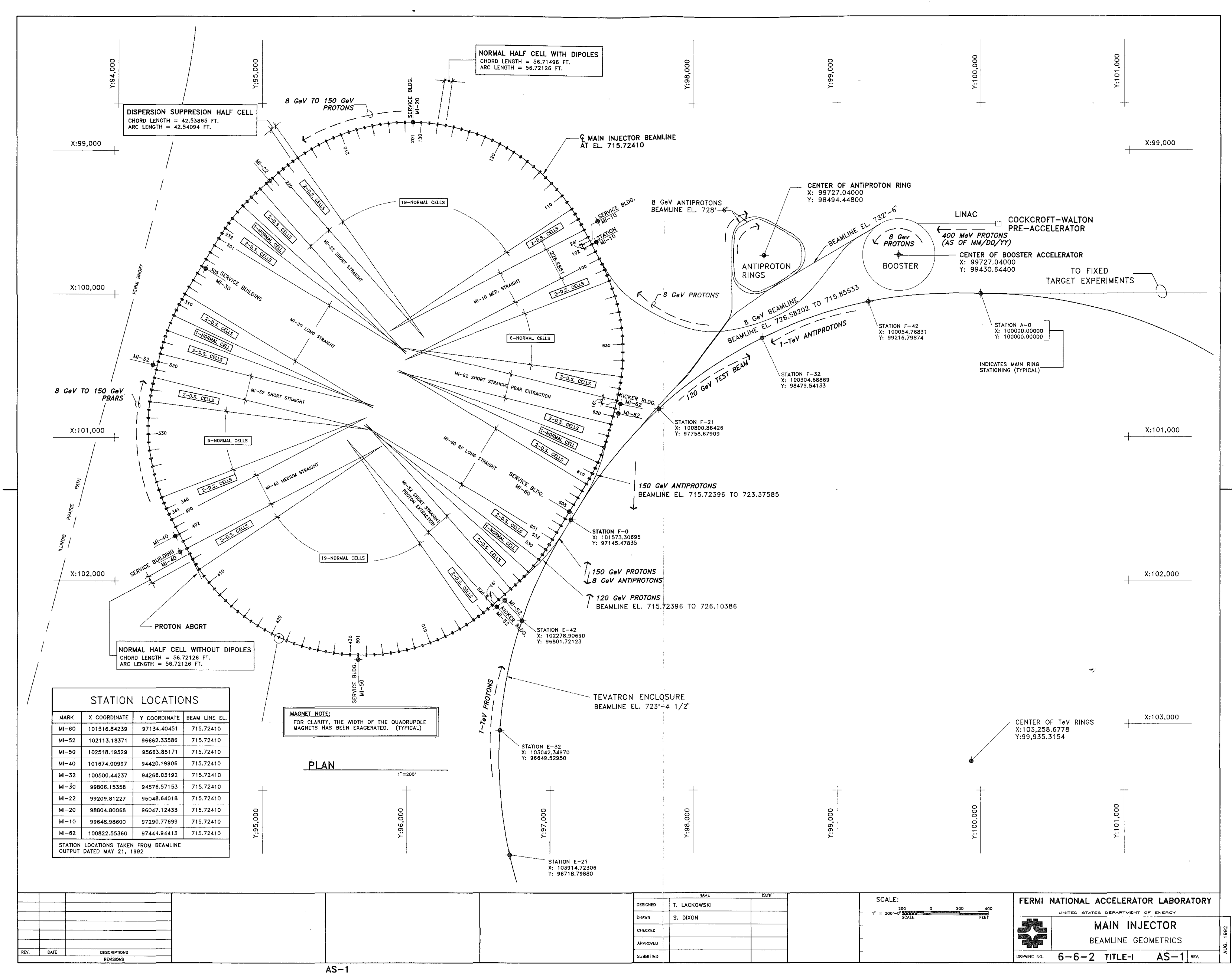




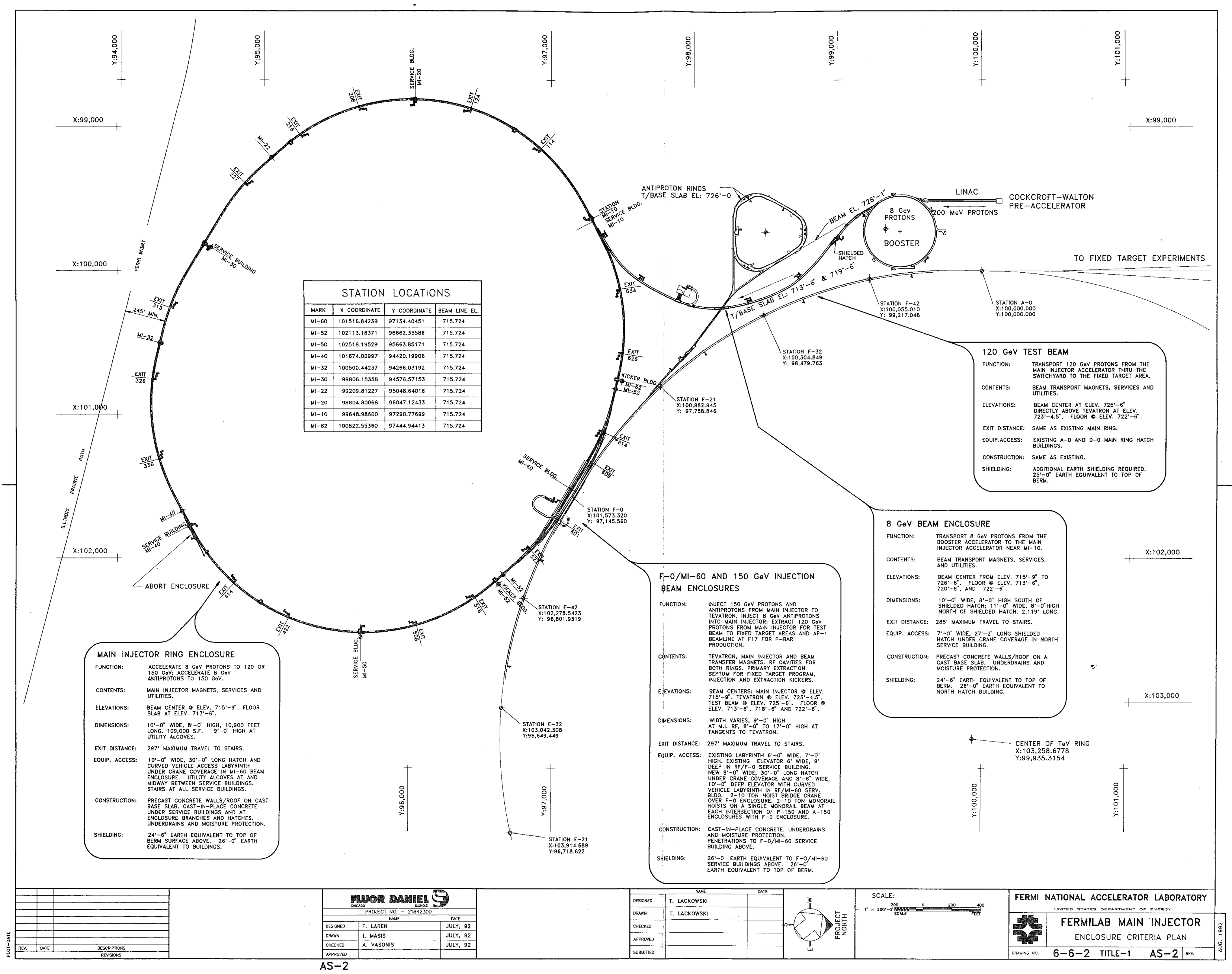




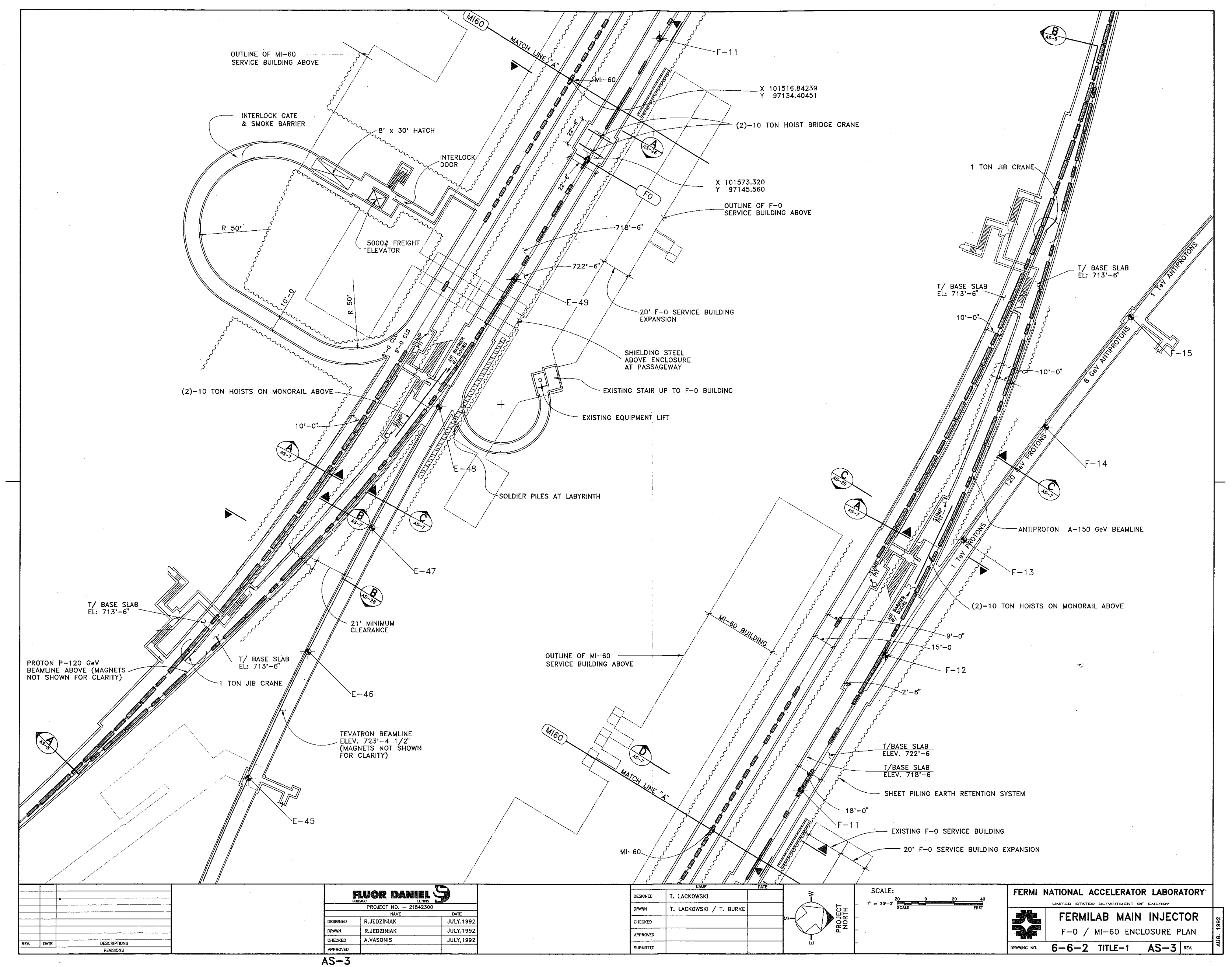




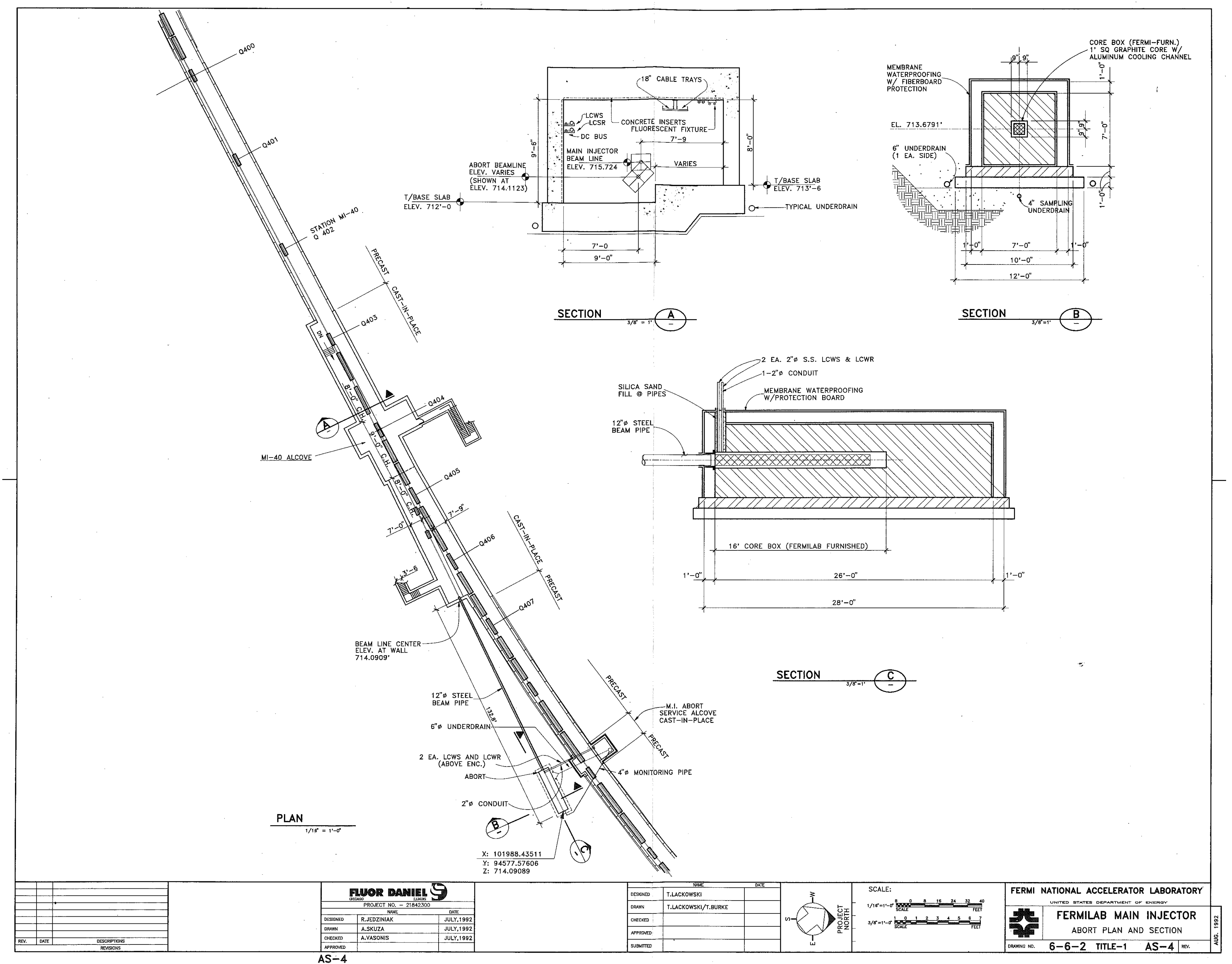




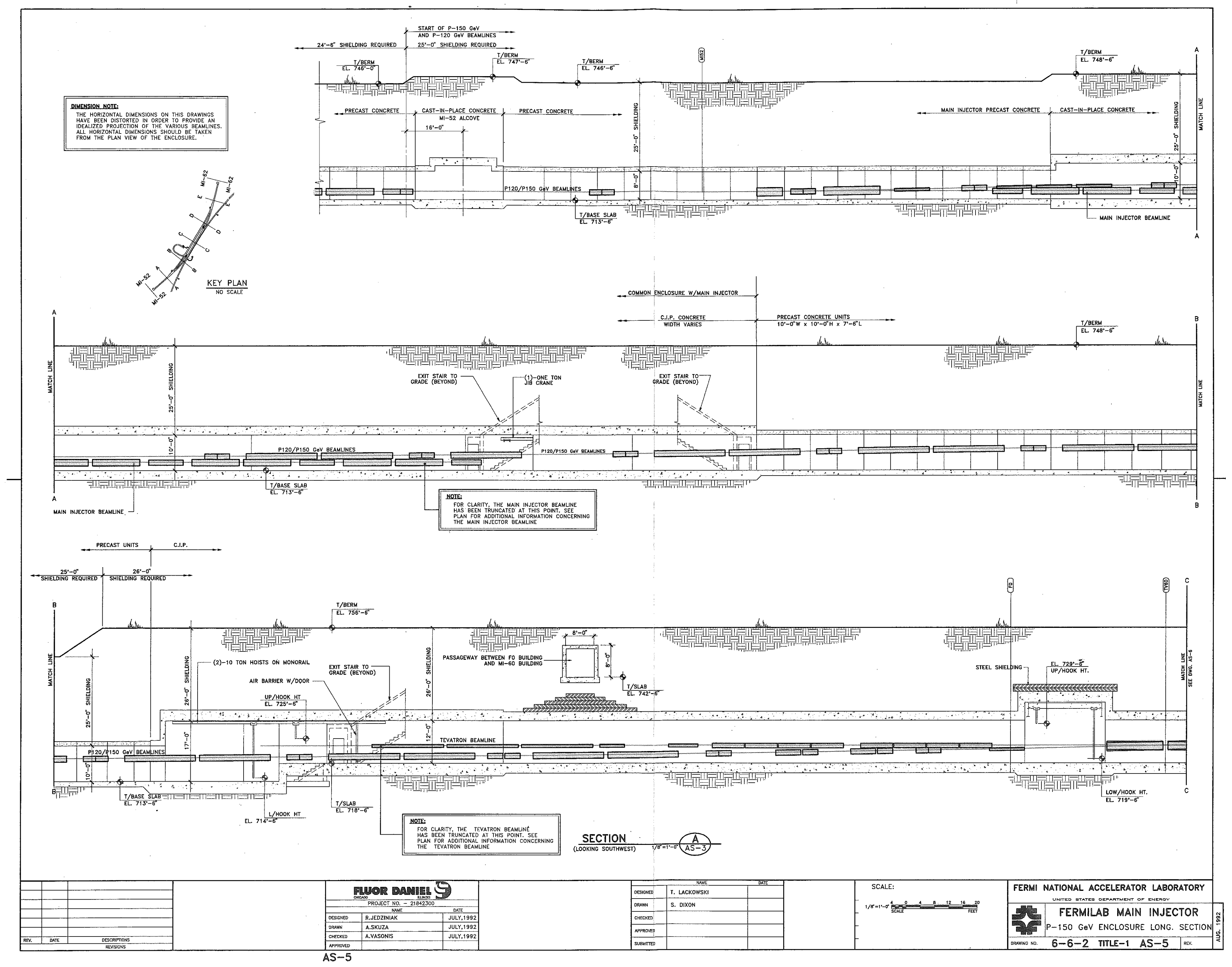




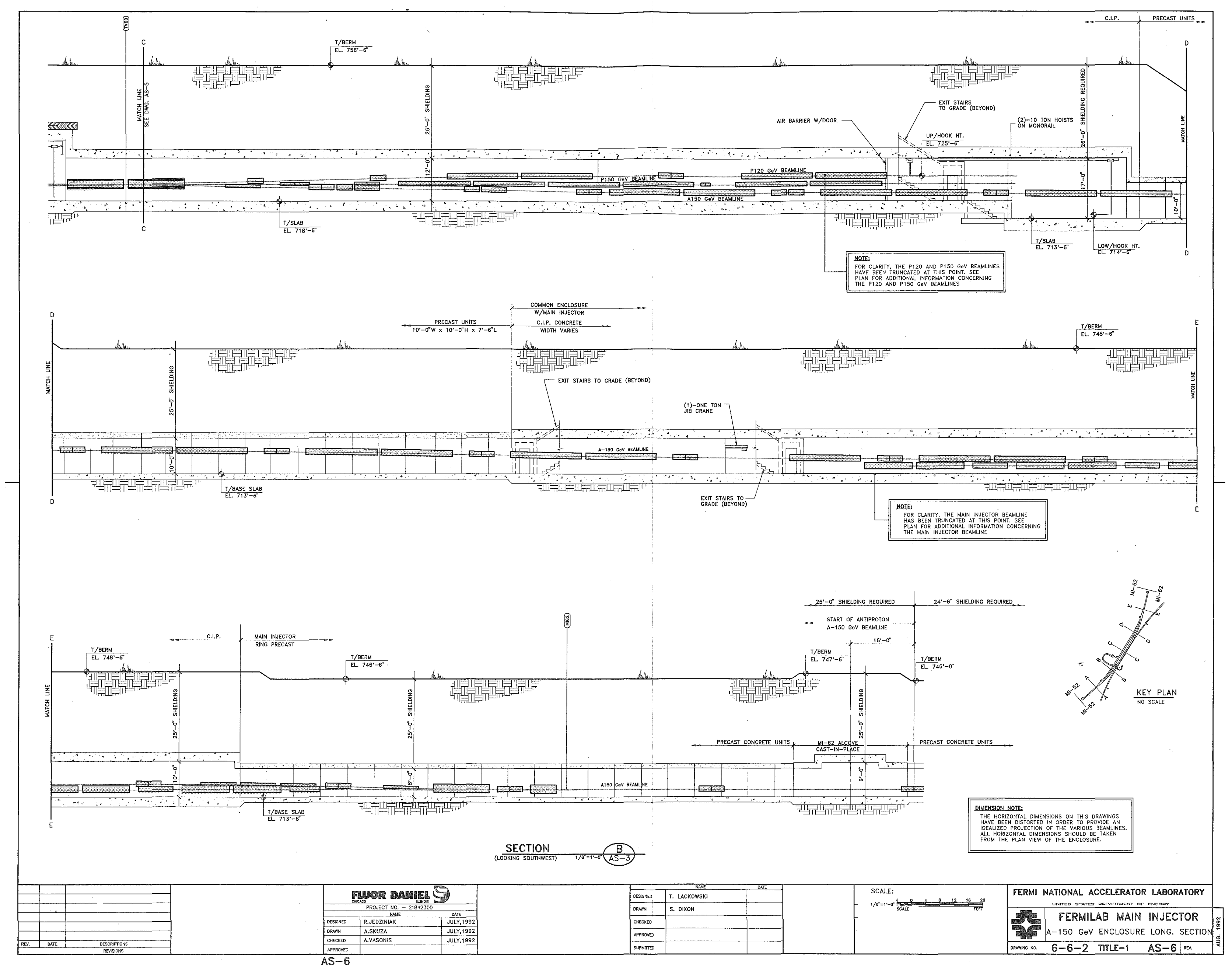




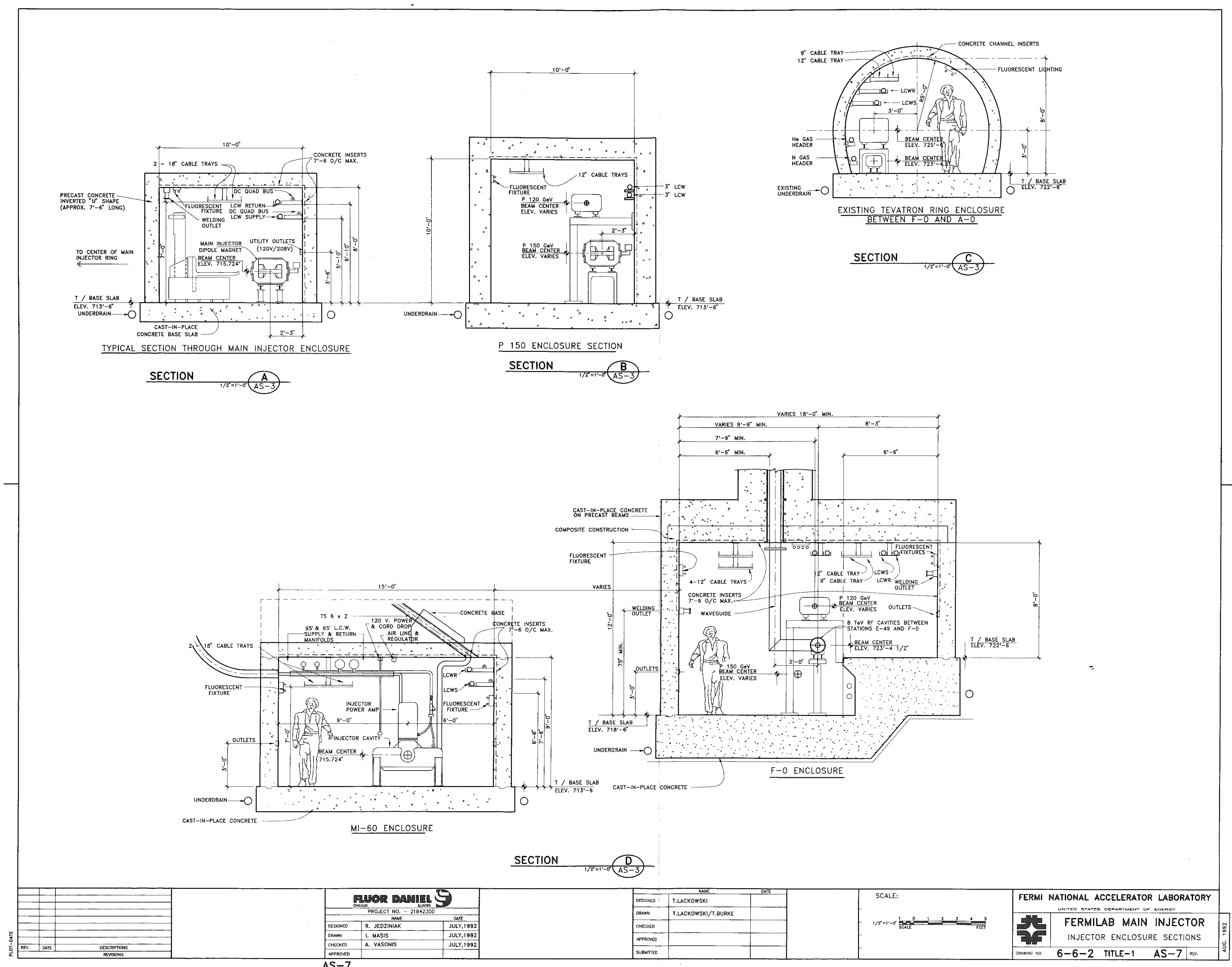




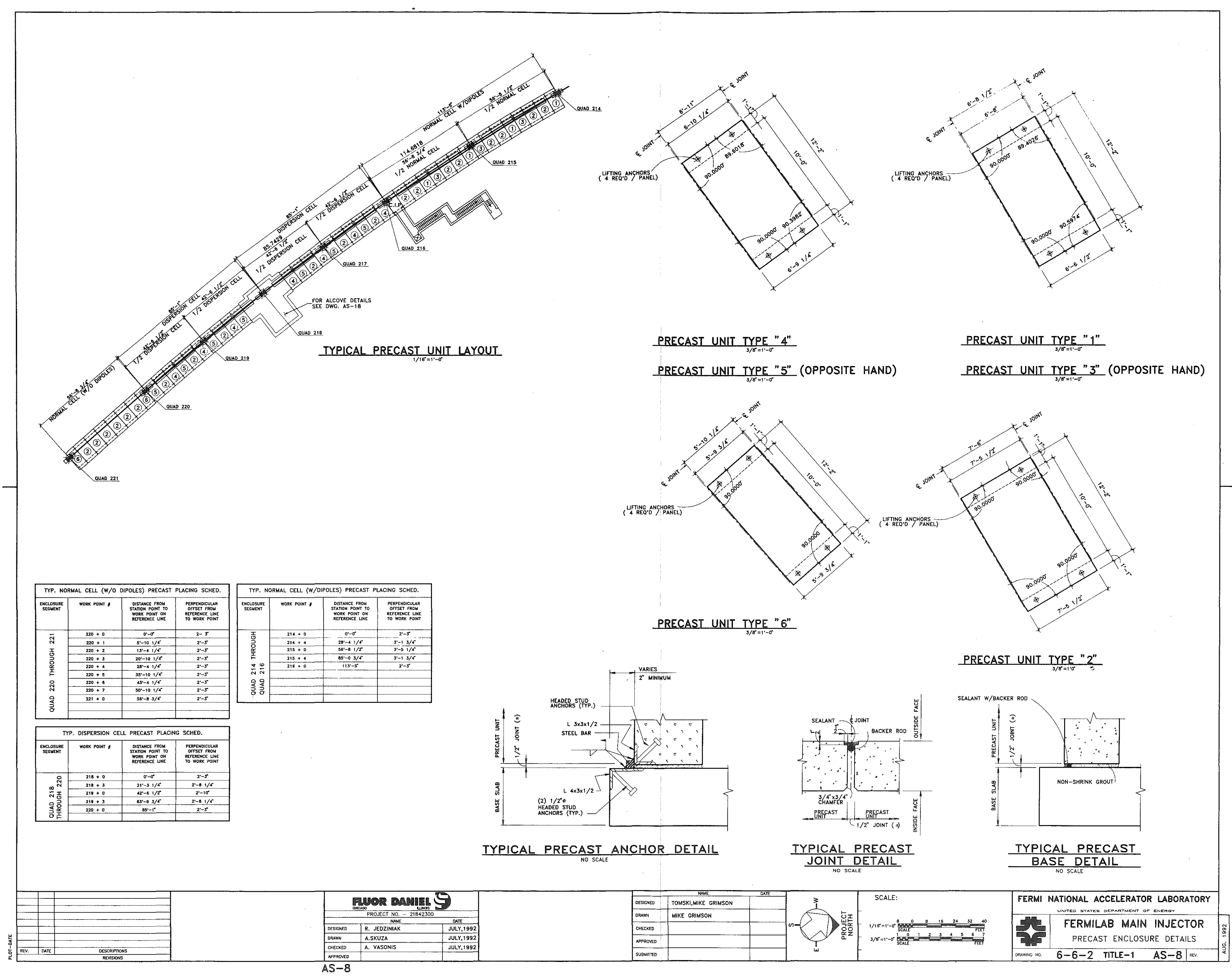




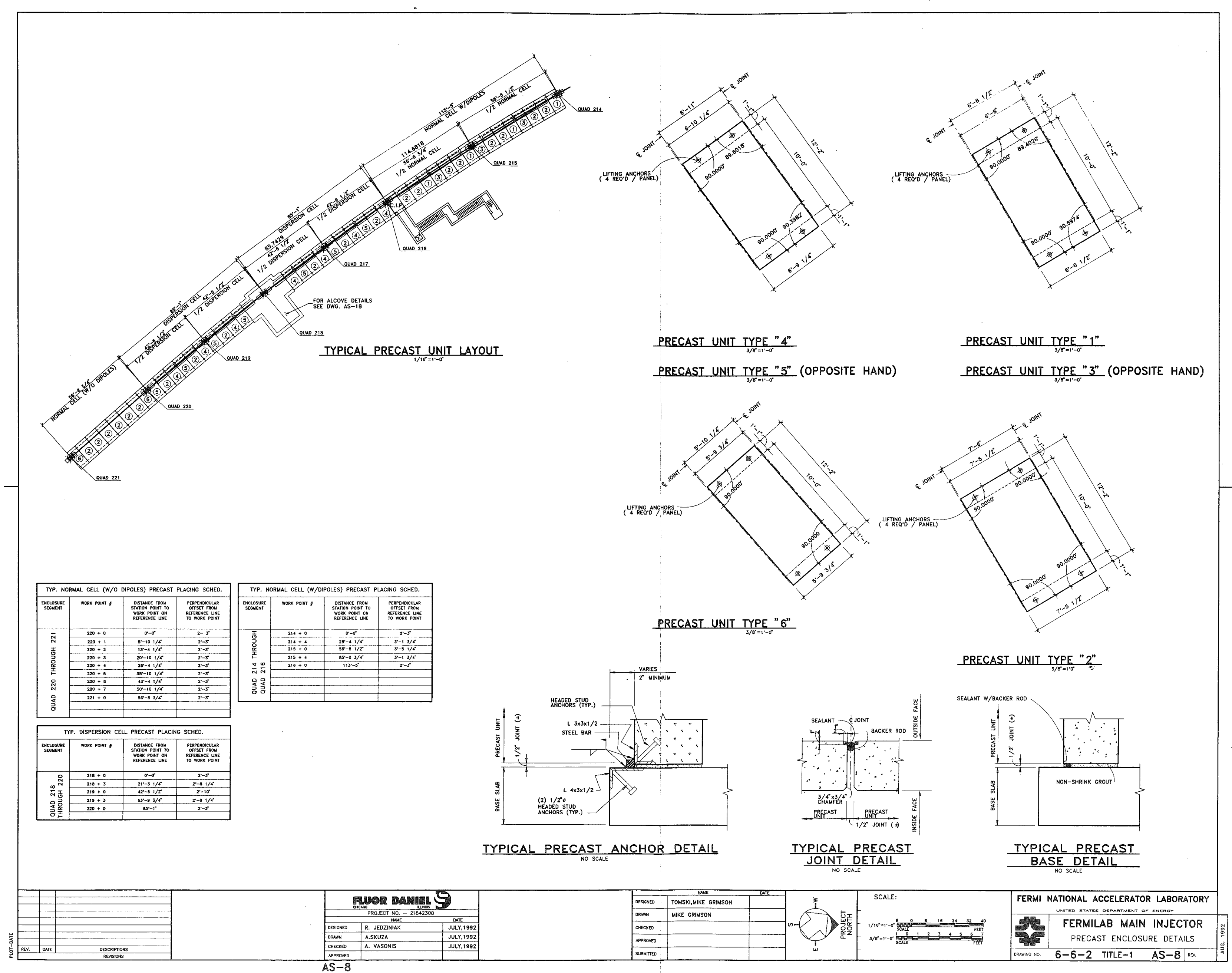




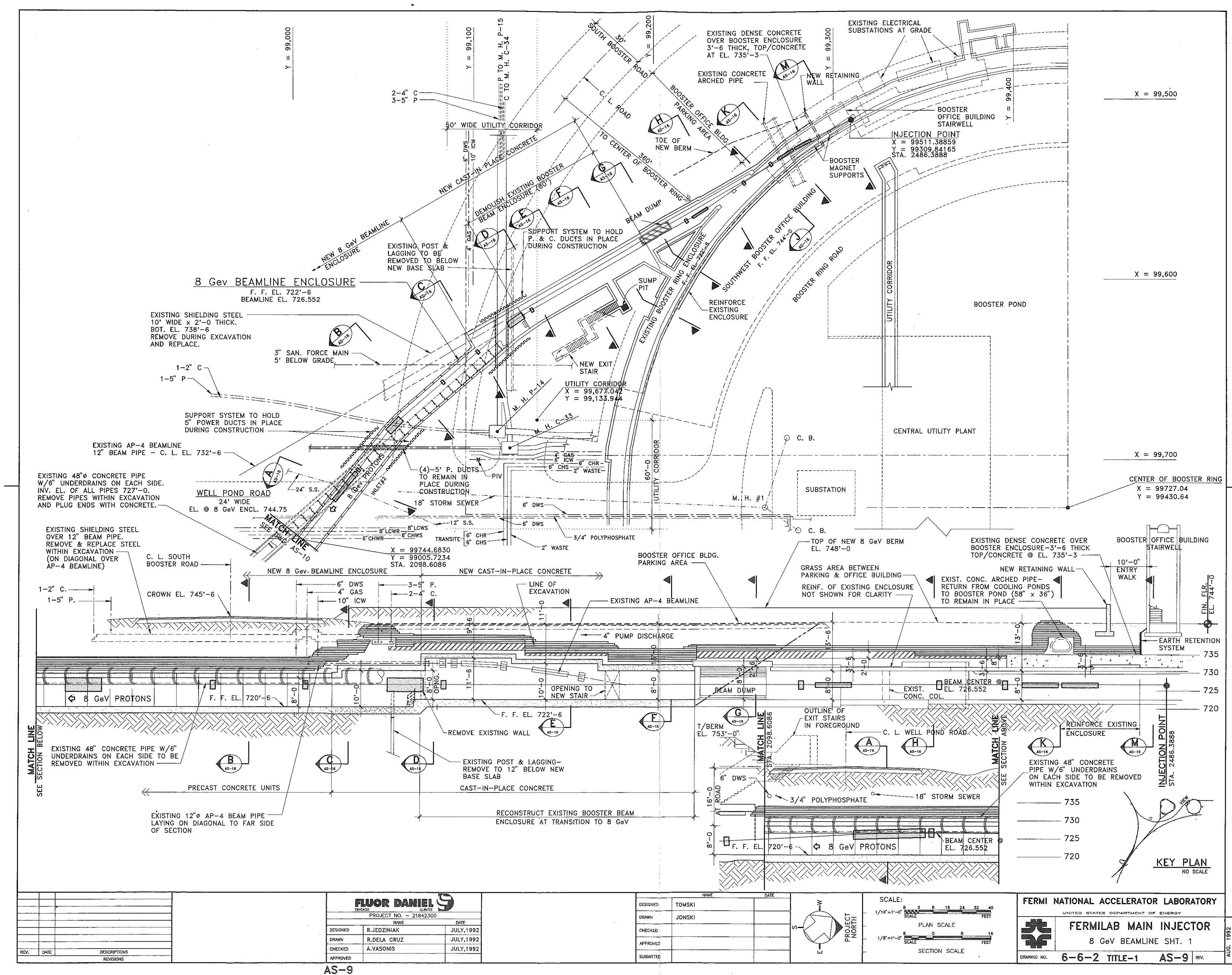




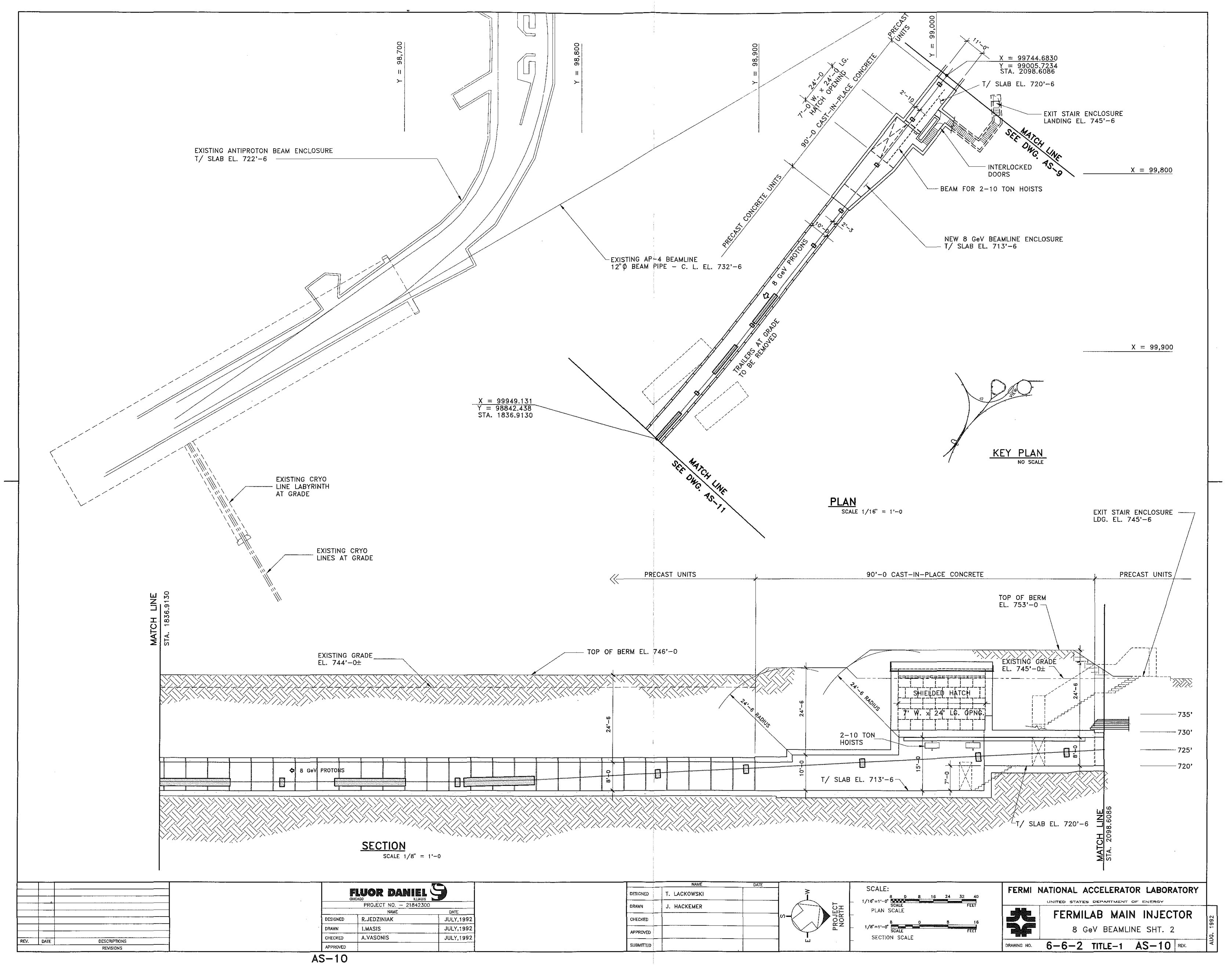




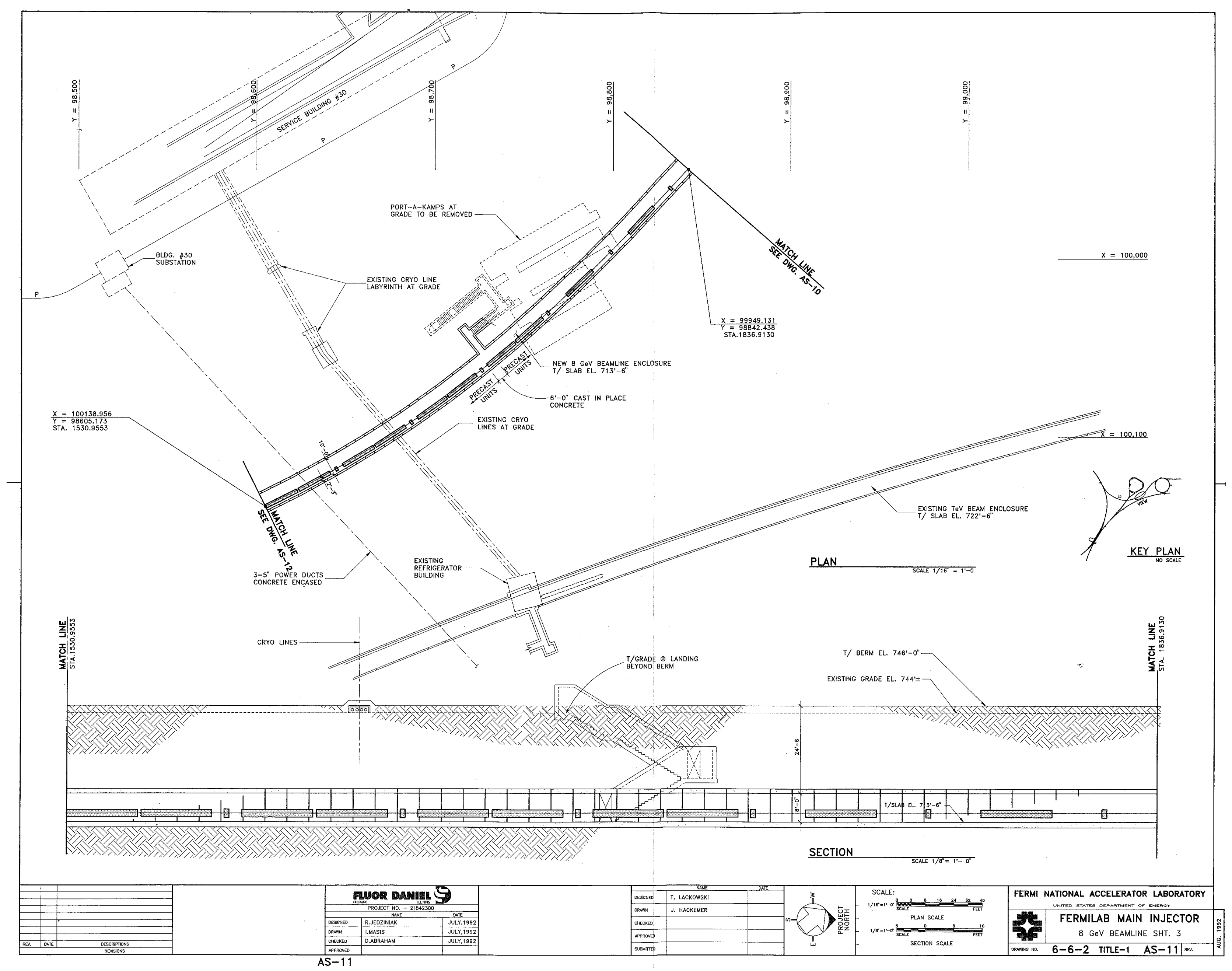




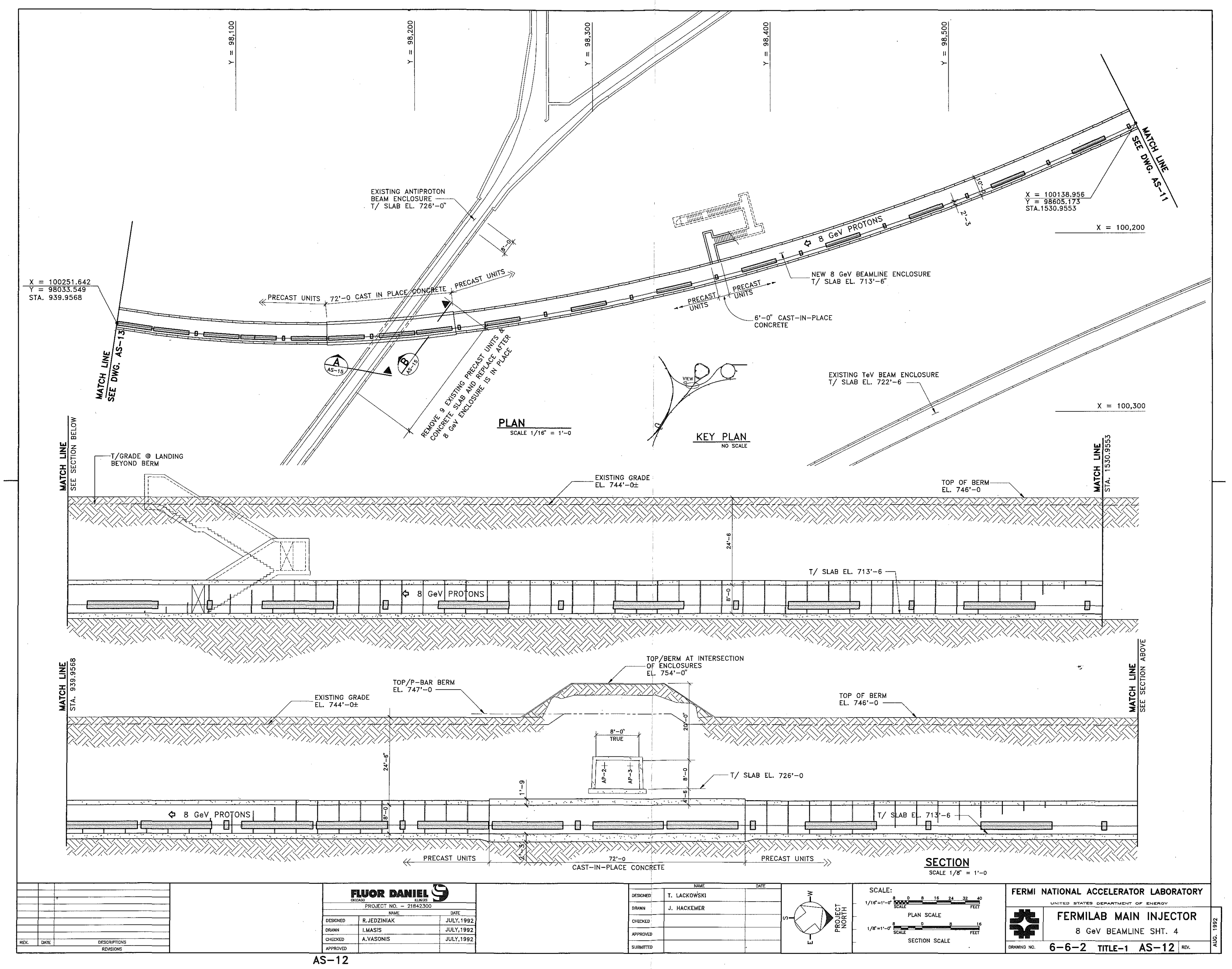




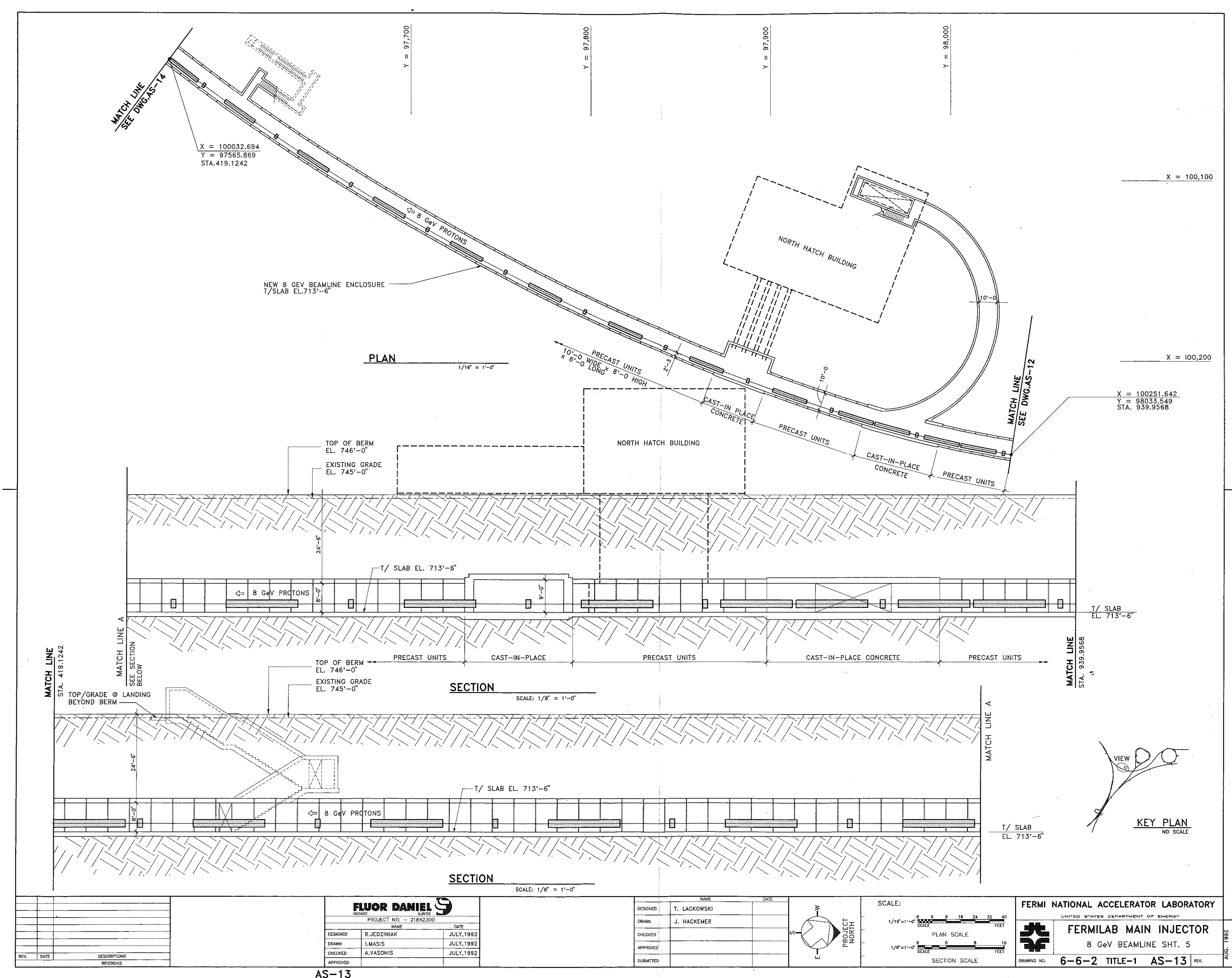




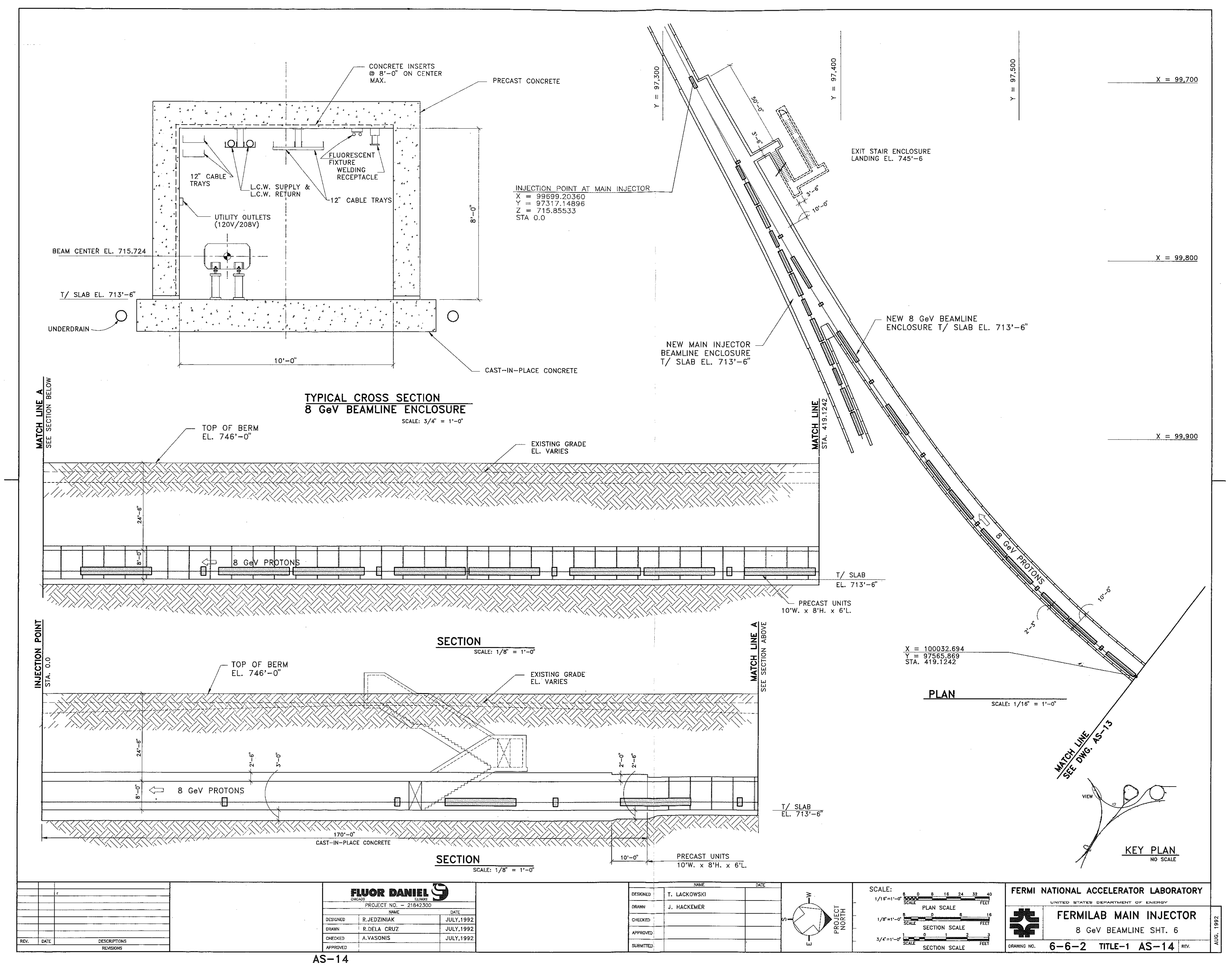




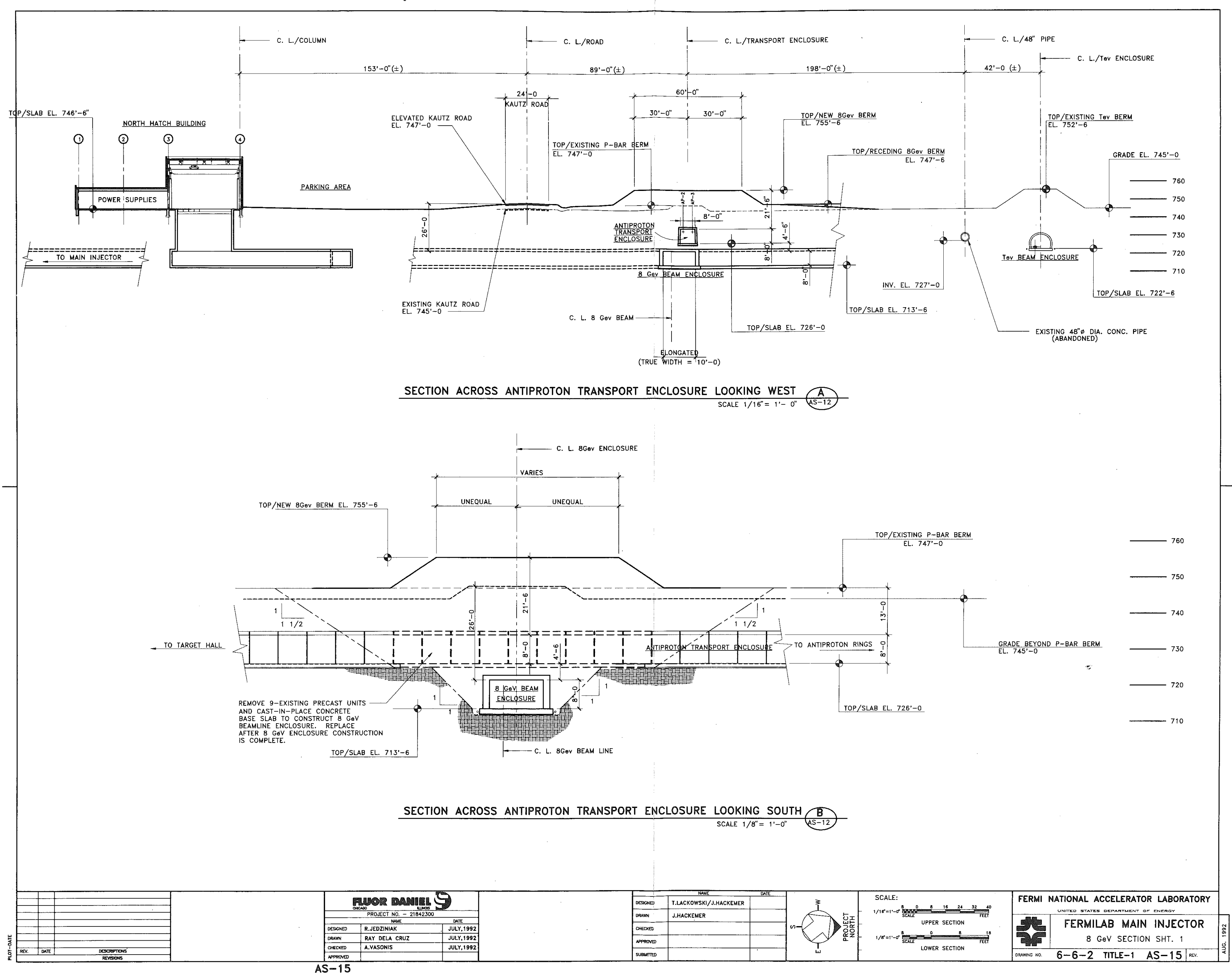




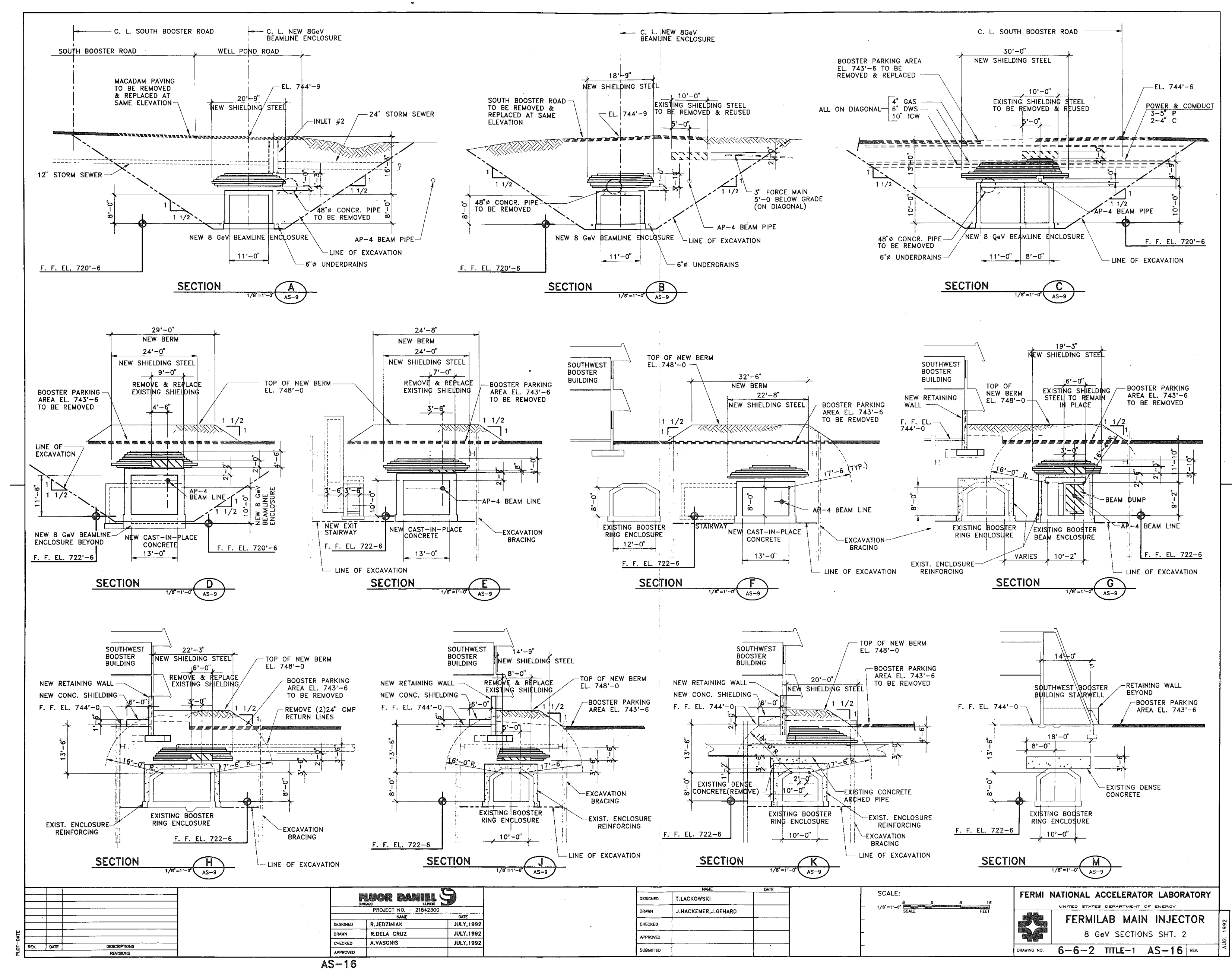




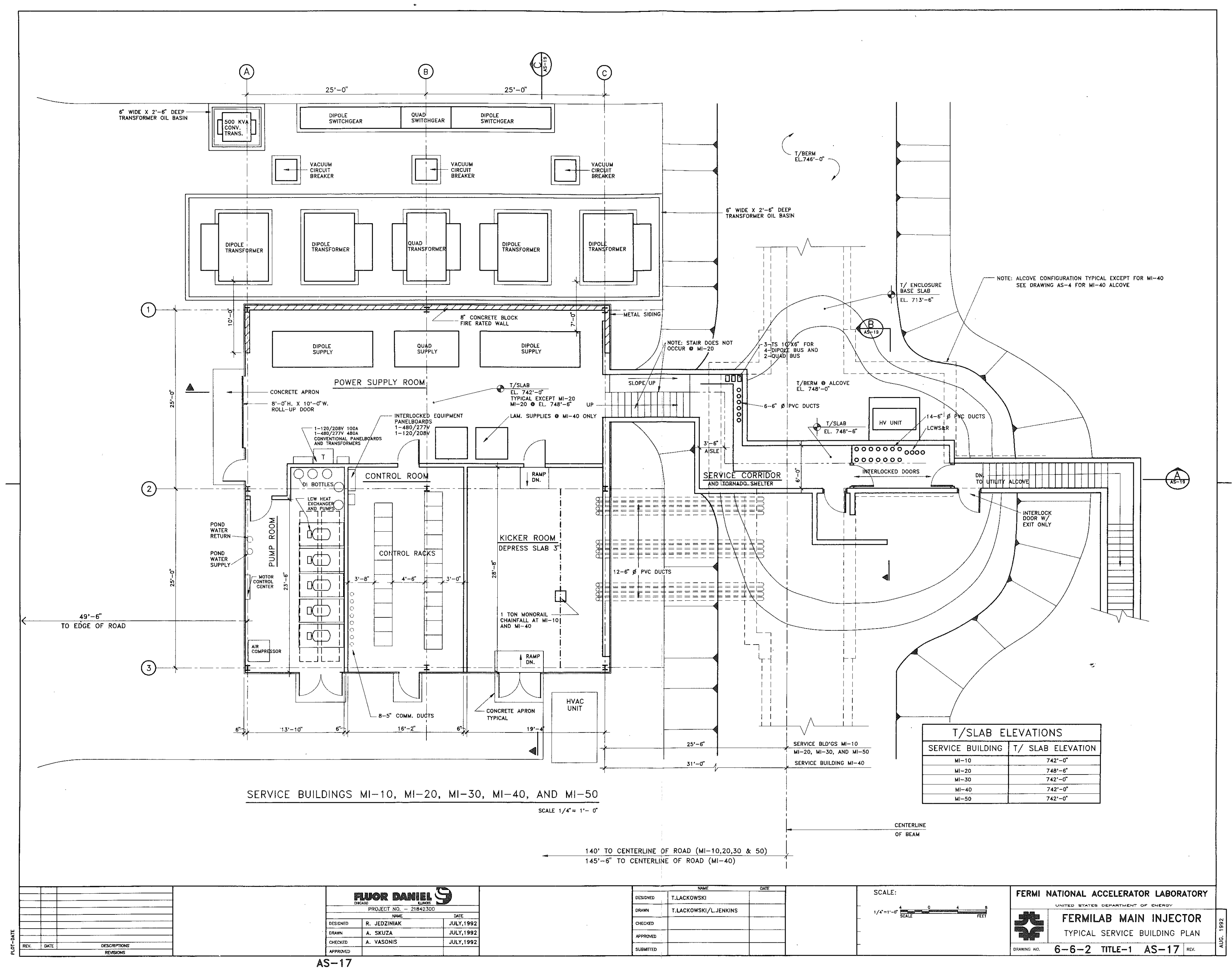




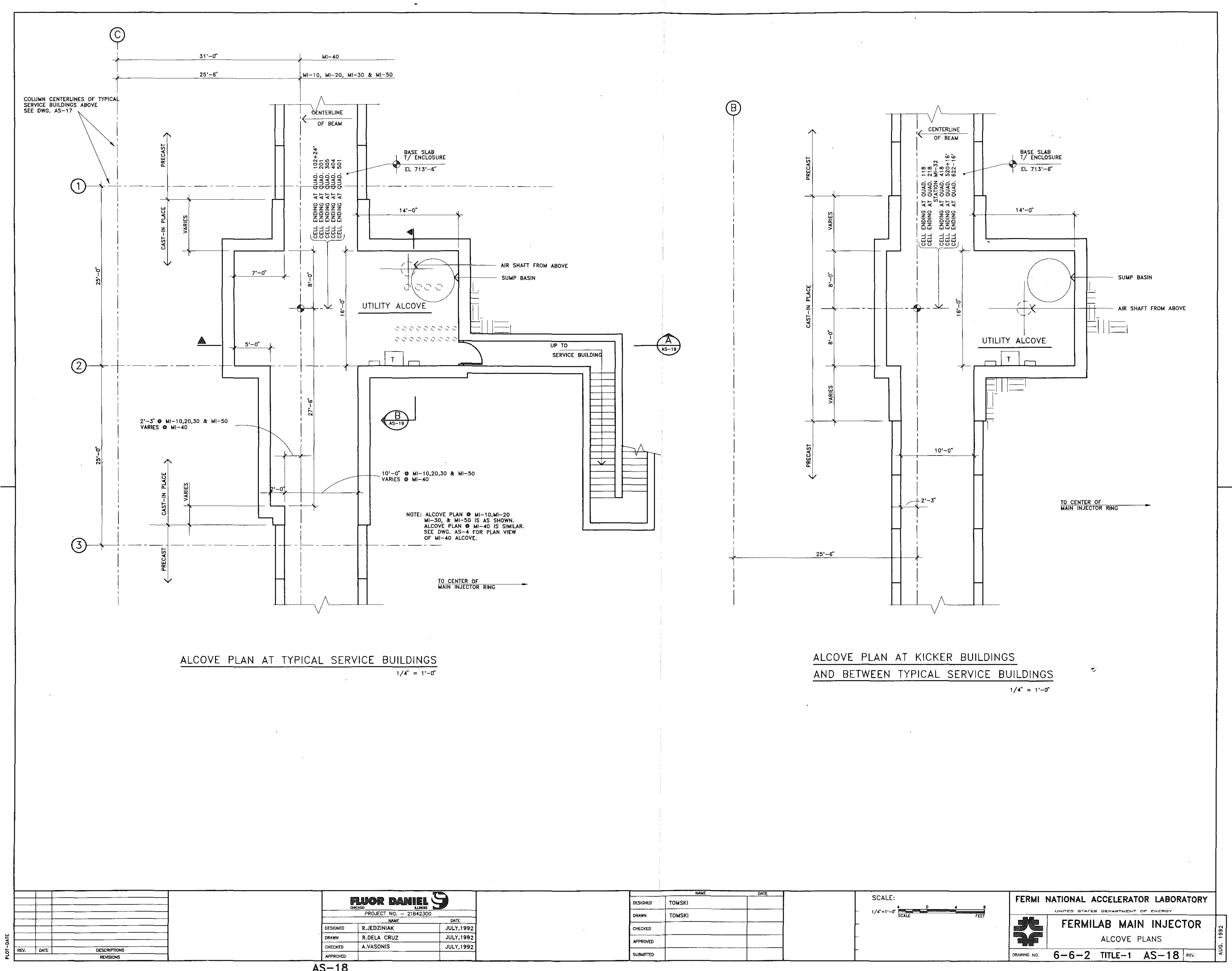




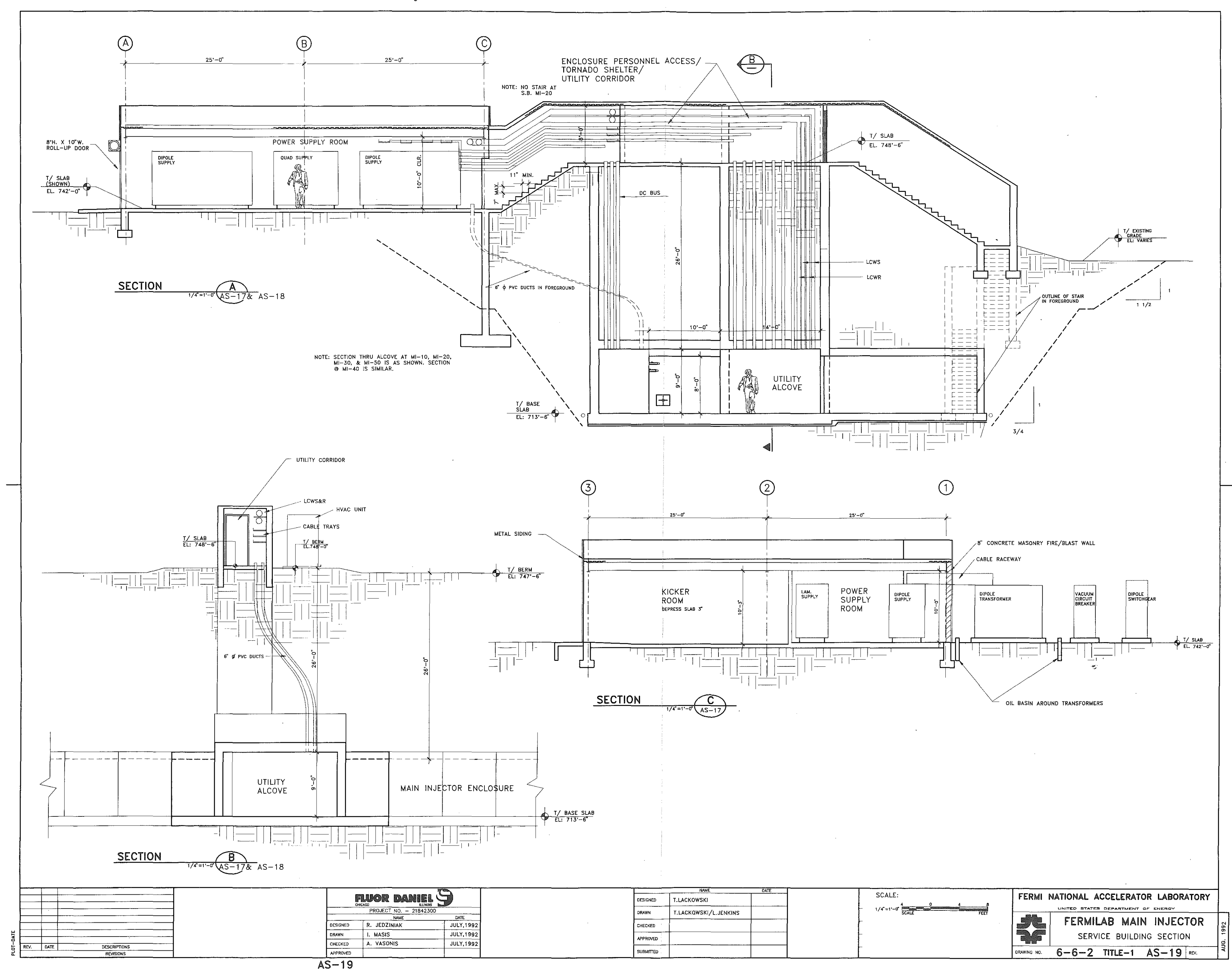




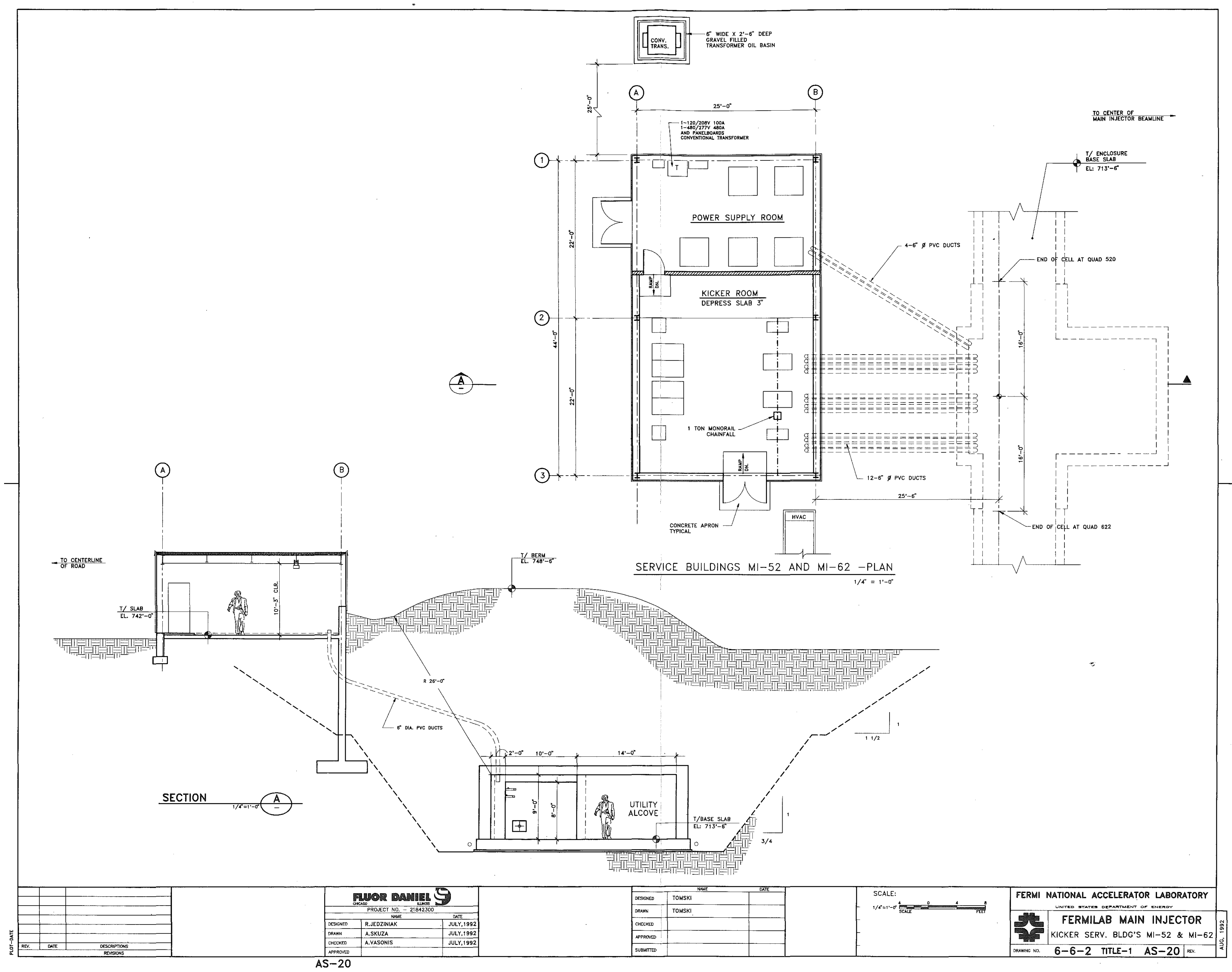




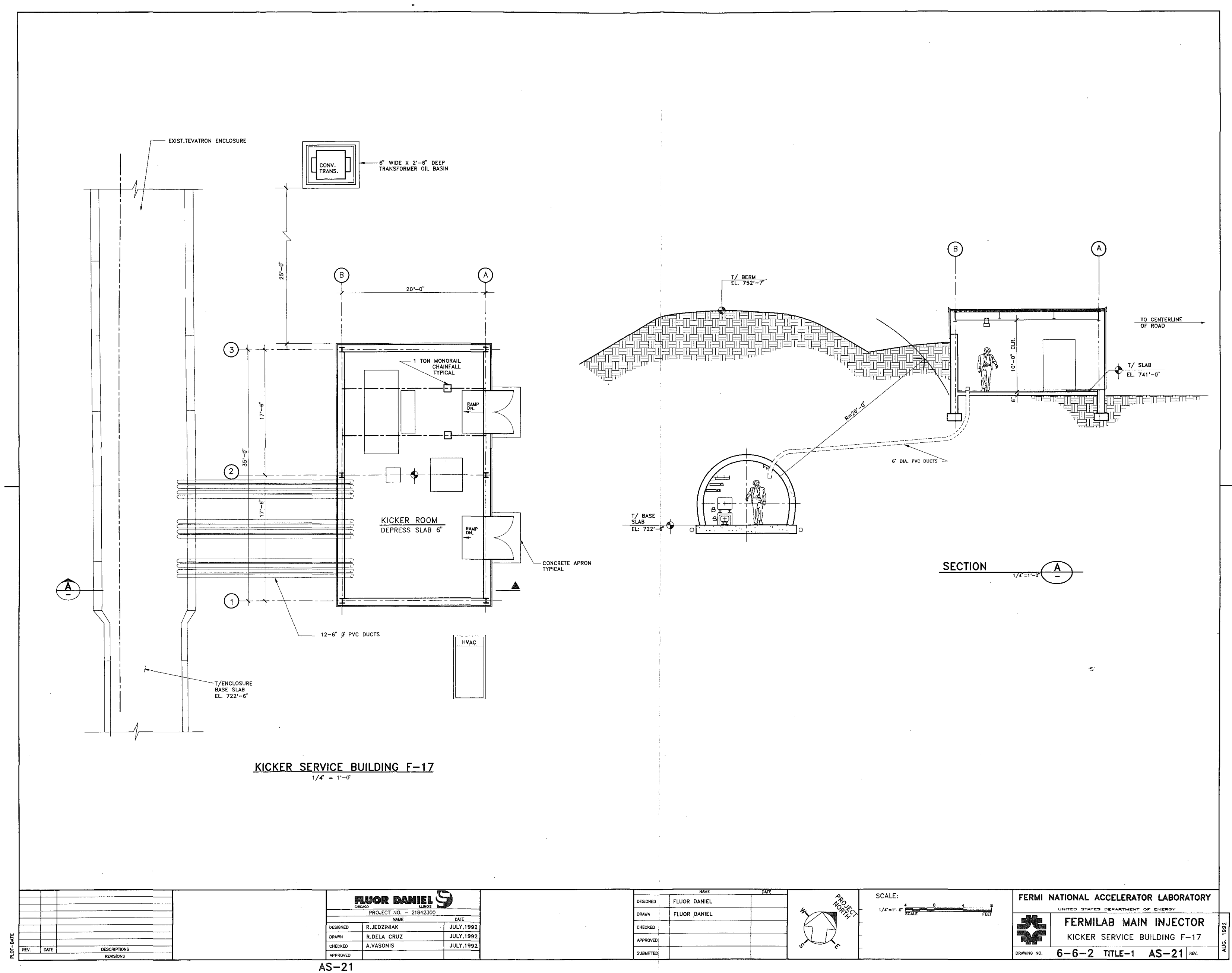




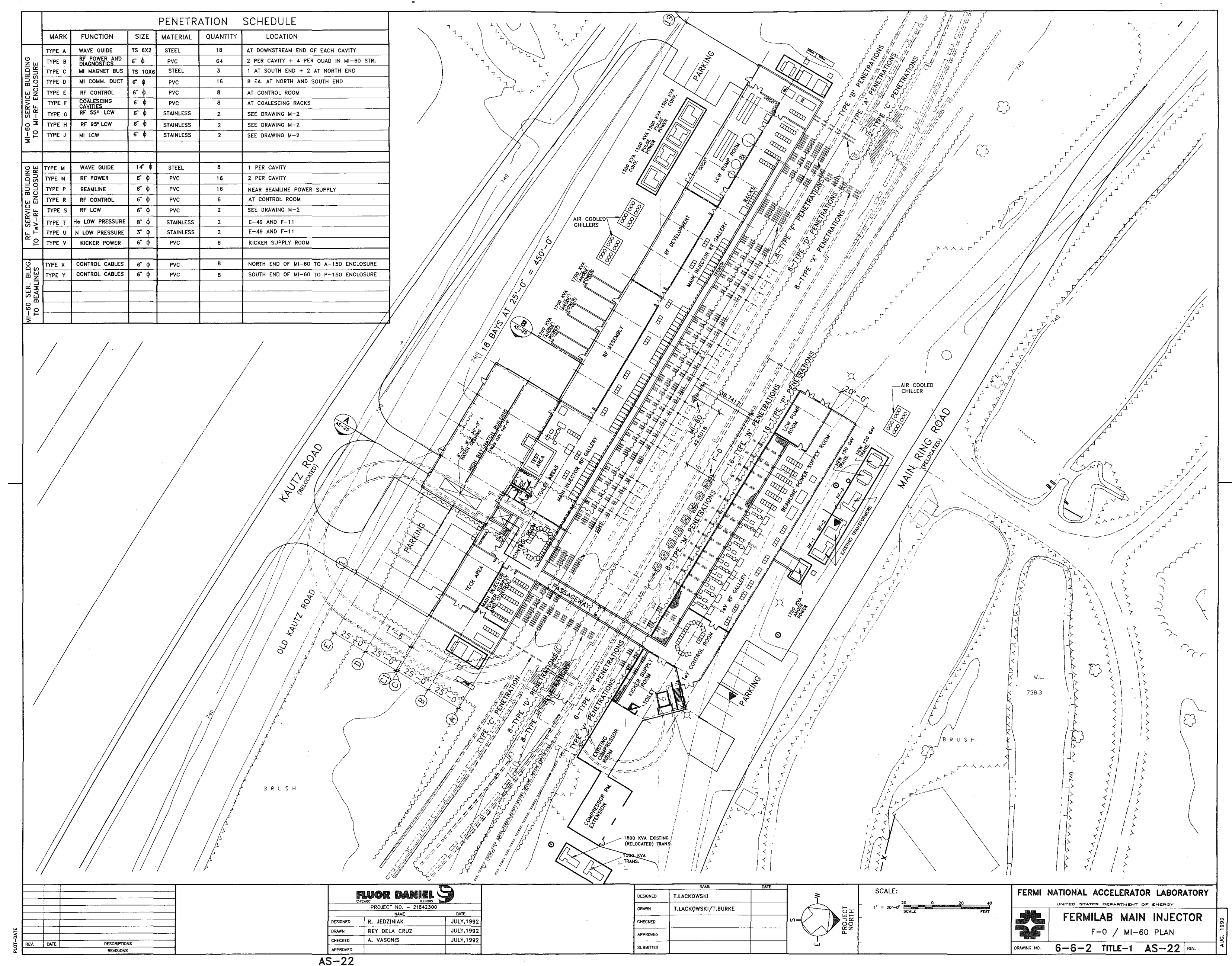




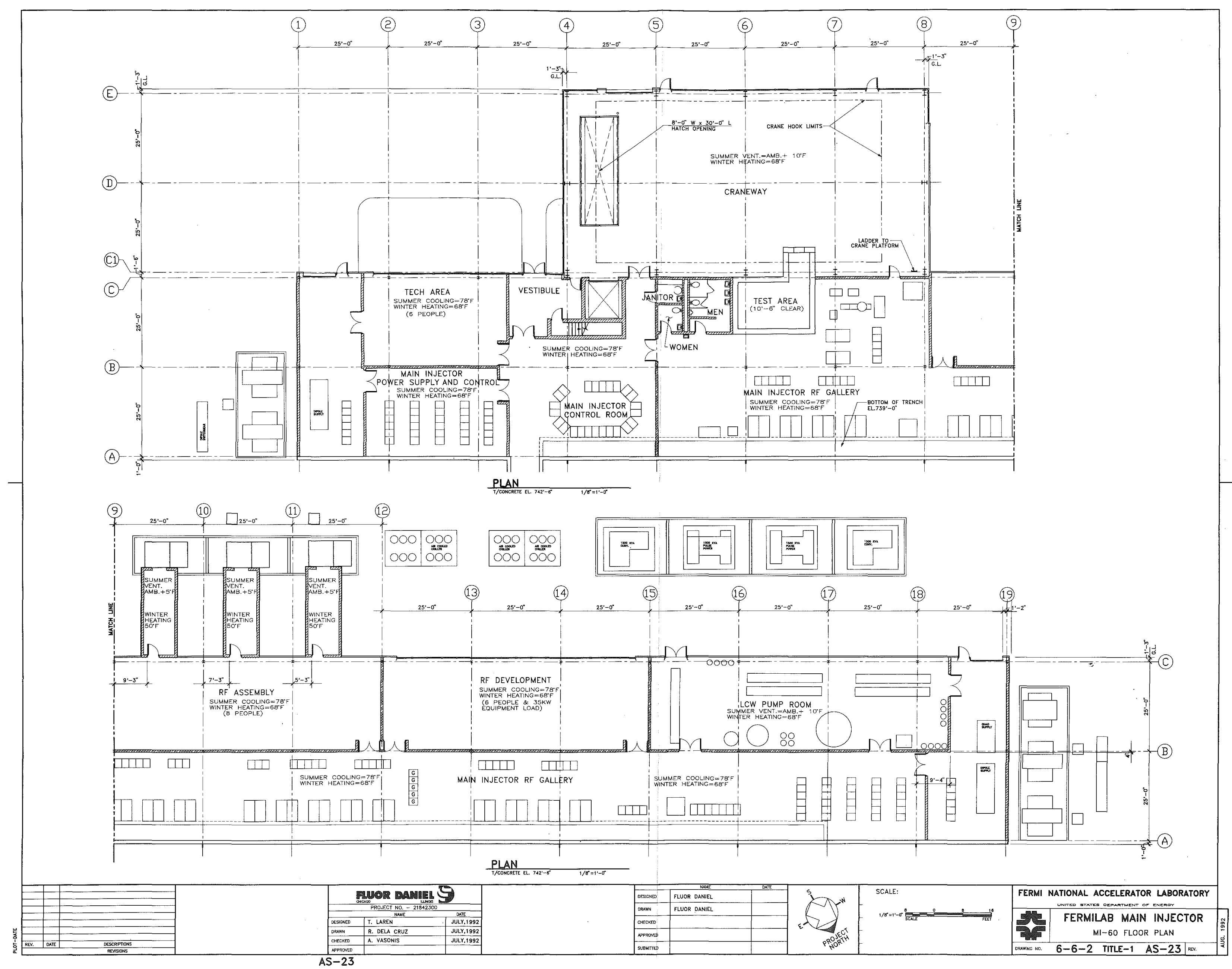




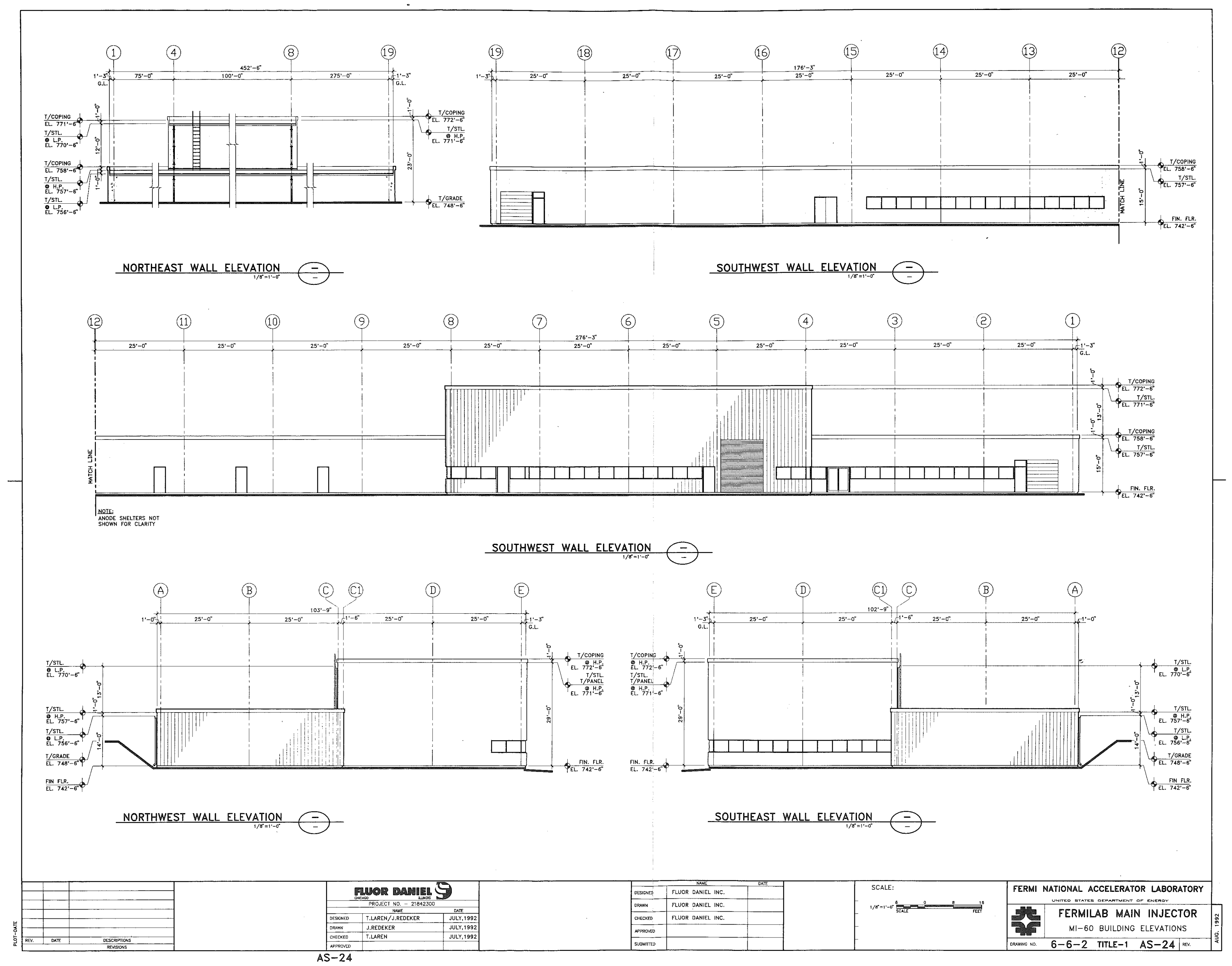




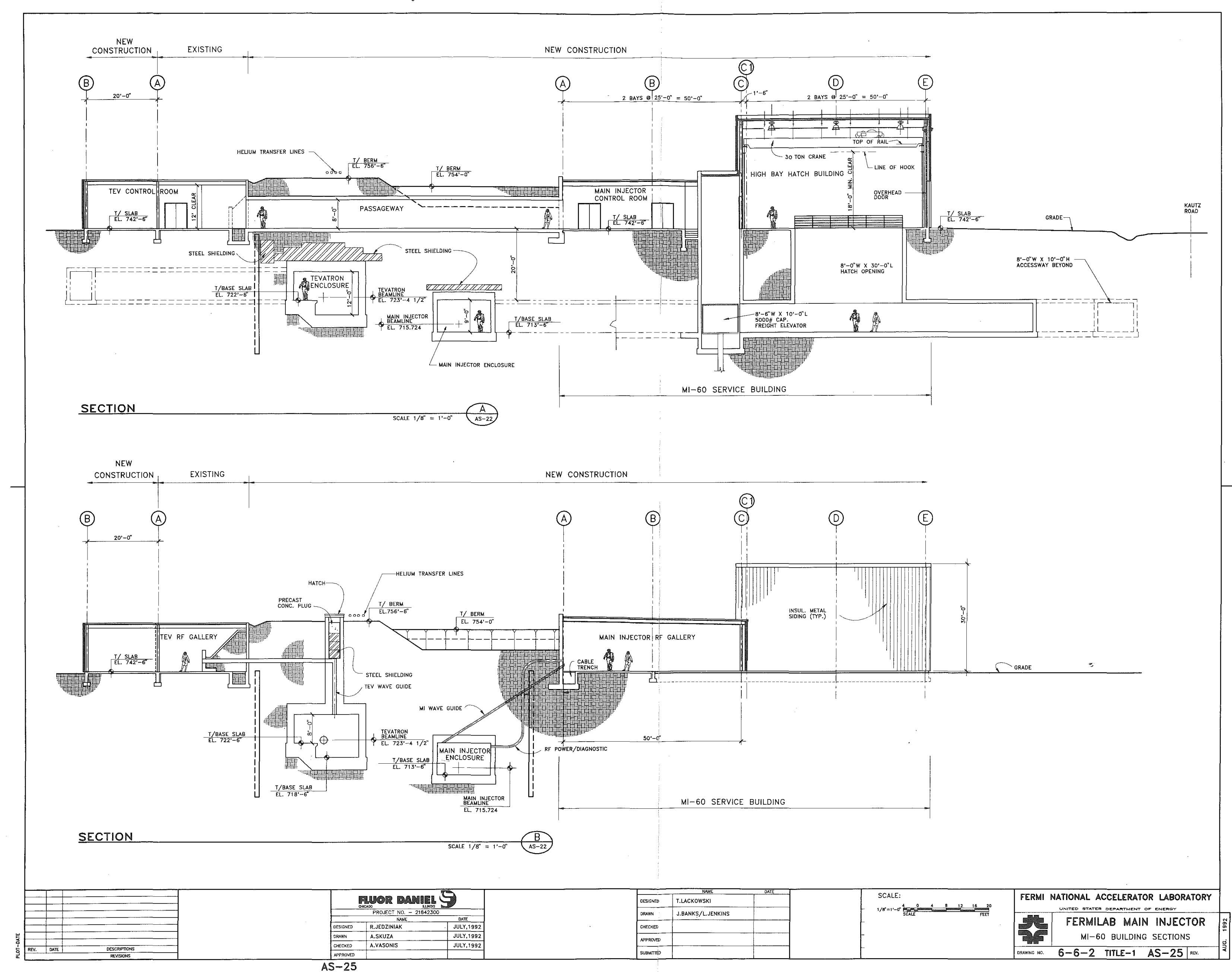




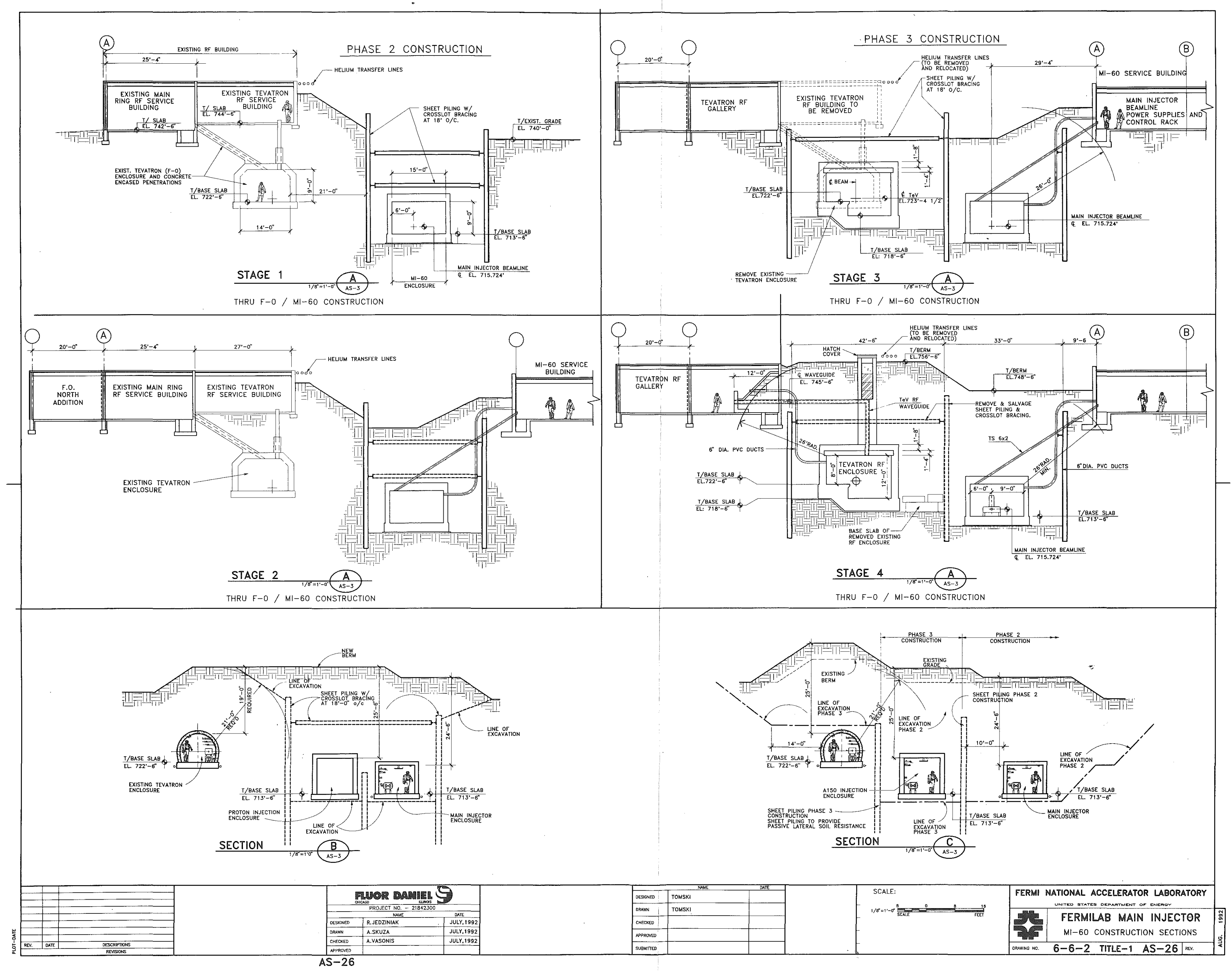




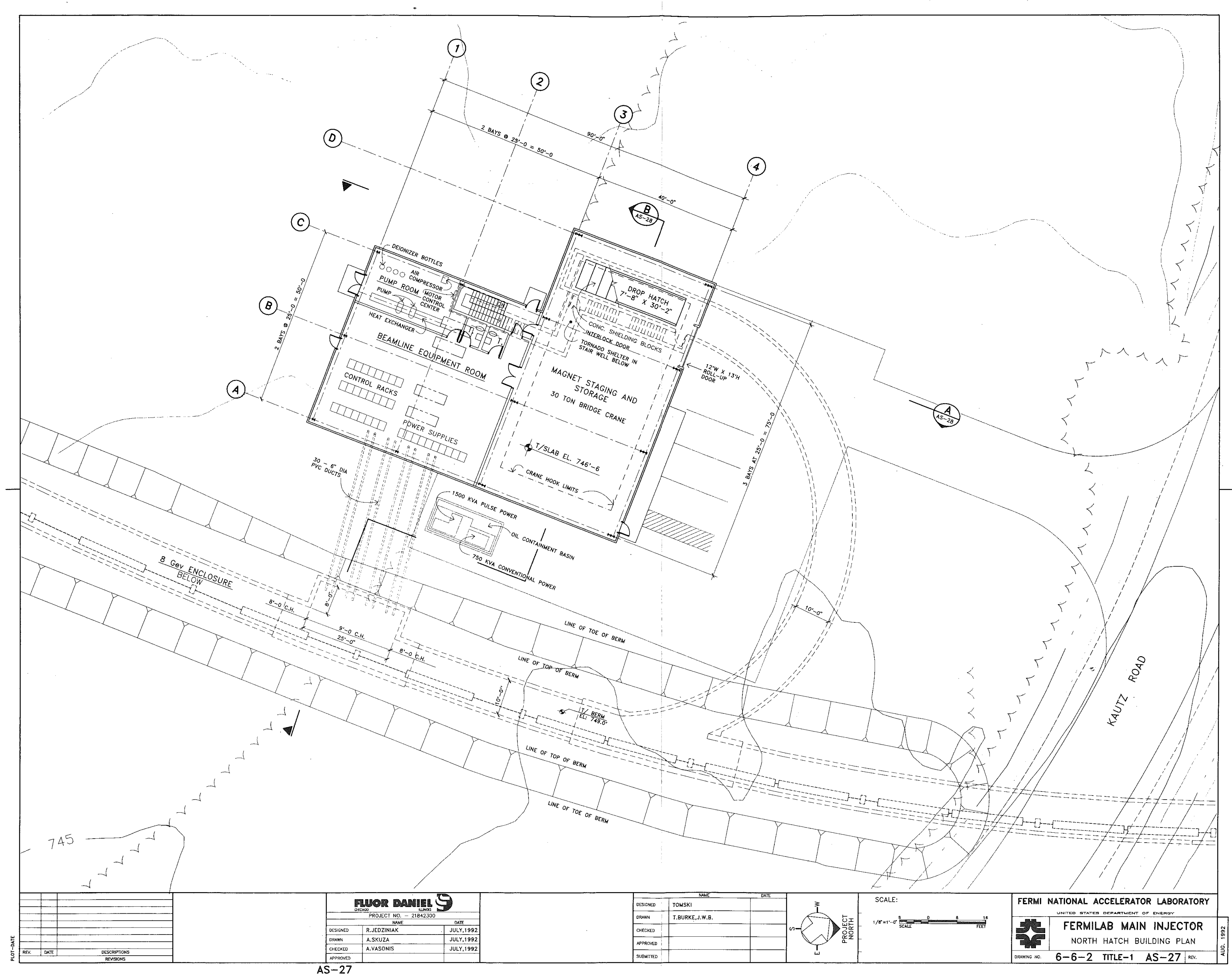




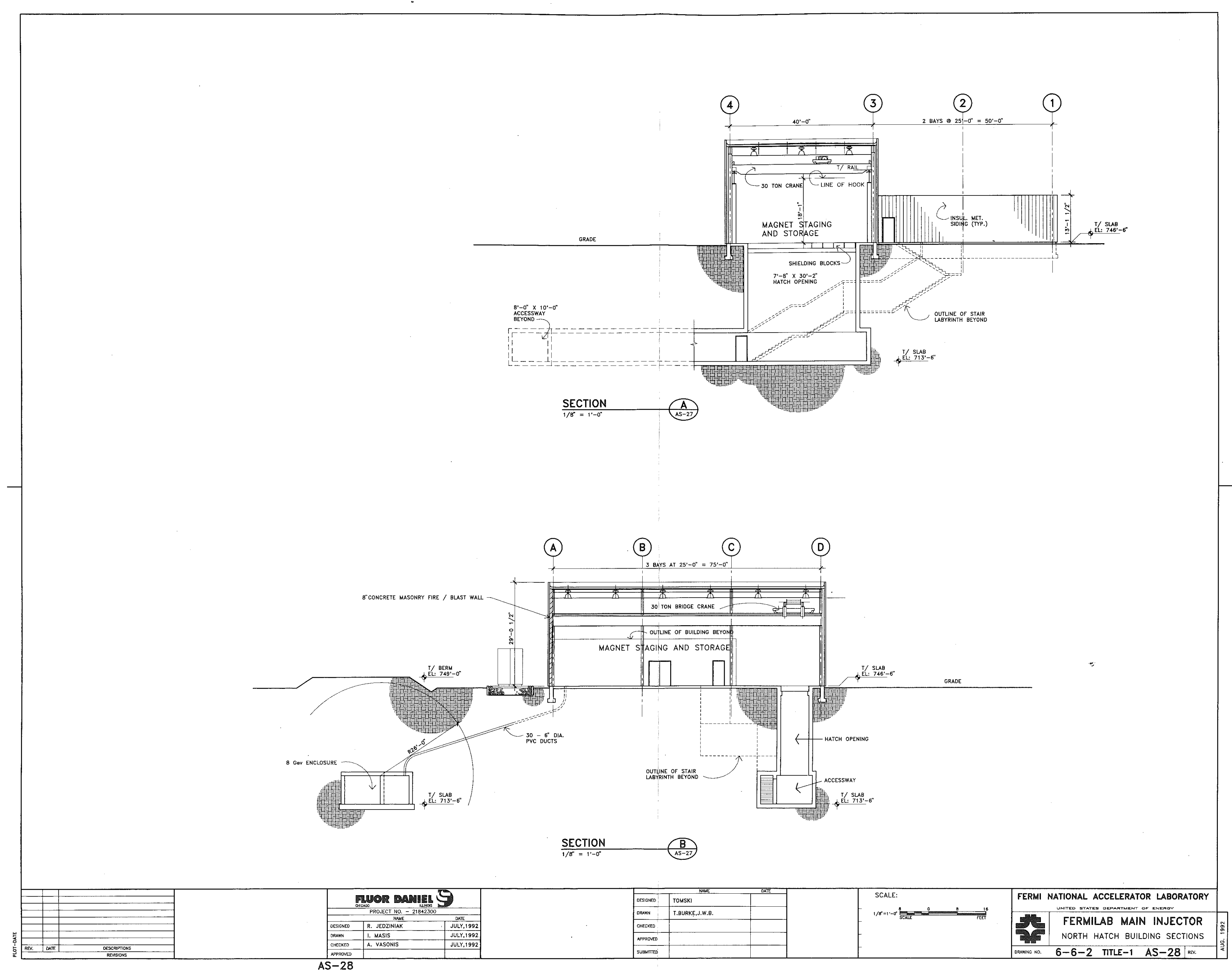




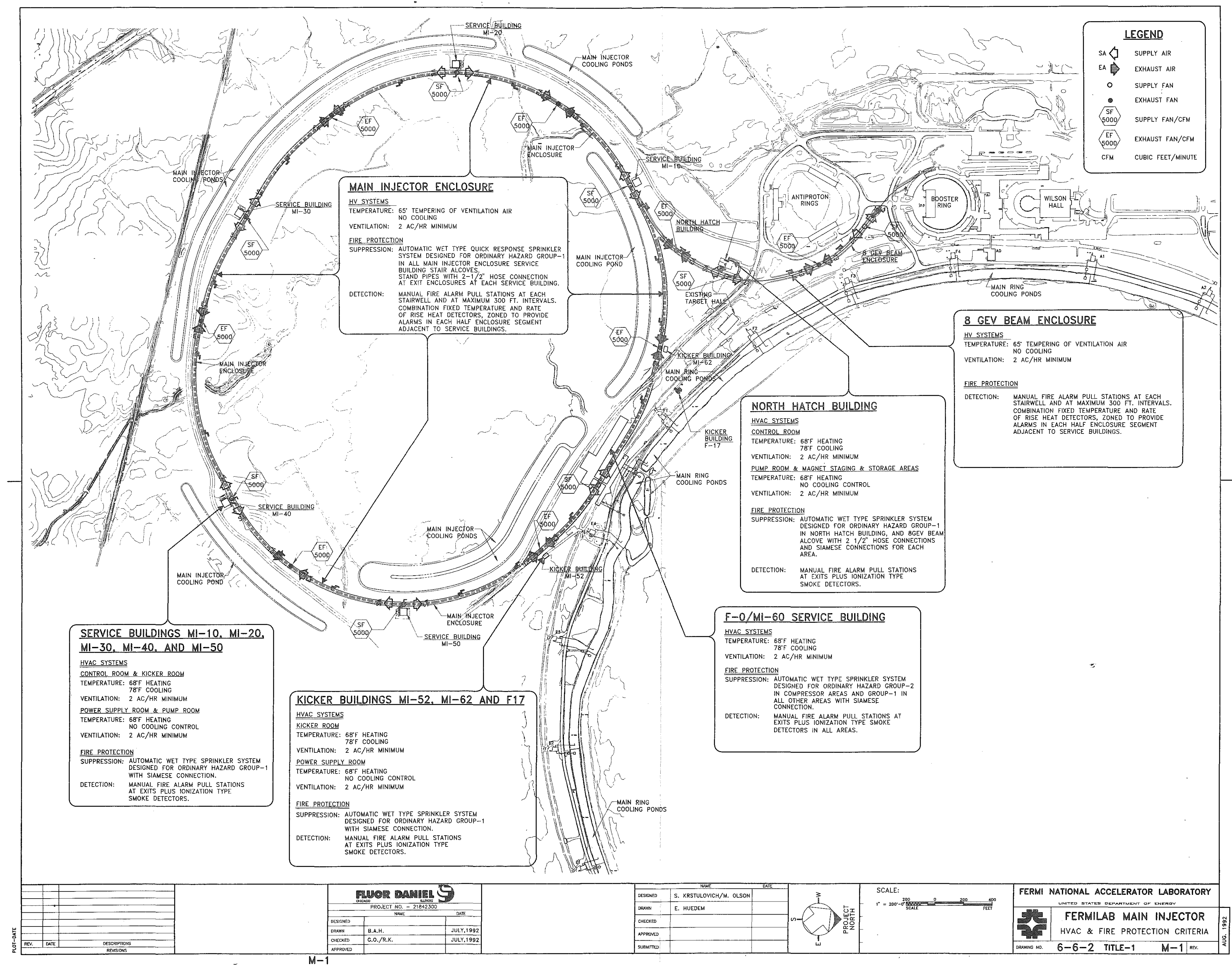




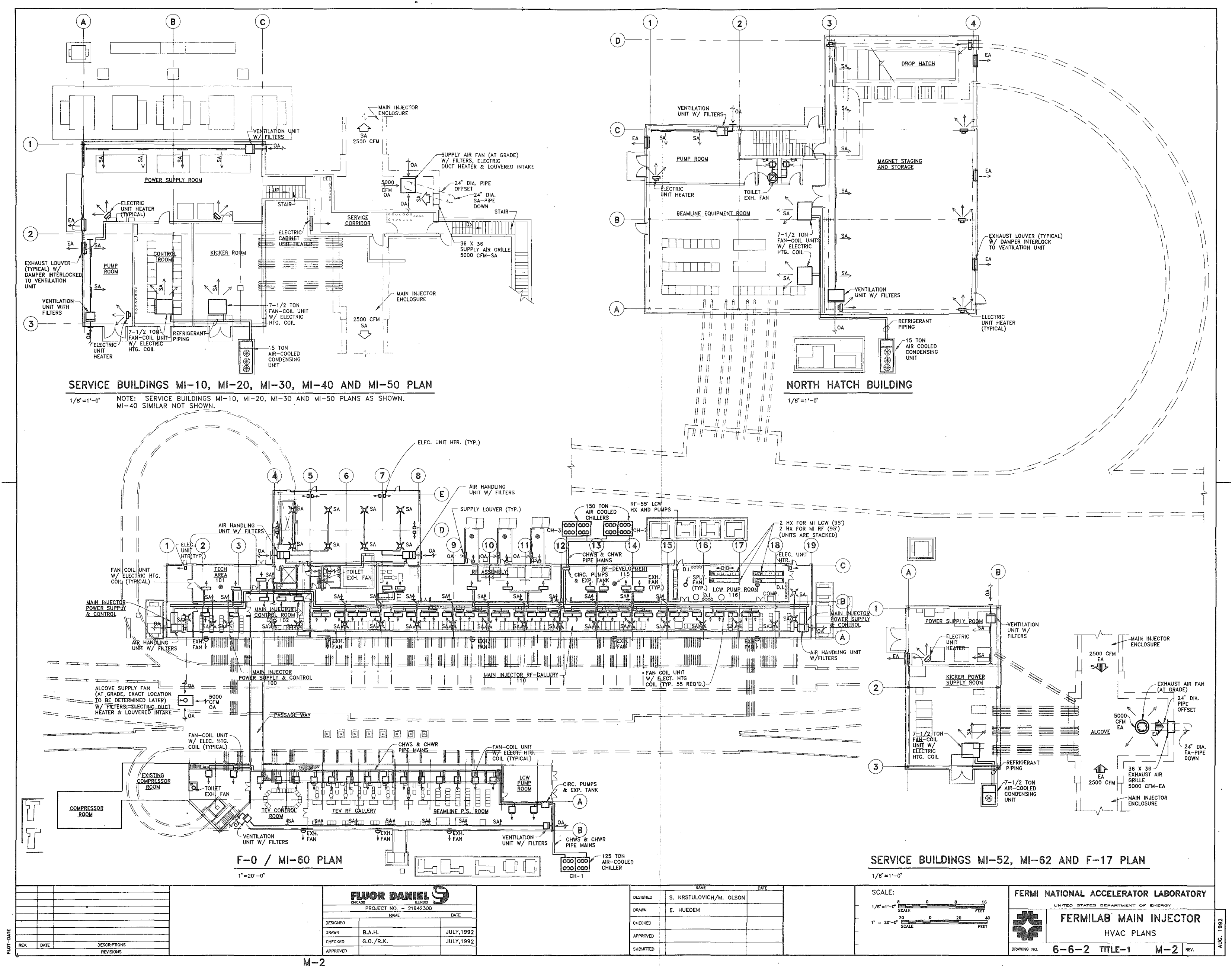




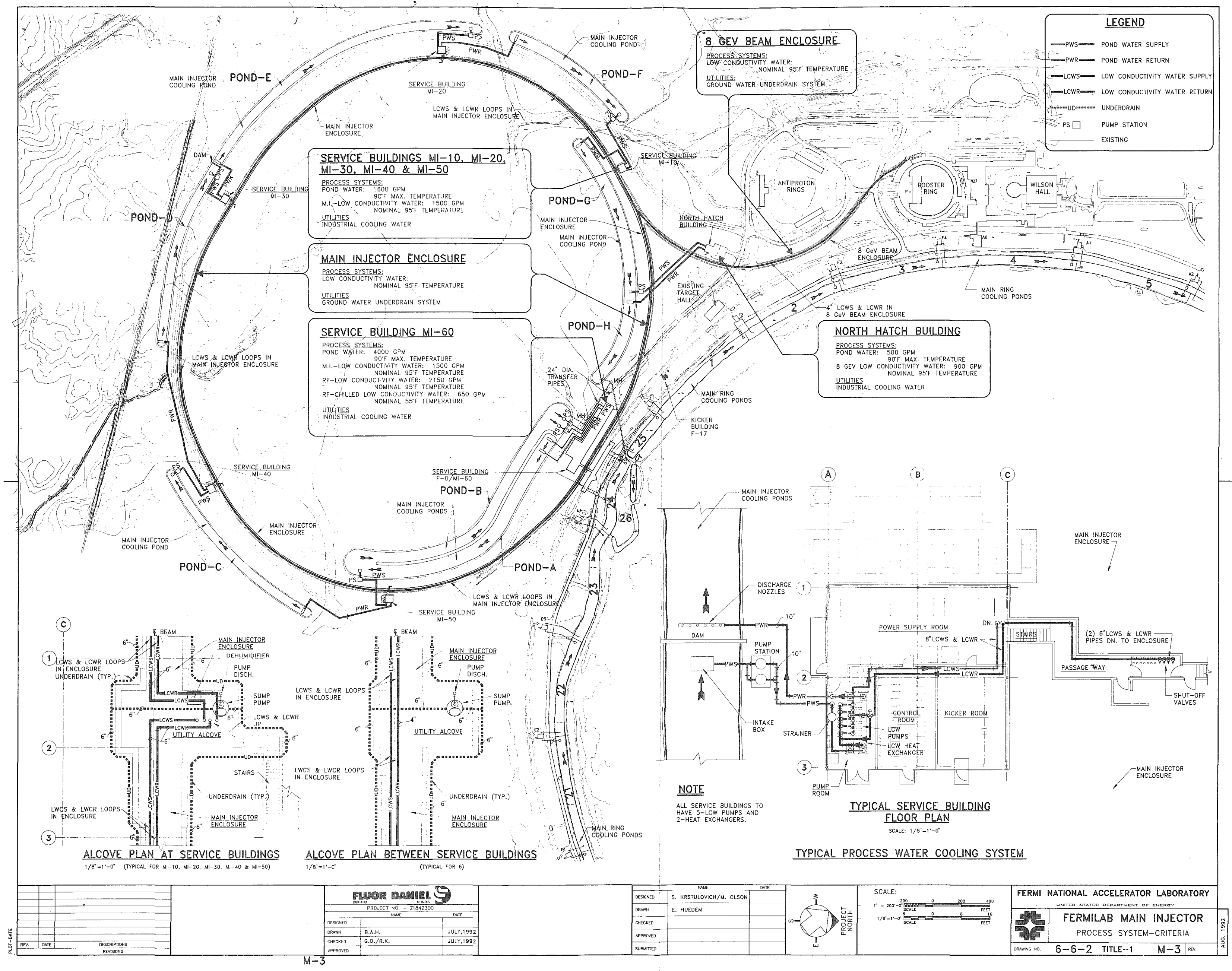




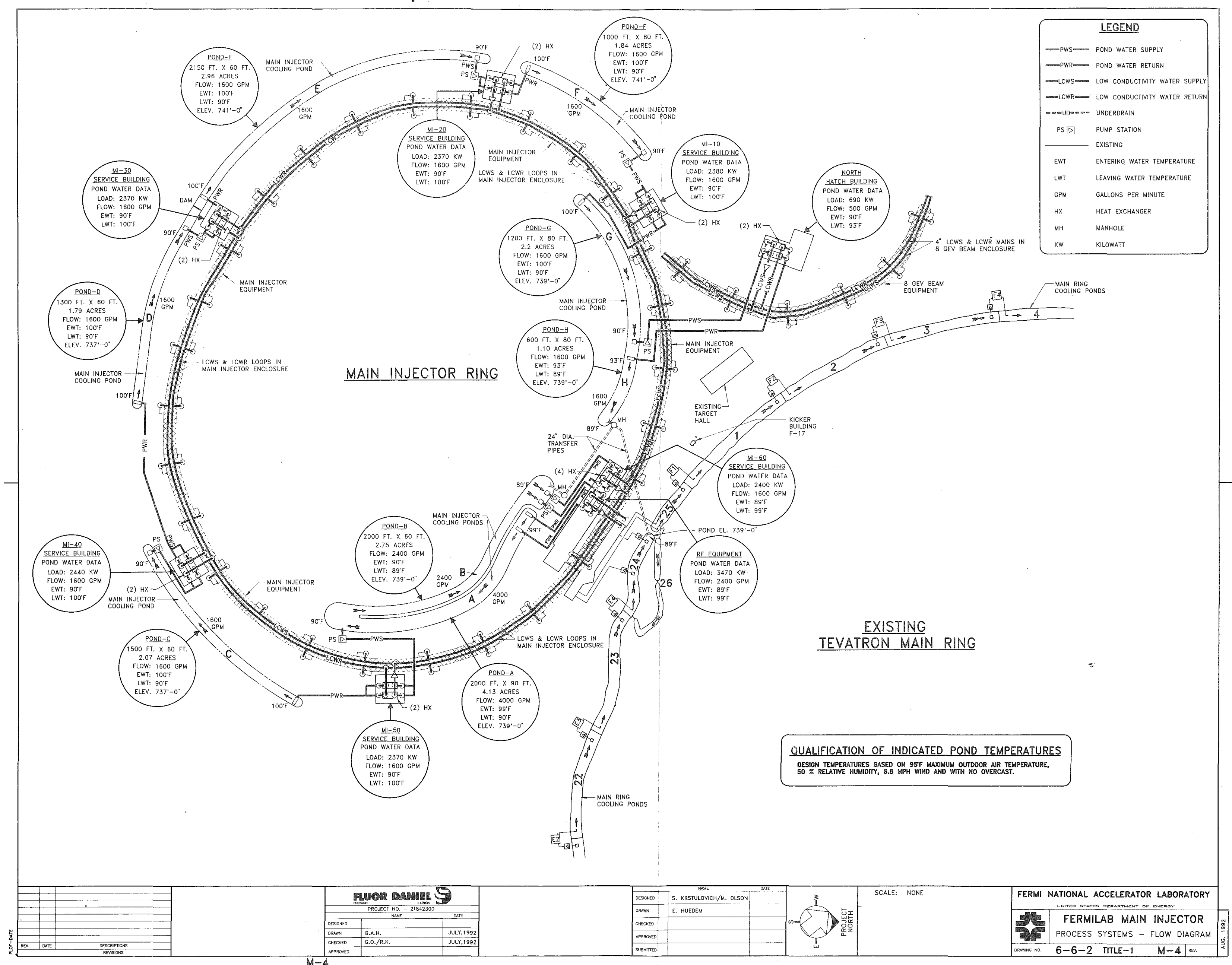




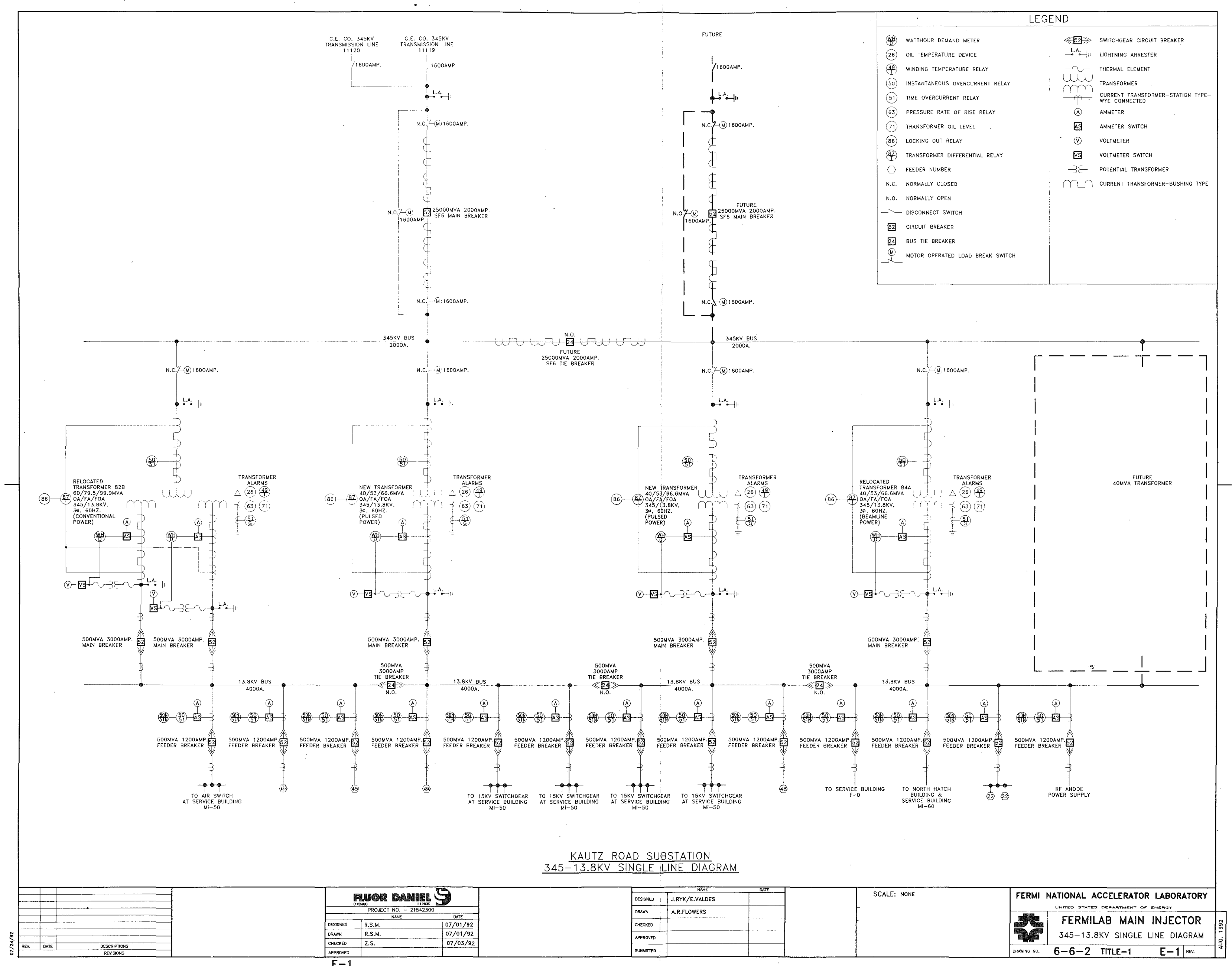




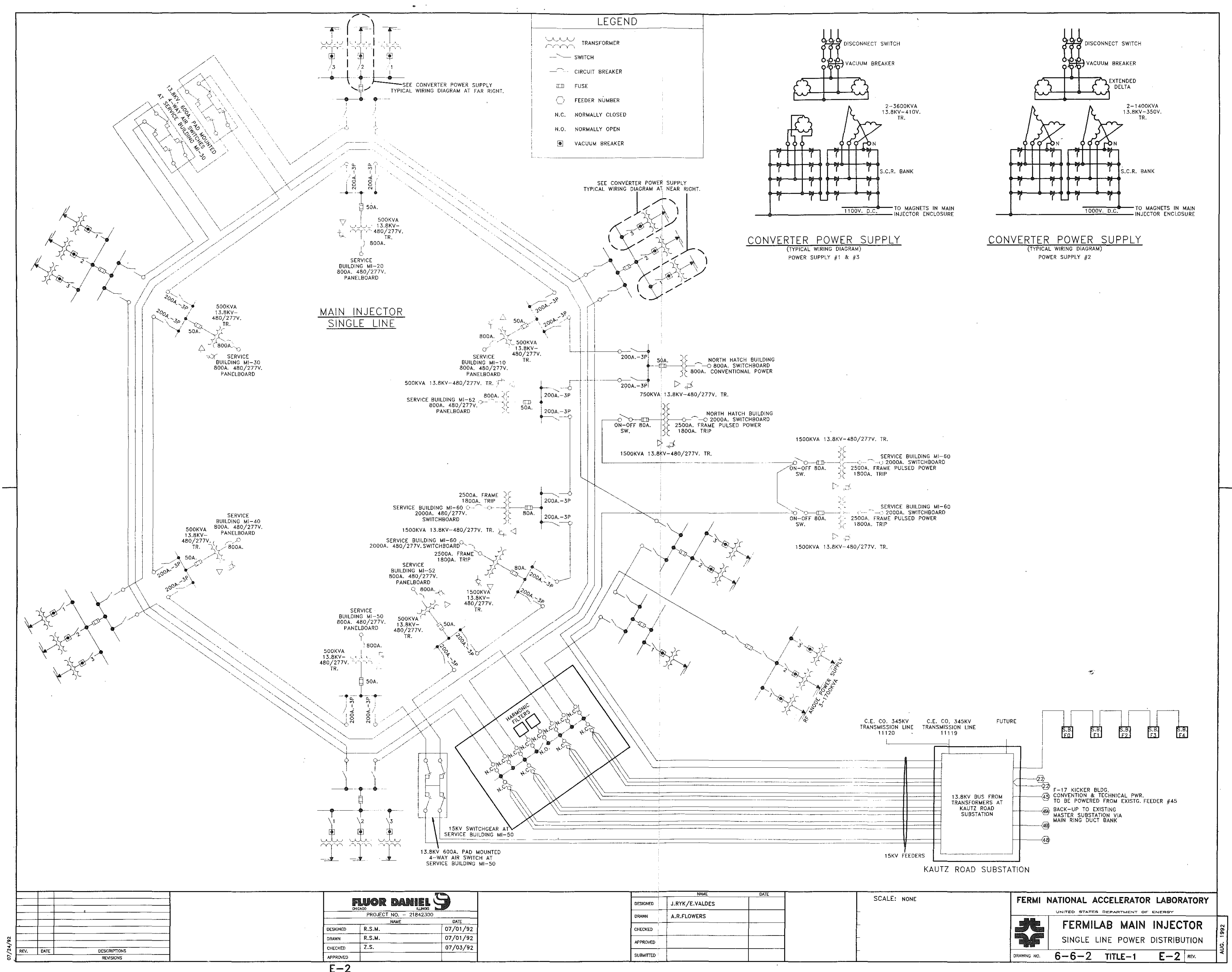




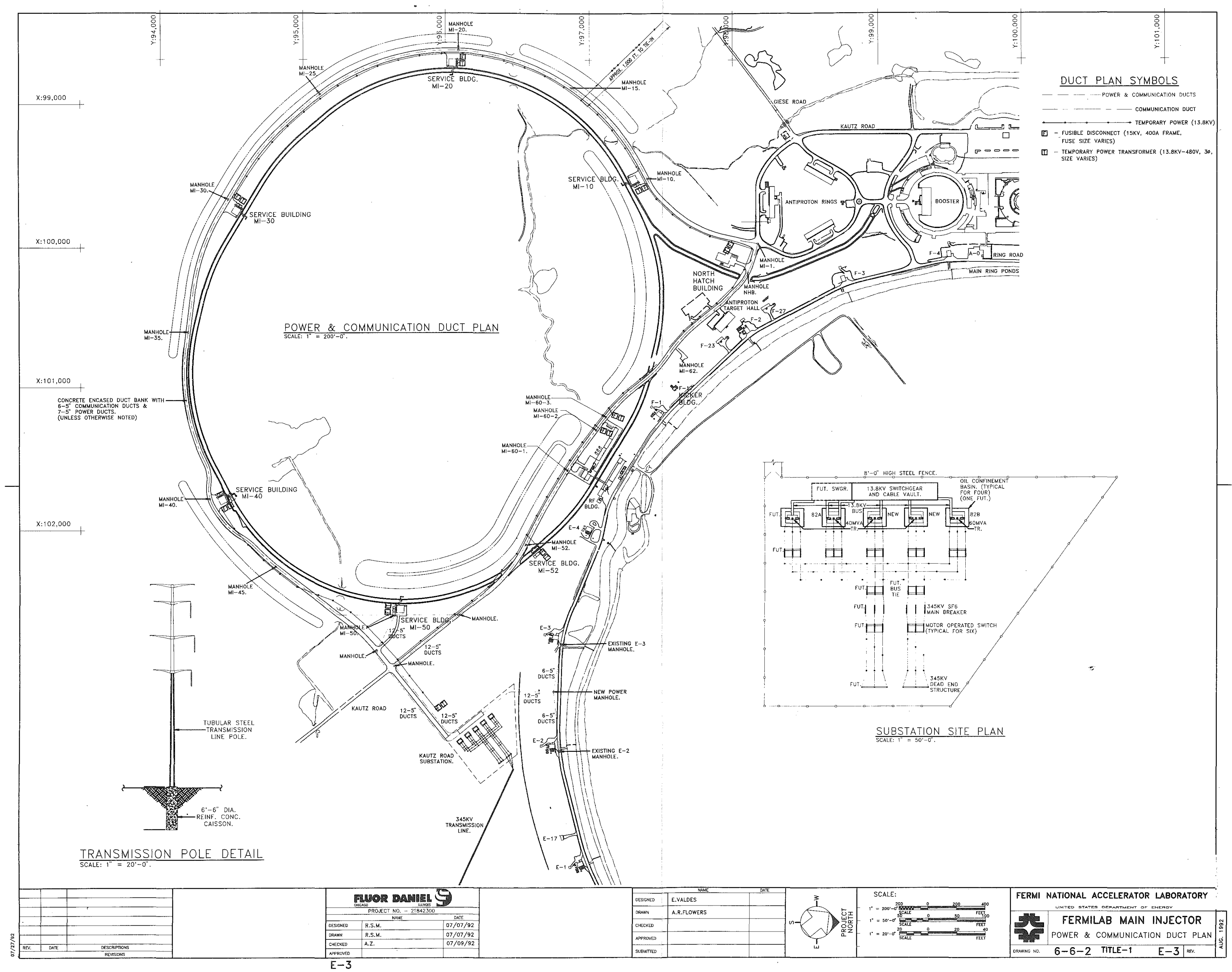




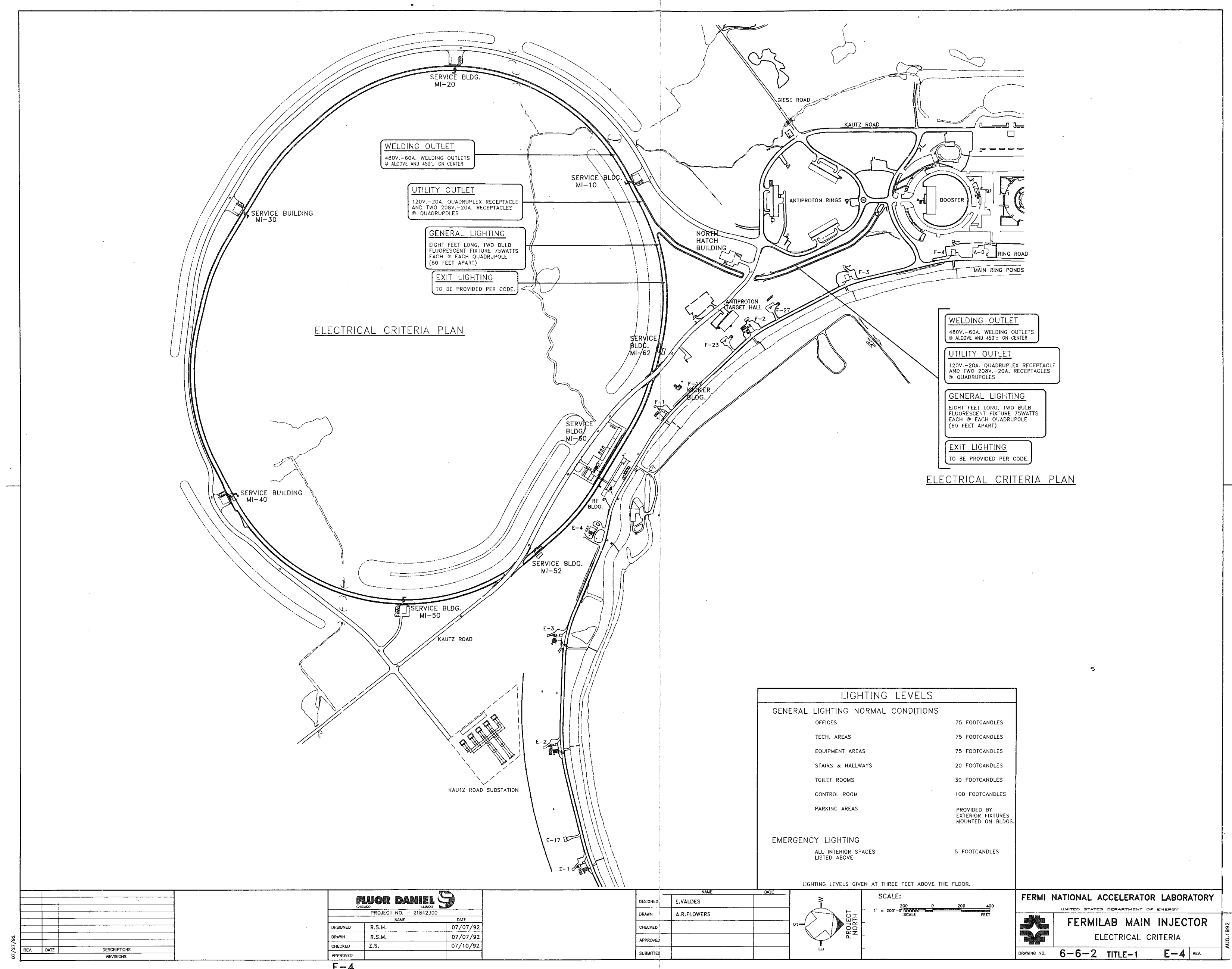

